\title{
Metabolic Modeling of Spatial Heterogeneity of Biofilms in Microbial Fuel Cells
}

\author{
by
}

Nadeera Jayasinghe

A thesis submitted in conformity with the requirements for the degree of Master of Applied Science

Graduate Department of Chemical Engineering and Applied Chemistry University of Toronto

(C)Copyright by Nadeera Jayasinghe, 2011 


\title{
ABSTRACT \\ Metabolic Modeling of Spatial Heterogeneity of Biofilms in Microbial Fuel Cells
}

\author{
Masters of Applied Science \\ 2011 \\ Graduate Department of Chemical Engineering and Applied Chemistry \\ University of Toronto \\ Nadeera Jayasinghe
}

Microbial fuel cells (MFCs) are alternative energy resources that generate electricity from organic matter, where microorganisms such as the Geobacter species oxidize organic waste and transfer electrons to an electrode. Mathematical models are used to study biofilm processes, in hopes of developing MFCs into commercial applications. Existing biofilm models are based on Nernst-Monod type expressions, and are restricted to studying extracellular electrochemical/microbiological components, separated from the metabolic behavior of microorganisms. In this thesis, a model was developed combining extracellular biofilm conditions, with the intracellular metabolic fluxes of microorganisms under spatial heterogeneities (electron donor/acceptor levels) across the biofilm. This model predicts biofilm processes under varying extracellular conditions (presence/absence of $\mathrm{NH}_{4}{ }^{+}$, shear stress in continuous mode MFCs), and intracellular conditions (ATP maintenance fluxes); and also provides a preliminary evaluation of the $\mathrm{pH}$ changes across the biofilm. A sensitivity analysis based on the cell density and the biofilm conductivity was also conducted. 


\section{ACKNOWLEDGEMENTS}

First and foremost, I would like to give my sincere gratitude to my supervisor, Dr. Radhakrishnan Mahadevan, for giving me constant support, motivation and guidance throughout the course of my MASc studies, and also in giving me the opportunity to work in Laboratory for Metabolic Systems Engineering (LMSE) group. I would also like to extend my gratitude to Dr. Ashley Franks from University of Massachusetts for providing me with the experimental data and background information for the $\mathrm{NH}_{4}{ }^{+}$experiments and $\mathrm{pH}$ modeling. In addition, I would like to acknowledge Dr. Derek Lovley for providing valuable discussions regarding Microbial Fuel Cells.

I would like to extend my deepest gratitude and appreciation for my parents for their loving support, guidance and encouragement throughout my studies and all other endeavors. Also my special gratitude goes to my sister for her continuous moral support and encouragement.

In addition, my thanks and appreciation must be given to all my group members of LMSE and my colleagues in Biozone for providing me with great support and encouragement on my studies.

The funding support that I received throughout the course of my program, by the office of science (BER), US Department of Energy (DOE) is also acknowledged. 


\section{TABLE OF CONTENTS}

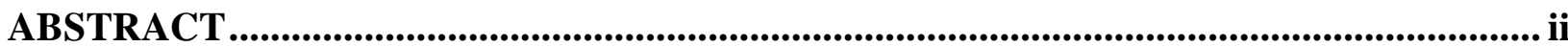

ACKNOWLEDGEMENTS .............................................................................................ii

TABLE OF CONTENTS ...................................................................................................................... iv

LIST OF TABLES............................................................................................................................... vii

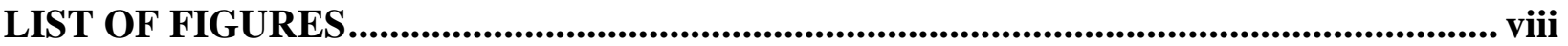

NOMENCLATURE ............................................................................................................................ $\mathrm{x}$

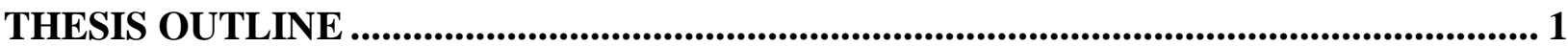

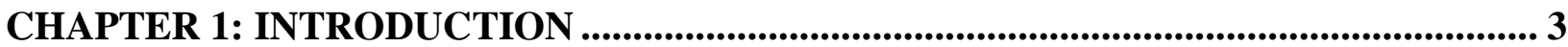

1.1 Importance of Microbial Fuel Cells (MFCs) as Alternative Energy Resources .......... 3

1.2 Microbial Fuel Cells................................................................................................................. 4

1.2.1 Sediment Microbial Fuel Cells (SMFCs) ................................................................ 6

1.3 Important Biofilm Processes ..................................................................................................... 7

1.3.1 Mechanism of Extracellular Electron Transfer .................................................... 7

1.3.2 Mechanisms of Proton Transfer ........................................................................... 9

1.3.3 Importance of G. sulfurreducens in MFC Research ............................................ 11

1.4 Outlook on Recent MFC research ..................................................................................... 12

1.4.1 Evaluation Criteria for MFC Performance........................................................ 12

1.4.2 Commercial Advancements in MFCs.............................................................. 14

1.4.3 Research Advancements in MFCs ....................................................................... 15

1.5 Mathematical Modeling of MFCs ............................................................................. 19

1.5.1 Picioreanu et al. Models (2007 and 2008) …......................................................... 19

1.5.2 Kato-Marcus et al. Models (2007, 2008 and 2010) ............................................. 21 
1.5.3 The Need for Metabolic Modeling of Biofilm Processes in MFCs ................ 25

1.5.4 The Use of Genome-scale Metabolic Model of G. sulfurreducens .................. 27

STATEMENT OF OBJECTIVES .................................................................................. 31

CHAPTER 2: MATERIALS AND METHODS......................................................... 32

2.1 Biofilm Model....................................................................................................................... 33

2.1.1 Electron Donor Mass Balance................................................................. 34

2.1.2 Electron Mass Balance ......................................................................................... 35

2.1.3 Biomass Mass Balance.......................................................................... 36

2.2 Flux Balance Analysis (FBA) Model ................................................................... 41

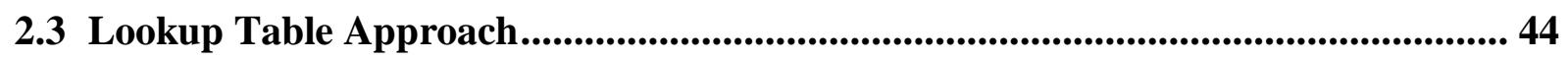

2.4 Coupled Model Framework................................................................................... 46

2.5 Continuation Technique for Complex Non-Linear Equations.................................... 47

2.6 Evaluation of the pH Levels Across the Biofilm Thickness ................................... 48

2.7 Modeling the Wild-type DL1 Strain ................................................................. 50

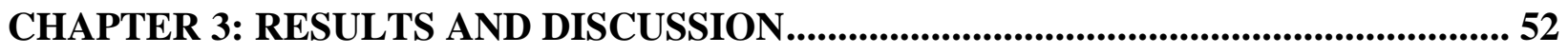

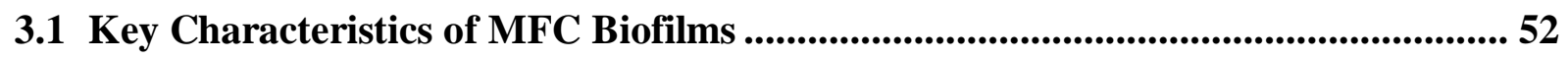

3.2 Effect of $\mathrm{NH}_{4}{ }^{+}$on the Current Production and the Biofilm Thickness ................... 56

3.3 Effect of Shear Stress in the Bulk Solution on the Biofilm Thickness ..................... 58

3.4 Effect of $\mathrm{ATP}_{\mathrm{M}}$ Levels on the Current Production and the Biofilm Thickness ........ 60

3.5 Effect of pH Variations across the Biofilm Thickness ................................................ 62

3.6 Sensitivity Analysis on Conductivity and Cell density Parameters ....................... 64

CHAPTER 4: CONCLUSIONS AND RECOMMENDATIONS .................................... 67

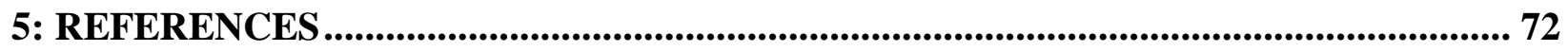

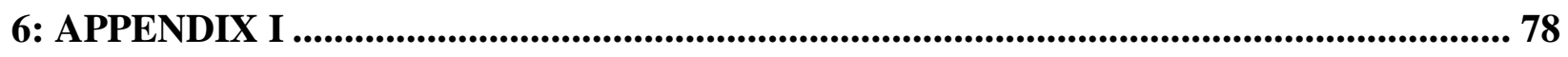

6.1 Equations and Parameters Used in the Biofilm Model Component of the Coupled Model Framework..................................................................................... 78 
6.2 Equations Used in the Genome-scale Model Component of the Coupled Model Framework ............................................................................................................................ 84

6.3 MATLAB Code for Coupled Model Framework ................................................... 85

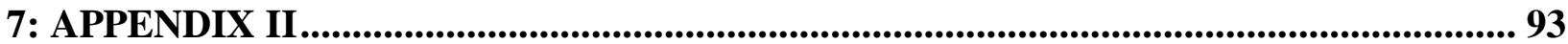




\section{LIST OF TABLES}

Table 1: Processes and Mass balances for each component used in $\mathrm{pH}$ calculations

Table 2: List of experimentally determined and adjusted model parameters for the DL1 strain

Table 3: Ordinary differential equations representing the mass balances for the components in the biofilm model

Table 4: Boundary conditions for the ordinary differential equations in Table 3

Table 5: Additional ordinary differential equations representing the components affecting the $\mathrm{pH}$ levels

Table 6: A complete list of model parameters based on Kato-Marcus et al. 2007 model and the experimental results 


\section{LIST OF FIGURES}

Figure 1.1: (A) Schematic of the key components of an MFC. (B) Experimental setup of the anode compartment prior to being connected to the cathode (C) Experimental setup of an MFC operating with an air-cathode.

Figure 1.2: The improvements of power densities normalized to the electrode surface area reported by different researchers, since 1996 -2009. (Adapted by permission from Macmillan Publisher Ltd: [Nature Review] (Logan, 2009), copyright (2009)).

Figure 1.3: Electron donor, electron acceptor (local potential) and $\mathrm{pH}$ gradients across the spatial location of the biofilm of a microbial fuel cell (Adapted by permission from Future Science Ltd: [Biofuels] (Franks et al., 2010), copyright (2010)).

Figure 1.4: Methodology of flux balance analysis (FBA). (a) The model systems contain 3 metabolites (A, B and C) with 3 reactions and exchange fluxes. (b) Mass balance equations representing all reactions and transport mechanisms. (c) The system fluxes are constrained based on thermodynamics and experimental findings. (d) Optimizing the system with different objective functions (Adapted by permission from Elsevier Ltd.: [Current Opinion in Biotechnology] (Kauffman et al., 2003), copyright (2003))

Figure 2.1: Illustration of biomass transformation: cell growth $\left(\mu_{\mathrm{g}}\right)$, rate of active biomass inactivation ( $\left.\mathrm{r}_{\mathrm{ina}}\right)$ and rate of active biomass conversion to respiring biomass $\left(\mathrm{r}_{\text {conv }}\right)$; and transport processes: advection (v) across the biofilm thickness.

Figure 2.2: Schematic representation of the coupling between the modified biofilm model and the FBA model, using ED and EA limited constraints. The FBA model schematic was adapted adapted by permission from Macmillan Publishers Ltd: [Nature Protocols] (Becker et al., 2007), copyright (2007). 
Figure 3.1: (A) The change of ED concentration and the local potential across the biofilm thickness. The shaded area shows the ED limited region. (B) The regions of cell death and cell growth across the biofilm thickness. (C) The distribution of all types of biomass across the biofilm thickness. (D) Comparison of total current density across the biofilm with the current densities produced due to growth independent and growth dependant biomass.

Figure 3.2: A comparison of experimental and model predicted (A) biofilm thicknesses and (B) maximum current densities under the presence and the absence of $\mathrm{NH}_{4}{ }^{+}$in the medium.

Figure 3.3: A comparison of the experimental and model predicted biofilm thicknesses under different shear stresses.

Figure 3.4: The effect of different ATP consumption levels on the current production and the biofilm thicknesses.

Figure 3.5: A comparison of model predicted and experimentally determined $\mathrm{pH}$ levels across the biofilm thickness

Figure 3.6: The effect of varying (A) cell density and (B) biofilm conductivity on the biofilm thickness and the current production of the biofilm.

Figure 4.1: Major achievement towards microbially assisted electrosynthesis (Adapted by permission from Macmillan Publisher Ltd: [Nature Review] (Rabaey and Rozendal, 2010), copyright (2010)).

Figure 7.1: Linear correlation used to establish the relationship between the detachment rate and the shear stress. 


\section{NOMENCLATURE}

$\mathrm{Ag} / \mathrm{AgCl}$ : Silver/Silver Chloride reference electrode (All voltages reported here are with respect to this reference electrode)

ATP $_{\mathrm{M}}$ : Rate of ATP consumption associated with non-biosynthetic maintenance activities of the microorganisms (mmol- ATP/gdw.hr)

BUG: Benthic Unattended Generator

BVP: Boundary Value Problem

DL1: Wild type G. sulfurreducens strain

EA: Electron Acceptor

ECE: Energy Conversion Efficiencies

ED: Electron Donor

EPS: Extracellular Polymeric Substances

FBA: Flux Balance Analysis

Fe (III): Soluble ferric ion

KN400: A newly isolated G. sulfurreducens strain that generates high current densities with thinner biofilms compared to DL1.

LP: (Linear Programming) A technique used to find an optimum solution of an under-determined set of equations, by specifying an objective function and constraints.

LSCV: Low Scan Cyclic Voltammetry

MFC: Microbial Fuel Cell

Mn (IV): Manganese (IV) 
$\mathrm{NH}_{4}^{+}$: Ammonium

Pili: Conductive nanowires that can promote extracellular electron transfer

SMFC: Sediment Microbial Fuel Cell

Spatial Heterogeneities: Variations in the biofilm processes that arise due to different availability of electron donor (ED), electron acceptor (EA) or protons across different spatial location across the biofilm thickness.

U (VI): Uranium (VI)

Uptake rate: Rate at which a metabolite is utilized by a microorganism (mmol/gdw. hr)

VS: Volatile solid content in biomass 


\section{MATHEMATICAL SYMBOLS}

$S:$ Stoichiometric matrix

$v_{i}$ : Flux through reaction

$m$ : Number of metabolites

$n$ : Number of reactions

F: Faraday constant $(96,485$ Coulomb/mol-e)

T: Temperature (298.15 K)

$\mathrm{R}$ : Ideal gas constant $\left(8.3145 \mathrm{~J} \mathrm{~mol}^{-1} \mathrm{~K}^{-1}\right)$

$\tau$ : Time conversion factor $(86,400 \mathrm{~s} /$ day $)$

A: Cross sectional area of the biofilm $\left(\mathrm{cm}^{2}\right)$

Y: Constant biomass yield (mg-VS/ mmol-ED)

$\mathrm{L}_{\mathrm{f}}$ : Biofilm thickness $(\mathrm{cm})$

L: Diffusion layer thickness (cm)

$\mathrm{S}_{\mathrm{i}}$ : Local concentration of component $i$ across the biofilm thickness $\left(\mathrm{mmol} / \mathrm{cm}^{3}\right)$

$\mathrm{S}_{\mathrm{i}, \text { bulk }}$ : Concentration of component $i$ in the bulk solution $\left(\mathrm{mmol} / \mathrm{cm}^{3}\right)$

$\mathrm{S}_{\mathrm{i}, \text { surface }}$ : Concentration of component $i$ at the biofilm surface $\left(\mathrm{mmol} / \mathrm{cm}^{3}\right)$

$\eta$ : Local potential (V)

j: Current density $\left(\mathrm{mA} / \mathrm{cm}^{2}\right)$

$\phi_{\mathrm{a}}:$ Active biomass fraction (dimensionless) 
$\phi_{\mathrm{i}}$ : Inert biomass fraction (dimensionless)

$\phi_{\mathrm{r}}$ : Respiring biomass (dimensionless)

v: Advection velocity due to cell growth (cm/day)

$\mathrm{v}_{\mathrm{d}}$ : Advection velocity due to cell death ( $\left.\mathrm{cm} / \mathrm{day}\right)$

$\mathrm{q}_{\max }$ : Maximum ED uptake rate ( $\mathrm{mmol} / \mathrm{mg} \mathrm{VS}$. day)

$\mathrm{q}_{\mathrm{ED}, \mathrm{oxd}}$ : ED uptake rate due to oxidation process $\left(\mathrm{mmol} / \mathrm{cm}^{3}\right.$. day)

$\mathrm{q}_{\mathrm{ED}, \mathrm{res}}$ : ED uptake rate due to endogenous respiration process $\left(\mathrm{mmol} / \mathrm{cm}^{3}\right.$. day)

$\mathrm{q}_{\mathrm{e}, \mathrm{oxd}}$ : Electron transfer rate due to oxidation process $\left(\mathrm{mmol} / \mathrm{cm}^{3}\right.$. day)

$\mathrm{q}_{\mathrm{e}, \text { res }}$ : Electron transfer rate due to endogenous respiration process (mmol-e/cm $\mathrm{cm}^{3}$. day)

$\mu_{\mathrm{g}}$ : Cell growth $\left(\right.$ day $\left.^{-1}\right)$

$\mu_{\mathrm{d}}$ : Death rate $\left(\right.$ day $\left.^{-1}\right)$

$\mu_{\mathrm{a}}$ : Net specific growth rate of active biomass $\left(\right.$ day $\left.^{-1}\right)$.

$\mu_{\mathrm{i}}$ : Net specific growth rate of inert biomass $\left(\right.$ day $\left.^{-1}\right)$

$\mu_{\mathrm{r}}$ : Net specific growth rate of respiring biomass $\left(\right.$ day $\left.^{-1}\right)$

$r_{\text {ina }}$ : Rate of active biomass inactivation $\left(\right.$ day $\left.^{-1}\right)$

$r_{\text {conv }}$ : Rate of active biomass conversion into respiring biomass $\left(\right.$ day $\left.^{-1}\right)$

$b_{\text {ina }}$ : Co-efficient of biomass inactivation $\left(\right.$ day $\left.^{-1}\right)$

$b_{\text {conv }}$ : Co-efficient of active biomass conversion to respiring biomass $\left(\right.$ day $\left.^{-1}\right)$

$\mathrm{b}_{\text {det }}:$ Rate of biomass detachment $\left(\right.$ day $\left.^{-1}\right)$

$\mathrm{K}_{\mathrm{sd}}$ : Half maximum rate ED concentration $\left(\mathrm{mmol}-\mathrm{ED} / \mathrm{cm}^{3}\right)$

$\mathrm{K}_{\text {bio }}$ : Conductivity of the biofilm $(\mathrm{mS} / \mathrm{cm})$

$\mathrm{X}_{\mathrm{f}, \mathrm{a}}$ : Density of active biomass $\left(\mathrm{mg}-\mathrm{VS} / \mathrm{cm}^{3}\right)$ 
$\mathrm{D}_{\mathrm{i}, \mathrm{f}}$ : Diffusion constant for component $i$ in the biofilm $\left(\mathrm{cm}^{2} /\right.$ day)

$\mathrm{D}_{\mathrm{i}, 1:}$ : Diffusion constant for component $i$ the bulk liquid $\left(\mathrm{cm}^{2} /\right.$ day)

АTP $_{\mathrm{M}}$ : Flux of ATP towards maintenance (0.45 mmol ATP/gdw.hr)

$\mathrm{Y}_{\max }$ : Maximum theoretical yield of ATP generation, with Fe (III) as the electron acceptor (0.5 $\mathrm{mmol} \mathrm{ATP} / \mathrm{mmol} \mathrm{ED})$

$\mathrm{S}_{\mathrm{d}, \min }$ : Minimum possible ED concentration to satisfy ATP energy for cell maintenance

$\eta_{\min }$ : Minimum possible local potential to satisfy ATP energy for cell maintenance 


\section{LIST OF EQUATIONS}

Equation: 1. The Nernst - Monod Expression (Kato- Marcus et al., 2007)

$$
\mathrm{q}=\mathrm{q}_{\max } \phi_{\mathrm{a}}\left(\frac{\mathrm{S}_{\mathrm{d}}}{\mathrm{S}_{\mathrm{d}}+\mathrm{Ks}_{\mathrm{d}}}\right)\left(\frac{1}{1+\left[-\frac{\mathrm{F}}{\mathrm{RT}} \eta\right]}\right)
$$

Equation: 2. Total concentration of component $j$, in complexed and uncomplexed form (KatoMarcus et al., 2010)

$$
C_{j}=c_{j}+\sum_{i=1}^{N_{p}} v_{i j} p_{i} \quad j=1, \ldots \ldots N_{C}
$$

Equation: 3. Mass balance for the component $j$, in the medium (Kato- Marcus et al., 2010)

$$
\frac{\partial C_{j}}{\partial t}=\frac{\partial L\left(C_{j}\right)}{\partial x}+\sum_{k} \lambda_{j, k} r_{k}
$$

Equation: 4. Transport operator $\mathrm{L}\left(C_{j}\right)$ (Kato- Marcus et al., 2007)

$$
-J_{j}=L\left(C_{j}\right)=D_{j} \frac{\partial c_{j}}{\partial x}+\sum_{i=1}^{N_{x}}\left(D_{i} \frac{\partial p_{i}}{\partial x}\right)
$$

Equation: 5. General FBA formulation

$$
\begin{aligned}
& \text { Maximize }\left(C^{T} v\right) \\
& \text { s.t } S . v=0 \\
& \boldsymbol{v}_{\boldsymbol{l b}} \leq \boldsymbol{v} \leq \boldsymbol{v}_{\boldsymbol{u} \boldsymbol{b}} \\
& i=1,2,3 \ldots \ldots \ldots n
\end{aligned}
$$

Equation: 6. General conservation of mass of a component in a dynamic and open system

$$
\left(\begin{array}{c}
\text { Net rate of } \\
\text { accumulation }
\end{array}\right)=\left(\begin{array}{c}
\text { Mass flows } \\
\text { into } \\
\text { the system }
\end{array}\right)-\left(\begin{array}{c}
\text { Mass flows } \\
\text { out of } \\
\text { the system }
\end{array}\right)+\left(\begin{array}{c}
\text { Rate of } \\
\text { production }
\end{array}\right)-\left(\begin{array}{c}
\text { Rate of } \\
\text { consumption }
\end{array}\right)
$$


Equation: 7. Steady state electron donor mass balance

$$
0=D_{E D, f} \frac{\partial^{2} S_{d}}{\partial z^{2}}-X_{f, a} \phi_{a} q_{E D, o x d}-X_{f, a} \phi_{r} q_{E D, r e s p}
$$

Equation: 8. Electron donor boundary condition at the anode - No flux boundary.

$$
0=\left.D_{E D, f} \frac{\partial S_{d}}{\partial z}\right|_{z=0}
$$

Equation: 9. Electron donor boundary condition at the external biofilm surface - Continuous flux boundary conditions.

$$
\left.D_{E D, f} \frac{\partial S_{d}}{\partial z}\right|_{z=L f}=\left(\frac{D_{E D, l}}{L}\right)\left(S_{d, \text { bulk }}-S_{d, \text { surface }}\right)
$$

Equation: 10. Steady state mass balance for the current density

$$
0=\frac{\partial j}{\partial z}+\frac{F}{\tau} X_{f, a} \phi_{a} q_{e, o x d}+\frac{F}{\tau} X_{f, a} \phi_{r} q_{e, r e s}
$$

Equation: 11. Ohm`s law

$$
0=K_{b i o} \frac{\partial \eta}{\partial z}+j
$$

Equation: 12. Steady state mass balance for the local potential

$$
0=K_{\text {bio }} \frac{\partial^{2} \eta}{\partial z^{2}}-\frac{F}{\tau} X_{f, a} \phi_{a} q_{e, o x d}-\frac{F}{\tau} X_{f, a} \phi_{r} q_{e, \text { res }}
$$

Equation: 13. Local potential boundary condition at the anode- fixed anode potential.

$$
\left.\eta\right|_{\mathrm{z}=0}=\mathrm{V}_{\text {anode }}
$$

Equation: 14. Local potential and current density boundary condition at the external biofilm surface - No flux boundary.

$$
\left.\frac{\partial \eta}{\partial z}\right|_{\mathrm{z}=\mathrm{Lf}}=\frac{\left.\mathrm{j}\right|_{\mathrm{z}=\mathrm{Lf}}}{\mathrm{K}_{\mathrm{bio}}}=0
$$

Equation: 15. Sum of volume factions of all types of biomass (active, respiring and inert biomass)

$$
\phi_{\mathrm{a}}+\phi_{\mathrm{i}}+\phi_{\mathrm{r}}=1
$$


Equation: 16 - 18. Derivation of the dynamic mass balance for the active biomass fraction

$$
\begin{gathered}
{\left[\phi_{\mathrm{a}}(\mathrm{t}+\Delta \mathrm{t}, \mathrm{z})-\phi_{\mathrm{a}}(\mathrm{t}, \mathrm{z})\right] \mathrm{A} \Delta \mathrm{z}=\mu_{\mathrm{a}} \mathrm{A} \Delta \mathrm{z} \Delta \mathrm{t}+\phi_{\mathrm{a}}(\mathrm{z}) \mathrm{v}(\mathrm{z}) \mathrm{A}-\phi_{\mathrm{a}}(\mathrm{z}+\Delta \mathrm{z}) \mathrm{v}(\mathrm{z}+\Delta \mathrm{z}) \mathrm{A}} \\
\frac{\left[\phi_{\mathrm{a}}(\mathrm{t}+\Delta \mathrm{t}, \mathrm{z})-\phi_{\mathrm{a}}(\mathrm{t}, \mathrm{z})\right]}{\Delta \mathrm{t}}=\mu_{\mathrm{a}}-\frac{\left[\phi_{\mathrm{a}}(\mathrm{z}+\Delta \mathrm{z}) \mathrm{v}(\mathrm{z}+\Delta \mathrm{z})-\phi_{\mathrm{a}}(\mathrm{z}) \mathrm{v}(\mathrm{z})\right]}{\Delta \mathrm{z}} \\
\frac{\partial \phi_{\mathrm{a}}}{\partial \mathrm{t}}+\frac{\partial\left(\mathrm{v} \phi_{\mathrm{a}}\right)}{\partial \mathrm{z}}=\phi_{\mathrm{a}} \mu_{\mathrm{g}}-\mathrm{r}_{\text {ina }}-\mathrm{r}_{\text {conv }} \equiv \mu_{\mathrm{a}}
\end{gathered}
$$

Equation: 19. Steady state mass balance for the active biomass

$$
\frac{\partial\left(\mathrm{v} \phi_{\mathrm{a}}\right)}{\partial \mathrm{z}}=\phi_{\mathrm{a}} \mu_{\mathrm{g}}-\mathrm{r}_{\mathrm{ina}}-\mathrm{r}_{\mathrm{conv}} \equiv \mu_{\mathrm{a}}
$$

Equation: 20. Steady state mass balance for the inert biomass

$$
\frac{\partial\left(\mathrm{v} \phi_{\mathrm{i}}\right)}{\partial \mathrm{z}}=\mathrm{r}_{\mathrm{ina}} \equiv \mu_{\mathrm{i}}
$$

Equation: 21. Steady state mass balance for the respiring biomass

$$
\frac{\partial\left(\mathrm{v} \phi_{\mathrm{r}}\right)}{\partial \mathrm{z}}=\mathrm{r}_{\mathrm{conv}} \equiv \mu_{\mathrm{r}}
$$

Equation: 22. Rate expressions for the biomass inactivation

$$
\mathrm{r}_{\mathrm{ina}}=\mathrm{b}_{\mathrm{ina}} \phi_{\mathrm{a}}
$$

Equation: 23. Rate expressions for the active biomass conversion into respiring biomass

$$
\mathrm{r}_{\mathrm{conv}}=\mathrm{b}_{\mathrm{conv}} \phi_{\mathrm{a}}
$$

Equation: 24. Change of advection velocity due to cell growth as a function of distance across the biofilm thickness.

$$
\frac{\partial \mathrm{v}}{\partial \mathrm{z}}=\mu_{\mathrm{a}}+\mu_{\mathrm{i}}+\mu_{\mathrm{r}}=\left(\phi_{\mathrm{a}} \mu_{\mathrm{g}}-\mathrm{r}_{\mathrm{ina}}-\mathrm{r}_{\mathrm{conv}}\right)+\mathrm{r}_{\mathrm{ina}}+\mathrm{r}_{\mathrm{conv}}=\phi_{\mathrm{a}} \mu_{\mathrm{g}}
$$

Equation: 25. Change of advection velocity due to cell death as a function of distance across the biofilm thickness.

$$
\frac{\partial \mathrm{v}_{\mathrm{d}}}{\partial \mathrm{z}}=\mu_{\mathrm{d}}
$$


Equation: 26. Change in thickness as a function of time due to advection velocities and biomass detachment.

$$
\frac{\partial \mathrm{L}_{\mathrm{f}}}{\partial \mathrm{t}}=\left.\mathrm{v}\right|_{\mathrm{z}=\mathrm{Lf}}-\left.\mathrm{v}_{\mathrm{d}}\right|_{\mathrm{z}=\mathrm{Lf}}-\mathrm{r}_{\text {lysis }} \mathrm{L}_{\mathrm{f}}-\mathrm{b}_{\operatorname{det}} \mathrm{L}_{\mathrm{f}}
$$

Equation: 27. Steady state form of Equation 26

$$
0=\left.v\right|_{z=L f}-\left.v_{d}\right|_{z=L f}-r_{\text {lysis }} L_{f}-b_{\text {det }} L_{f}
$$

Equation: 28. Electron donor constraint used in FBA calculations

$$
q_{E D, c o n s t r a i n t}=q_{\max }\left(\frac{S_{d}}{S_{d}+K_{S d}}\right)
$$

Equation: 29. Electron acceptor constraint used in FBA calculations

$$
\mathrm{q}_{\mathrm{e}, \text { constraint }}=8 \times \mathrm{q}_{\max }\left(\frac{1}{1+\exp \left[-\frac{\mathrm{F}}{\mathrm{RT}}(\eta-(-0.345))\right]}\right)
$$

Equation: 30. Cell growth as a function of biomass yield and electron donor uptake rate (KatoMarcus et al., 2007)

$$
\mu_{\mathrm{g}}=\mathrm{Y} \times \mathrm{q}_{\mathrm{ED}}
$$

Equation: 31. Rate of electron donor uptake rate due the growth independent respiration process

$$
q_{E D, \text { res }}=q_{\max }\left(\frac{S_{d, \text { min }}}{S_{d, \text { min }}+K_{S d}}\right)=q_{M}
$$

Equation: 32. Change in various rates under electron donor and electron acceptor limitations.

$$
\mathrm{q}_{\mathrm{ED}}, \mu_{\mathrm{g}}, \mathrm{q}_{\mathrm{e}}, \mu_{\mathrm{d}}= \begin{cases}q_{E D}, \mu_{\mathrm{g}}, \mathrm{q}_{\mathrm{e}} \neq 0 \text { and } \mu_{\mathrm{d}}=0 & \text { if } \mathrm{s}_{\mathrm{d}}>\mathrm{S}_{\mathrm{d}, \min } \text { and } \eta>\eta_{\min } \\ q_{E D}, \mu_{\mathrm{g}}, \mathrm{q}_{\mathrm{e}}=0 \text { and } \mu_{\mathrm{d}} \neq 0 & \text { Else }\end{cases}
$$

Equation: 33. Minimum electron donor uptake rate required to satisfy ATP energy demand for cell maintenance.

$$
\mathrm{q}_{\mathrm{M}}=\frac{\operatorname{ATP}_{\mathrm{M}}}{\mathrm{Y}_{\max }}
$$


Equation: 34. Minimum electron donor concentration to satisfy ATP energy demand for cell maintenance

$$
\mathrm{S}_{\mathrm{d}, \min }=\frac{\mathrm{K}_{\mathrm{sd}}}{\left[\left(\mathrm{q}_{\max } / \mathrm{q}_{\mathrm{M}}\right)-1\right]}
$$

Equation: 35. Minimum local potential to satisfy ATP energy demand for cell maintenance

$$
\eta_{\min }=\left[\ln \left[\left(\mathrm{q}_{\max } / \mathrm{q}_{\mathrm{M}}\right)-1\right] \times \frac{-\mathrm{RT}}{\mathrm{F}}\right]+(-0.345)
$$

Equation: 36. Mathematical representation of homotopy used for the continuation method

$$
H\left(x, s_{i}\right)=F(x)-s_{i} F\left(x_{1}\right) \quad \text { where, } s \in\left[1=s_{0}, \ldots \ldots s_{1}=0\right]
$$

Equation: 37.Steady state mass balance for $\mathrm{CO}_{2}$.

$$
0=\mathrm{D}_{\mathrm{CO}_{2}, \mathrm{f}} \frac{\partial^{2} \mathrm{C}_{\mathrm{CO}_{2}}}{\partial \mathrm{z}^{2}}+\mathrm{X}_{\mathrm{f}, \mathrm{a}} \mathrm{q}_{\mathrm{CO}_{2}}
$$

Equation: 38. Steady state mass balance for protons

$$
0=\mathrm{D}_{\mathrm{H}^{+}, \mathrm{f}} \frac{\partial^{2} \mathrm{C}_{\mathrm{H}^{+}}}{\partial \mathrm{z}^{2}}+\mathrm{X}_{\mathrm{f}, \mathrm{a}} \mathrm{q}_{\mathrm{H}^{+}}
$$

Equation: 39. Steady state mass balance for carbonate buffer

$$
0=\mathrm{D}_{\mathrm{HCO}_{3}{ }^{-}, \mathrm{f}} \frac{\partial^{2} \mathrm{C}_{\mathrm{HCO}_{3}{ }^{-}}}{\partial \mathrm{z}^{2}}+\frac{\mathrm{FD}_{\mathrm{HCO}_{3}}{ }^{-}, \mathrm{f}}{\mathrm{RT}} \frac{\partial}{\partial \mathrm{z}}\left(\mathrm{z} * \mathrm{C}_{\mathrm{HCO}_{3}}{ }^{-} * \frac{\partial \eta}{\partial \mathrm{z}}\right)
$$

Equation: 40. Steady state mass balance for phosphate

$$
0=\mathrm{D}_{\mathrm{H}_{2} \mathrm{PO}_{4}{ }^{-}, \mathrm{f}} \frac{\partial^{2} \mathrm{C}_{\mathrm{H}_{2} \mathrm{PO}_{4}{ }^{-}}}{\partial \mathrm{z}^{2}}+\frac{\mathrm{FD}_{\mathrm{H}_{2} \mathrm{PO}_{4}{ }^{-}, \mathrm{f}}}{\mathrm{RT}} \frac{\partial}{\partial \mathrm{z}}\left(\mathrm{z} * \mathrm{C}_{\mathrm{H}_{2} \mathrm{PO}_{4}}{ }^{-} * \frac{\partial \eta}{\partial \mathrm{z}}\right)
$$




\section{THESIS OUTLINE}

This is a Masters of Applied Science thesis that conforms to the guidelines of the Department of Chemical Engineering and Applied Chemistry, University of Toronto. The main focus of this thesis is to develop a metabolic model that combines the intracellular and extracellular biofilm processes under spatial heterogeneities across biofilms in microbial fuel cells. The model was constructed by coupling a modified version of Kato-Marcus et al., 2007 biofilm model, with the genome-scale model for G. sulfurreducens published by Mahadevan et al., 2006. The model presented in the thesis, was validated using previous experimental studies. A portion of this work has been adapted from the conference paper "Metabolic Modeling of Spatial Heterogeneity of Biofilms in Microbial Fuel Cells" which was presented in $11^{\text {th }}$ Computer Applications in Biotechnology Symposium, Leuven, Belgium. Nadeera Jayasinghe was the primary author of this paper. These published results were extended to include further validations of experimental studies and a sensitivity analysis to identify the biofilm characteristics that can be optimized for enhanced current production by microbial fuel cells. A complete set of model predictions is drafted in a manuscript titled "Metabolic Modeling of Spatial Heterogeneity of Biofilms in Microbial Fuel Cells" and is intended to be submitted to Biotechnology and Bioengineering journal, with Nadeera Jayasinghe as the primary author. This complies with the Department of Chemical Engineering Graduate program regulations which permit the submission of a research paper as a thesis document, with the addition of sufficient background information.

The thesis contains four chapters. Chapter 1 provides a detailed introduction as to the importance of microbial fuel cells as an alternative energy resource to support increasing energy demand. This chapter also illustrates the critical need for mathematical models that can accurately predict intracellular and extracellular biofilm processes in microbial fuel cells, in order to optimize the current generation. Chapter 1 is followed by the statement of objectives. The materials and methods used in formulating this model are discussed in Chapter 2. Chapter 3 discusses the results obtained from the model, and these results were compared with 
experimental data, if available. Lastly, Chapter 4 summarizes the results and provides future recommendations to further improve model accuracy and applicability. 


\section{CHAPTER 1: INTRODUCTION}

\subsection{Importance of Microbial Fuel Cells (MFCs) as Alternative Energy Resources}

Although the depletion of fossil fuels and the adverse environmental effects due to the emission of $\mathrm{CO}_{2}$ during fossil fuel combustion have raised major concerns in the society, approximately $86 \%$ of energy generation today continues to be based on fossil fuel resources (Lee et al., 2008). If substantial changes in present energy production methods are not implemented in the near future, it will significantly increase the accumulation of $\mathrm{CO}_{2}$ in the atmosphere, accelerating global warming and climate change (Logan, 2007). Furthermore, the continuous use of these scarce natural resources can lead us into an energy crisis. Thus, finding sustainable, carbon-neutral and cost-effective alternative energy resources is an essential requirement in meeting the rapidly increasing energy demands.

A considerable amount of this energy demand is due to water and wastewater treatment processes. In the US, approximately $4-5 \%$ of the energy expenditure is due to wastewater collection, water treatment, and distribution alone. In addition, the maintenance and operational cost for the required infrastructure is significantly large, with an annual cost of about $\$ 25$ billion (Logan, 2007; Aelterman et al., 2006a). However, wastewater contains energy in the form of biodegradable organic matter that could be used in powering wastewater treatment plants. It was estimated that, on average, a wastewater treatment plant in Canada contains about 9.3 times more energy in wastewater than that was used in the treatment process (Shizas and Bagley, 2005). Recovering this energy can make the water infrastructure self-sufficient (Logan, 2007). The production of methane through anaerobic digestion processes and the production of electricity from MFCs are two key forms of energy generation, using these waste materials. The ability of MFCs to produce energy directly without combustion has made it a more attractive choice among these alternatives (Lee et al., 2008). Thus, research on MFCs has gained substantial attention in bringing this technology into the commercial stage. As a result, some projects have achieved commercial success, in the pilot plant-scale. For instance, the Megawatter system developed by Emefcy Ltd. produces electricity and hydrogen gas based on MFC technology while treating wastewater from industrial, municipal and agricultural sources (Megawatter 
webinar). The system developed by Bilexys utilizes a similar approach, focused on using MFCs to produce chemicals as opposed to electricity (Bilexys Website). Although some applications have reached potential commercial feasibility in the pilot plant-scale, significant improvement of the power density is still necessary in order to expand the applicability of this technology to power portable handheld devices, small automated marine robots and other household equipment (Lovley, 2006a). Hence, this motivates the research in optimizing MFC processes for improved current producing capabilities.

\subsection{Microbial Fuel Cells}

MFCs are electrochemical devices that are similar to conventional fuel cells in which energy from a chemical reaction is converted into useful electricity. However, compared to the most commonly known abiotic hydrogen and methanol fuel cells, MFCs have significant advantages. Both hydrogen and methanol fuel cells rely on expensive catalysts such as platinum to activate the oxidation process, whereas the oxidation in MFCs are catalysed by naturally occurring microorganisms. In addition, most abiotic fuel cells operate at high temperature making them unsuitable for some applications; MFCs can operate at room temperature and could be designed to operate at higher temperatures that permit microbial activity. Another attractive feature of MFCs is their ability to utilize a large range of organic substrates as the fuel at the anode, eliminating the need for complex and highly regulated storage and distribution systems that are typically required for hydrogen and methanol fuel cells. This allows widespread application of MFC technology in remote locations or in developing countries that have limited access to a well-developed and centralized power grid (Lovley, 2006a; Rabaey and Verstraete, 2005).

The MFC consists of an anode and a cathode compartment separated by a semi permeable cation-selective membrane, whereas the anode and the cathode are connected by an external circuit. However, the latest trend in MFC designs have been directed towards using membrane-less fuel cells, where the culture medium acts as the proton transferring electrolyte. The anode compartment is typically maintained under anoxic conditions, whereas the cathode can be either suspended in aerobic water, or exposed to air. The diffusion of oxygen from the cathode to the anode compartment is restricted by the semi permeable membrane (Lovley, 2006a). In MFCs, the microorganisms act as the catalyst to the oxidation of the organic matter 
(electron donor), and transfer the electrons to the anode (electron acceptor). During this oxidation process, some microorganisms such as Geobacter species have the ability to conserve energy to support their cell growth (Lovley, 2006b). These microorganisms can either be present as suspended cells or be attached to the anode surface forming biofilms. The MFCs described in this thesis are considered to have a biofilm on the anode and utilizes a proton exchange membrane (Fig. 1.1). As seen in Fig. 1.1, after the electrons reach the anode, they are transferred on to the cathode across the external circuit producing the electric current. The protons produced in the oxidation migrate to the cathode through the cation - selective membrane, completing the charge balance. At the cathode, the electrons and protons are combined together with a terminal electron acceptor such as oxygen, through a reduction process forming water as a by-product (Franks et al., 2010; Lovley, 2006b; Rabaey et al., 2007).

(A)

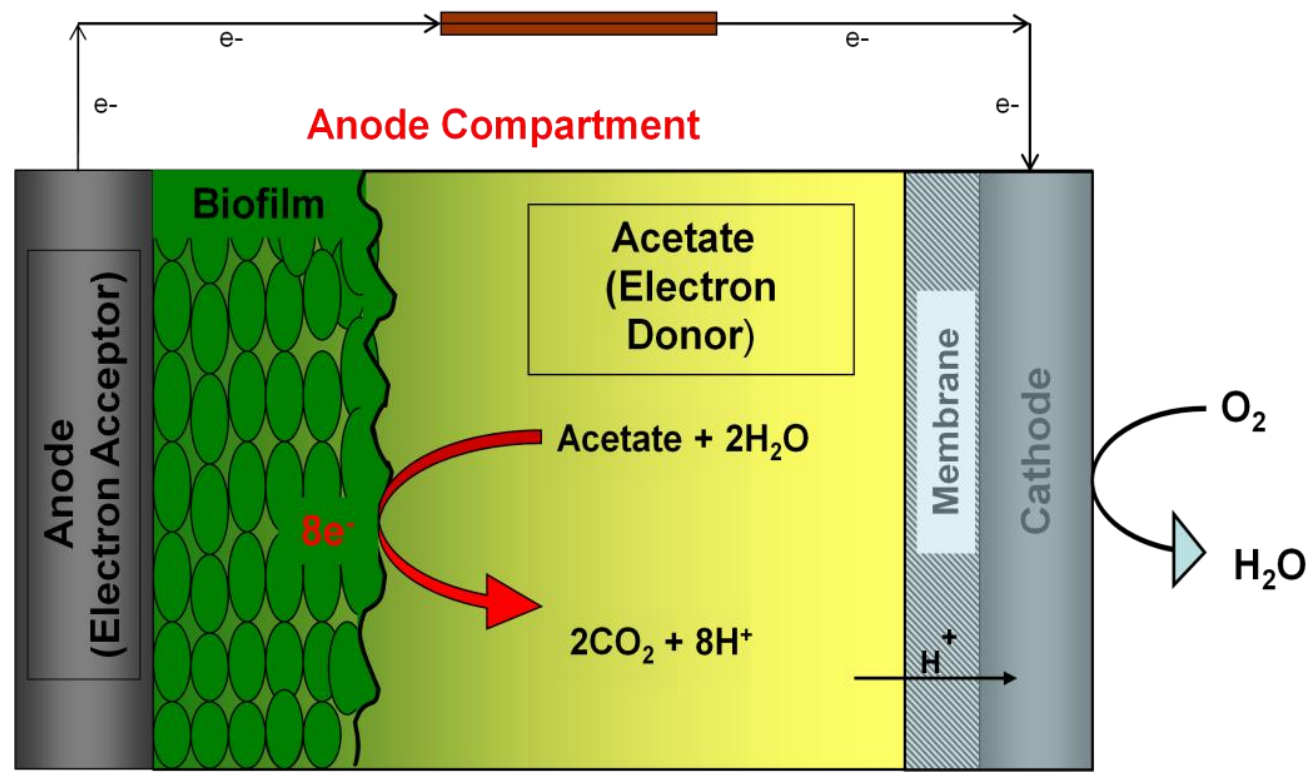

(B)

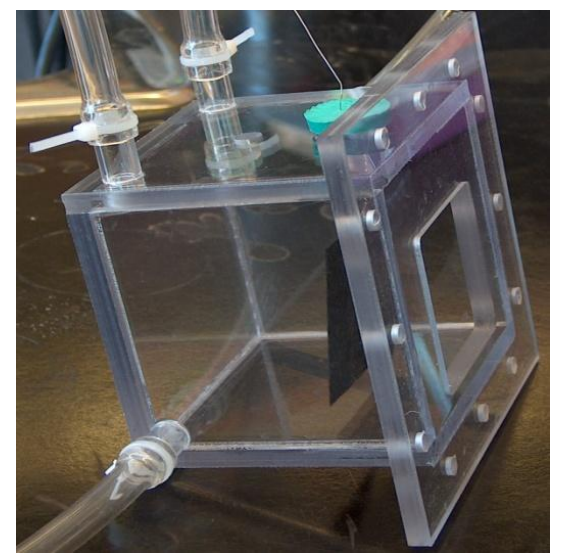

(C)

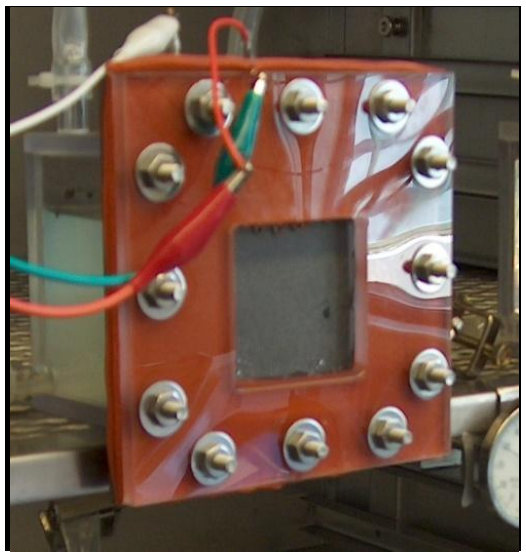


Figure 1.1: (A) Schematic of the key components of an MFC. (B) Experimental setup of the anode compartment prior to being connected to the cathode (C) Experimental setup of an MFC operating with an air-cathode (Courtesy of Nicholas Bourdakos).

\subsubsection{Sediment Microbial Fuel Cells (SMFCs)}

The SMFC or the Benthic Unattended Generator (BUG) is one of the most important discoveries of recent MFC research. These are designed to power electronic devices, such as monitoring equipment at the bottom of the ocean and in other aquatic environments, where the use of traditional batteries could be expensive and difficult to maintain. The SMFCs consist of an anode submerged in anoxic marine sediments that is connected to a cathode suspended in the overlying aerobic water (Bond and Lovley, 2003). The peak sustained electric power achievable by an SMFC is about $0.055 \mathrm{~W} / \mathrm{m}^{2}$ (Scott et al., 2007).

The marine sediment environments are commonly composed of microbial consortia such as fermentative microorganisms and metal-reducing microorganisms. However, the analysis of microbial community colonizing the anode surface from a variety of marine/freshwater sediments and organic waste matter showed that the anode was highly enriched with microorganisms of the Geobacteraceae family. Hence it was determined that the complex organic matter in marine sediments is broken down by various hydrolytic enzymes and fermentative microorganisms into acetate and other electron donors, which Geobacteraceae completely oxidize into $\mathrm{CO}_{2}$ with electron transfer to the anode (Lovley, 2006a; Lovely, 2006b). The pure culture studies that were conducted on Geobacteraceae demonstrated that these microorganisms are able to conserve energy to support their growth by completely oxidizing acetate and other organic matter (Bond et al., 2002). The species of Geobacteraceae that has the ability to promote this form of oxidation includes Geobacter sulfurreducens, Geobacter metallireducens, Geobacter psycrophilus, Desulfuromonas acetoxidans, and Geopsycrobacter electrodiphilus.

However, further understanding of the colonization and the extracellular electron transfer

of Geobacteraceae and other microorganisms that attach to the anode is essential in optimizing MFC processes. 


\subsection{Important Biofilm Processes}

\subsubsection{Mechanism of Extracellular Electron Transfer}

In recent years, significant research activity focused on exploring the extracellular electron transfer mechanisms in microorganisms that are relevant for environmental applications, such as bioremediation and MFCs. Extracellular electron transfer is defined as the process in which the electrons released in the oxidation of an electron donor are transferred out of the microorganism to reduce an extracellular electron acceptor. These extracellular electron acceptors can be either soluble or insoluble. The soluble electron acceptors, such as Fe (III) chelated with citrate and $\mathrm{U}(\mathrm{VI})$ complexed with carbonate, are normally reduced extracellularly, as they are too large to enter the microorganisms. However in MFC research, understanding the electron transfer to insoluble electron acceptors is of critical importance. In natural biochemical processes, minerals such as Fe (III) and Mn (IV) oxides act as insoluble electron acceptors, whereas in electricity production electrons are transferred to an anode (Lovley et al., 2008a).

To date, three mechanisms in which electrons are transferred from the microorganisms to the anode have been identified (Leang et al., 2010). These are:

\section{a) Electron Transfer through Soluble Electron Mediators}

The electron mediators provide a means for shuttling the electrons from inside of the microorganisms to the anode. These mediators are either provided externally to facilitate the electron transfer (exogenous mediators), or self-produced by the microorganisms (endogenous mediators). Examples of exogenous mediators include potassium ferric cyanide, anthraquinone 2, 6 disulfonic acid (AQDS), cobalt sepulchrate, thionine, azura A and neutral red (Bond and Lovley, 2003; Min and Logan, 2004). However, most of these mediators are toxic and pose environmental and health concerns in using MFCs to harvest electricity in open environments (Bond and Lovley, 2003). The short lifetime, and the expenses also prove the use of exogenous mediators to be impractical (Min and Logan, 2004). However, the studies done by Rabaey et al., 2004 were able to characterize an endogenous mediator, pyocyanin, excreted by Pseudomonas aeruginosa. These experiments were conducted in a batch reactor to allow the accumulation of the mediator to high concentrations in order to sustain current densities of $3.1 \mathrm{~W} / \mathrm{m}^{3}$ to $4.2 \mathrm{~W} / \mathrm{m}^{3}$ (Rabaey et al., 2004). Pure culture studies that were done on Geothrix fermentans by Bond and Lovely, 2004 also showed evidence for the production of an endogenous electron mediator. 
However, they found that the replacement of the medium from the fuel cell decreased the power production by 50\% (Bond and Lovely, 2005). Also it has been found that mediators may only be effective across a short range of approximately $1 \mu \mathrm{m}$ in biofilms, favouring microorganisms that are only in close contact with the anode (Franks et al, 2010). Hence, MFCs that rely on either exogenous or endogenous mediators do not play an important role in open flow-through systems that are required for wastewater treatment (Lovely, 2006a; Marsili et al., 2008).

However, the presence of microorganisms such as Shewanella putrefaciens, Geobacter sulfurreducens, Geobacter metallireducens, and Rhodoferax ferrireducens which have been shown to generate electricity in mediator-less MFC systems, eliminates the need for toxic electron mediators (Min and Logan, 2004).

\section{b) Conduction of electrons Across Conductive Nanowires or Other Filamentous Structures}

Several studies have been conducted on S. oneidensis (Gorby et al., 2006) and $G$. sulfurreducens (Reguera et al., 2005) to confirm the role of conductive nanowires on electron transfer to the anode. Scanning tunneling microscopy (STM) studies conducted by Gorby et al., 2006 demonstrated the conductivity across the nanowires in S. oneidensis. Reguera et al., 2005 were also able to confirm and measure the radial conductance across these filaments on $G$. sulfurreducens through conductive-probe atomic force microscopy experiments. These nanowires can promote long-range electron transfer across multilayer biofilms as thick as approximately 40-50 $\mu \mathrm{m}$, and also acts as structural components of biofilm formation (Reguera et al., 2006). In addition, Ritcher et al., 2009 reported that deleting pilA gene in $G$. sulfurreducens gave rise to thinner biofilm formation and significantly lower current densities compared to the wild type strain. These results demonstrate the involvement of conductive pilA in biofilms, on electron transfer.

\section{c) Electron Transfer through Direct Contact between Redox-Active Proteins on the Cell Outer Surface and the Electron Acceptor}

G. sulfurreducens has also demonstrated the presence of numerous c-type cytochromes and multicopper proteins that are essential for extracellular electron transfer (Leang et al., 2010; Lovley, 2008a). Cyclic voltammetry studies conducted on wild type and mutant $G$.

sulfurreducens show the involvement of outer membrane c-type cytochrome, OmcZ, in homogeneous electron transfer (across biofilm), while OmcB participates in heterogeneous 
(biofilm-to-anode) electron transfer. The mid-point potential for heterogeneous electron transfer was also reported, along with a mathematical representation for this electron transfer based on Butler-Volmer equation (Richter et al., 2009). In addition, the recent studies conducted by Leang et al., 2010 have shown that OmcS acts as a capacitor cytochrome along the nanowires and allows temporary storage of electrons when an electron acceptor is not readily available.

\section{Mechanisms of Proton Transfer}

Although the primary goal in MFC research is to obtain high current densities by improving the electron transfer across biofilms, the transfer of protons produced during the oxidation process also plays a crucial role in determining the amount of current producible by a biofilm (Franks et al., 2010). Until recent years, MFC researchers considered the final electron transfer steps to an electron acceptor, to be the direct energy conservation method in microorganisms (Lovely, 2008b). However, bacterial cells also gain energy by pumping protons across the inner membrane. This forms a proton gradient that drives the conversion of ADP to ATP through membrane bound ATPases, and this mechanism is essential for cellular respiration (Franks et al., 2010).

\section{a) Effect of Intracellular and Extracellular Electron Acceptors on the Proton Transfer}

The proton transfer across microorganisms coupled to extracellular electron acceptors is significantly different compared to the reduction of soluble electron acceptors, such as oxygen, nitrate, sulfate or fumarate. In the latter case, the soluble electron acceptors are reduced intracellularly, and the protons produced in the oxidation are directly consumed by the electron acceptor. However, in the case of extracellular electron acceptors such as, Fe (III) oxides and electrodes, there is a net production of protons in the cytoplasm. This causes the proton gradient across the inner membrane to decrease, resulting in high energetic requirements to drive the protons out of the microorganism (Franks et al., 2009; Franks et al., 2010; Srinivasan and Mahadevan, 2008). Although the proton production during Fe (III) oxides reduction does not pose a significant impact due to low cell numbers and environmental buffering capacities, in high current density MFCs the rate of oxidation is higher, resulting in high proton production rates. Moreover, the biofilms formed in MFCs are usually of high cell density and can grow up to approximately $50 \mu \mathrm{m}$ (Reguera et al., 2006). Thus, the limitations in proton diffusion across 
the biofilm can potentially cause acidification of the overall anode medium, in addition to localized proton accumulation within the biofilm (Franks et al., 2009).

\section{b) Proton Transfer across MFC Compartments}

Most previous studies have been related to proton transfer across the cation-exchange membrane, from anode to the cathode compartment. Effective proton transfer between anode and the cathode compartments is necessary in maintaining the electro-neutrality in the anode compartment. Slow proton transfer across the membrane can cause the acidification of the anode and the alkalization of the cathode (Franks et al., 2009). In abiotic fuel cells that require proton transfer across membranes, an acidic $\mathrm{pH}$ medium can be used to promote proton transfer between anode and cathode (Torres et al., 2008a; Torres et al., 2008b). However, most microorganisms used in MFCs require near neutral $\mathrm{pH}$ conditions; thus, decreasing the $\mathrm{pH}$ in the anode medium can suppress microbial activity resulting in low current densities (Franks et al., 2009). The efficiency of proton transfer between the anode and the cathode compartment depends on several factors such as, the material used for the proton exchange membrane, the type and concentration of the buffering medium used and, the physical distance between the anode and the cathode (Franks et al., 2010). Rozendal et al., 2007 reported that poor proton transportation across various cation exchange membranes operated at neutral $\mathrm{pH}$ values resulted in significant decrease in the voltage efficiency. Although, the addition of excess buffer can control the $\mathrm{pH}$ levels in the MFC anode compartment, this might not be a practical approach in real-world applications. In flow-through systems used for water treatment, continuous addition of buffer might be required, increasing the cost and a mechanism to remove the buffer after power production (Franks et al., 2010).

\section{c) Proton Transfer Across the Biofilm Thickness}

In some cases, poor proton transfer can cause large $\mathrm{pH}$ gradients across the biofilm, even when the bulk solution is at neutral $\mathrm{pH}$ levels. Hence, in improving the current production of the MFC, facilitating an effective proton transfer across the biofilm and its diffusion layer is more significant than addressing the $\mathrm{pH}$ gradient across the anode and the cathode compartments (Torres et al., 2008b; Franks et al., 2009). Torres et al., 2008b conducted a model based analysis of $\mathrm{pH}$ gradient across the biofilm; they reported that G. sulfurreducens become metabolically 
inactive when the $\mathrm{pH}$ levels are at 6 or lower, thus a substantial region of the biofilm near the anode did not contribute to current production. However, these model predictions were on qualitative basis and, better understanding of these processes is required in order to develop models that can fully predict the changes in current production based on different MFC designs and biofilm proton fluxes. Hence, Franks et al., 2009 conducted a series of studies using realtime confocal scanning laser microscopy that made the accurate measurement of proton accumulation associated with current production in biofilms, possible. These studies also showed how the proton flux is affected by the biofilm structure. Their experiments proved that the growth of G. sulfurreducens biofilms in pH 7 medium was significantly better compared to pH 6 medium, and the metabolic activity was inhibited under low $\mathrm{pH}$ levels. These experiments validated the model predictions reported in Torres et al., 2008b. Furthermore, they pointed out that the modification of the structure and material of the MFCs, as well as the engineering microorganisms to form more porous and homogeneous biofilms that have higher $\mathrm{pH}$ tolerance levels could maximize the current productions of the biofilms (Franks et al., 2009).

\subsubsection{Importance of G. sulfurreducens in MFC Research}

As seen by the nature of the above studies, most MFC research conducted on elucidating these phenomena is based on G. sulfurreducens, as it is closely related to the Geobacteraceae species that colonize the anode in SMFCs, and also it is enriched in MFC anodes designed to study their potential in wastewater treatment. Furthermore, the ability of G. sulfurreducens to produce a conductive biofilm matrix promoting uninterrupted high current densities, without the reliance on mediators makes it the most effective microorganisms known for harvesting electricity in MFCs. The availability of the complete genome sequence and a genetic system of G. sulfurreducens also makes the in-depth analysis of its cellular components related to its current producing capabilities, possible (Richter et al., 2009; Izallalen, et al., 2008; EsteveNunez et al, 2008). 


\subsection{Outlook on Recent MFC research}

Despite the considerable success achieved by the SMFCs and pilot-scale wastewater treatment applications such as Megawatter and Bilexys, full-scale MFCs with high current and power densities are yet to be developed. In recent years, extensive research studies have been conducted in order to improve MFC performances based on the design, material of construction, and the choice of pure/mixed microbial communities. An outlook of current research advancements, and some essential evaluation criteria required to analyze and compare these advances are presented below.

\subsubsection{Evaluation Criteria for MFC Performance}

Power density is an essential criterion in evaluating electricity production capacity of an MFC. It is the rate at which the energy is produced, either based on the electrode surface area $\left(\mathrm{W} / \mathrm{m}^{2}\right)$ or the total reactor volume $\left(\mathrm{W} / \mathrm{m}^{3}\right)$ (Logan, 2007). Rabaey and Verstraete, 2005 estimated that more than $1 \mathrm{~kW} / \mathrm{m}^{3}$ of power density is required for the MFCs to reach a commercial stage, based on the current densities produced by burning methane for powering anaerobic sludge blanket reactors. The power densities attainable by MFCs are dependent on both electrochemical and biological processes (Rabaey and Verstraete, 2005; Torres et al., 2008b). Thus, enhancing the MFC power production requires the simultaneous optimization of both components.

While the main goal of MFC research is to enhance the power production, it is also essential to improve the Coulombic efficiency and the potential efficiency of the fuel cells. The Coulombic efficiency is defined as the fraction of electrons recovered as the current, versus that in the starting organic material used as the electron donor. This is mainly dependant on the type of electron donor used (Logan, 2007; Lee et al., 2008).

The potential efficiency is the fraction of the potential difference captured as useful energy versus the potential difference between the electron donor and the acceptor. The potential efficiency is generally based on over-potentials at the anode and the cathode, and Ohmic losses. Ohmic losses are proportional to the current and the Ohmic resistance of the system (R $\Omega$ ), whereas the over-potentials of the electrodes are generally current dependent and arise from (i) 
activation losses, (ii) bacterial metabolic losses, and (iii) mass transport or concentration losses (Logan et al., 2006; Logan, 2007; Lee et al., 2008; Fan et al., 2008a).

Ohmic losses: These are the most important losses to overcome in achieving optimum MFC architecture. Ohmic losses occur due to the resistance to the current flow at the electrodes and the interconnections, and the resistance to ion flow across the anodic and the cathodic electrolytes and the cation exchange membrane. These losses can be minimized by reducing the electrode spacing, choosing low resistance electrode coating and membranes, ensuring good contact between interconnections, and increasing solution conductivity and buffering capacity within the limits permitted by the microorganisms used.

Activation Losses: These occur as a result of the energy loss in initiating oxidation/reduction reactions, and in transferring electrons from within the microorganism to the electrode surface across nanowires, mediators or terminal cytochromes at the cell surface. These can be eliminated by improved catalyst at the cathode, different microorganisms at the anode, and improved electrode surface area.

Bacterial metabolic losses: These losses occur when the microorganism capture energy from the potential difference between the electron donor and anode, across its electron transport chain. Increasing potential at the anode will increase the potential difference between anode and the electron donor enabling high metabolic energy gain for the microorganism, and thereby MFC potential will be decreased. Thus, the anode potential should be as low as possible within the range that still allows extracellular electron transfer.

Mass transport losses: These losses are caused by the formation of large concentration gradients of the electron donor and/or the protons between the bulk solution and the locations within the biofilm, due to the mass transfer resistance. These can limit the growth and the current producing capabilities of the microorganisms. Maintaining high buffering capacities and engineering the microorganisms to form thinner biofilms with high coulombic efficiency can reduce some of the mass transport losses. 


\subsubsection{Commercial Advancements in MFCs}

The systems developed by Emefcy Ltd. and Bilexys have found considerable success in using MFC technology in pilot plant-scale. These advances are discussed in this section.

The main goal of the Megawatter system developed by the Emefcy Ltd. was to eliminate energy consumption of waste water by applying the principles of MFC for the direct production of electricity or hydrogen. These systems have found a broad range of applications in high salinity and high sulfate conditions, where conventional anaerobic water treatment processes are not suitable. The Megawatter systems are constructed by the serial stacking of small modules that comprise of an anode, membrane, cathode, and electricity/air connections. The components in the MFCs such as the anodes, cathodes, mixing hydraulic components and power control units were designed to allow scalability, along with high performance and durability. In addition, the modules were standardized using modeling tools allowing custom sizing and arrangements to meet the requirements of each case. The installation of a Megawatter system in an existing water treatment tank requires only minor changes to the infrastructure. In general, the Megawatter system can be used to treat waste water from industrial, agricultural and municipal sources with direct electricity production. In addition to the electricity production, the Megawatter system allows the production of hydrogen gas, with an energy input in the form of a voltage. The hydrogen produced using this method was 2-3 folds higher than the energy input during production. The success achieved by the Megawatter systems enabled the Emefcy Ltd. to be awarded and recognized as one of the pioneers in waste water treatment industry (Megawatter website).

The Queensland, Australia based company Bilexys has also found commercial success in utilizing MFC technology. The Bilexys system was developed as a scalable technology that can produce valuable products in a high and stable manner, utilizing real waste water. During the early stages of the Bilexys project, pilot-scale MFCs were used to produce electricity using brewery waste water for approximately 1 year. However, the current focus of Bilexys has been on producing chemicals such as caustic soda and hydrogen peroxide using the same set up used in MFCs with the addition of external power. The MFCs driven with an external power input are called bioelectrochemical systems (BESs), and the process of using biocatalysts to achieve electricity driven synthesis of chemicals is called microbially assisted electrosynthesis. Bilexys 
have found bioelectrosynthesis to be more effective in establishing a profitable market rather than producing electricity (Bilexys website).

\subsection{3 $\quad \underline{\text { Research Advancements in MFCs }}$}

The construction of an MFC for practical applications requires the identification of sustainable materials and a scalable architecture that maximizes the power generation, while minimizing the cost (Logan, 2007). The most commonly used " $H$ " shape MFCs are inexpensive to construct and are used for basic parameter research, such as examining the effect of power production based on new materials and microorganisms. These types of fuel cells can be constructed by connecting two bottles with a tube containing either a cation exchange membrane or a salt bridge, and are operated in batch mode. These systems tend to have low current densities due to high internal resistances and the potential losses at the electrodes (Logan et al., 2006). However, significant variations in the power production can be seen by changing the anode surface area. The H-shaped MFCs have produced $1430 \mathrm{~mW} / \mathrm{m}^{3}$ using graphite brush electrodes, $1100 \mathrm{~mW} / \mathrm{m}^{3}$ using random graphite fibres and, $600 \mathrm{~mW} / \mathrm{m}^{3}$ using plain carbon electrodes Although graphite fiber brush electrodes allow higher power generation, the long term sustainability of these materials has not been well studied (Logan, 2007).

The cathode material and the configuration can also be changed to obtain higher current densities. The H-shaped MFCs, using ferricyanide as the terminal electron acceptor in the cathode compartment at high concentrations has increased the power production by 1.5 to 1.8 times compared to oxygen and a Pt carbon cathode (Oh and Logan, 2006). Nevertheless, the use of ferricyanide is usually restricted to laboratory studies, as its use is unsustainable and must be chemically regenerated (Logan et al., 2006). When oxygen is used at the cathode, the cathode can be placed in a separate water bath or be directly exposed to air (known as the air cathode). The air cathodes have proven to be more effective in power generation due to their high oxidation potential, availability, sustainability and the lack of chemical waste production (Rabaey and Verstraete, 2005). In one of the recent studies, Fan et al., 2008 reported a power density of $1010 \mathrm{~W} / \mathrm{m}^{3}$ using air cathode MFCs with cloth electrode assemblies (CEAs) (Fan et al., 2008b). In a later study Fan et al., 2008a were able to achieve a power density of $6.9 \mathrm{~W} / \mathrm{m}^{2}$ with a cathode 14 times greater than the anode surface areas. However, if the power was normalized to the cathode surface area, the power density decreased to $490 \mathrm{~mW} / \mathrm{m}^{2}$; thus the 
MFC did not necessarily increase in power production. Nevertheless, this shows that the anode can be maintained at high power densities if the cathode processes are optimized (Fan et al., 2008a).

These MFCs can operate either in the presence or absence of a cation exchange membrane (Logan et al., 2006). Nafion is commonly used as the membrane material in lab-scale MFCs; however, the excessive cost makes its use prohibitive in large-scale applications (Logan, 2007). Other material such as Ultrex is also found to be an inexpensive alternative to Nafion, with promising results (Logan et al., 2006; Rabaey and Verstraete, 2005). However, the complete elimination of the cation exchange membrane has also been considered, and these experiments were reported in Lui and Logan, 2004. With this setup, although the power densities increased due to the decrease in the internal resistances, Coulombic efficiency was decreased, indicating substantial oxygen diffusion to the anode compartment (Lui and Logan, 2004). However, with the increasing market for new membrane materials, more systematic studies are required to evaluate the effect of membrane on the MFC performance and the long term stability (Logan et al., 2006).

In contrast to operating the MFCs under batch conditions, they can also be operated with continuous flow through the anode compartment. Cheng et al., 2006 determined that flow directed through the anode while decreasing the electrode spacing, increased power densities from $811-1540 \mathrm{~mW} / \mathrm{m}^{3}$ in an air cathode MFC. They related the increase in the power density to the restricted air diffusion towards the anode, and the effective proton transfer towards the cathode, facilitated by the advection flow (Cheng et al., 2006).

It has also been found that connecting MFCs in stacks can improve the fuel cell performance. Aelterman et al., 2006b conducted a set of experiments to evaluate the power outputs with MFCs stacked in series and parallel configurations. These experiments determined that although the power production remained comparable with an individual MFC setup, the potential and the coulombic efficiencies increased, considerably.

Determining the most suitable electron donor at the anode compartment is also essential in enhancing power production. Lee et al., 2008 determined the energy conversion efficiencies (ECEs) in MFCs utilizing fermentable (glucose) and non-fermentable (acetate) electron donors. 
The ECE using acetate was recorded to be $42 \%$ with a power density of $360 \mathrm{~mW} / \mathrm{m}^{2}$, whereas the ECE and power density using glucose were only $3 \%$ and $9.8 \mathrm{~mW} / \mathrm{m}^{2}$, respectively. The low performance of glucose-fed MFC was due to the formation of thicker biofilms with low microorganism density that gave rise to low kinetics and high concentration losses. Thus, acetate is considered to be the best electron donor in MFCs used in lab-scale experiments (Lee et al., 2008).

Adapting G. sulfurreducens to produce higher current densities is another approach that is evaluated in optimizing MFC current generation. Yi et al., 2009, has reported that with the appropriate selective pressure on wild type DL1 strain, a new strain (KN400) with enhanced current producing capacities can be recovered. Under similar MFC operating conditions, KN400 strain formed thinner biofilms with a power density of $3.9 \mathrm{~W} / \mathrm{m}^{2}$ compared to thicker biofilm forming DL1 strain that produced a power density of $0.5 \mathrm{~W} / \mathrm{m}^{2}$. Hence on per cell basis $\mathrm{KN} 400$ strain was proven to be more effective than DL1 strain (Yi et al., 2009).

Experiments with mixed microbial cultures have also been performed to evaluate the possibility of increasing the current production of MFCs. This was done by allowing higher current producing microorganisms to dominate the anode over time, leading to their selection in a mixed community of current producing and non-current producing microorganisms. This method showed increased levels of current production and it was associated with the reduced overpotential observed at the anode (Rabaey et al., 2004).

The Fig. 1.2 illustrates the improvements of power densities normalized to the electrode surface area reported since 1996 -2009 by different researchers. The studies represented by the circles show the increasing trend of power densities with MFCs using air cathodes, reported from 1996- 2006. Higher power densities obtained from a series of recent studies with power normalized to the cathode surface area are shown by the triangles. In these studies the power densities were limited by the cathode processes rather than the anode processes. The study shown by the rectangle corresponds to the study reported in Fan et al., 2008a, with a cathode surface area 14 times larger than the anode. 


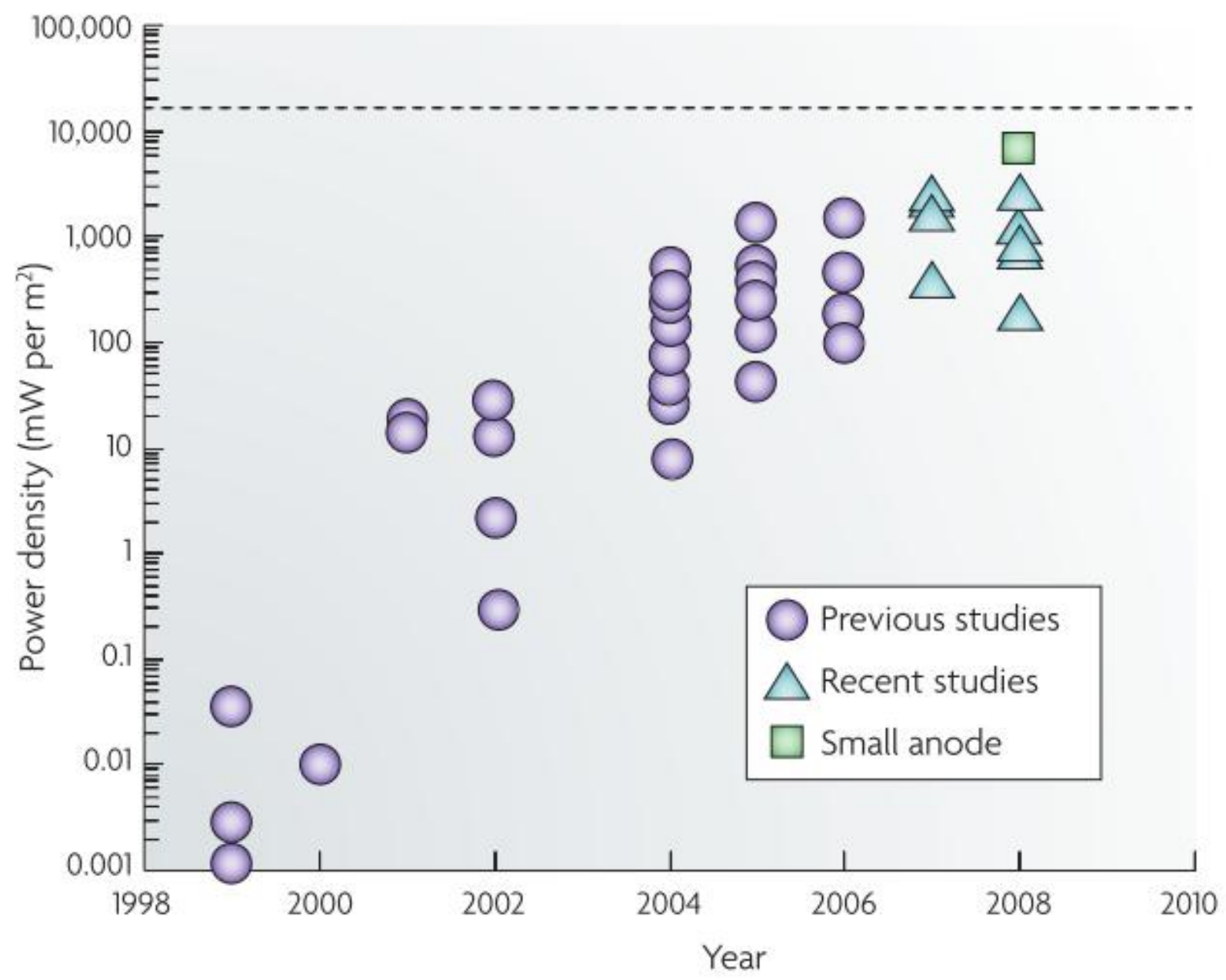

Figure 1.2: The improvements of power densities normalized to the electrode surface area reported by different researchers, since 1996 -2009 (Adapted by permission from Macmillan Publisher Ltd: [Nature Review] (Logan, 2009), copyright (2009)). 


\subsection{Mathematical Modeling of MFCs}

The scope of these experimental studies indicate that a diverse range of multidisciplinary concepts such as microbiology, materials and chemical engineering, electrochemistry and also insights on the metabolic behaviour of G. sulfurreducens, are essential in enhancing the power production in MFC. Thus, research tools that can incorporate most of these aspects are crucial in determining the future applicability of MFCs. Among these tools, mathematical models have proven to be very effective in providing a systematic framework in integrating various disciplines and generating simplified representations of complex real world processes (IWA Task Group on Biofilm Modeling, 2006). Several mathematical models for MFCs already exist; they are mainly focused on understanding the anodic biofilm processes. The key characteristics and the limitations of the existing models are discussed below. In addition, this section introduces the genome-scale metabolic model of G. sulfurreducens that can be used to improve existing MFC models.

\subsubsection{Picioreanu et al. Models (2007 and 2008)}

\section{a) 2007 Model}

Picioreanu et al., 2007 developed a general MFC model based on electron transfer through diffusible mediators, including both suspended and attached cells in the form of biofilms (Picioreanu et al., 2007). This model was specifically formulated for a MFC that is operated in batch mode, utilizing acetate as the electron donor. It is developed by combining an electrochemical model and a biofilm/bulk liquid model.

The electrochemical model represents the electrode reactions, based on the reactant/product concentrations at the anode surface and the anode potential. The current density was calculated using the Butler-Volmer equation, where as the total current and charge were calculated by integrating the local current and charge densities over the anode surface area. The actual fuel cell voltage $\left(\mathrm{V}_{\text {cell }}\right)$ was determined as follows: $\mathrm{V}_{\text {cell }}=\mathrm{E}_{\text {cell }}-$ Losses. The actual fuel cell voltage is lower than the cell voltage at equilibrium $\left(\mathrm{E}_{\text {cell }}\right)$ due to a series of irreversible potential losses. The cell voltage at equilibrium is determined as the difference between the ideal equilibrium potentials of the anode and the cathode. The potential losses are caused by the overpotentials and Ohmic losses of the system. 
The biofilm model component is composed of mass balances for mediator concentration and other soluble chemicals at the electrode surface, based on transport and reaction processes across the biofilms. These were represented in terms of partial differential equations that balance diffusion and reaction rates in the biofilms. One-, two- or three- dimensional evaluations along the spatial distributions of the biofilm are possible with this model. The biomass attached to the anode was modelled to follow dynamics of spatial distributions of the microbial population. The biomass exchange between the attached and the suspended phases were also included. The $\mathrm{pH}$ calculations were done at each location across the biofilm, and the electrochemical mediator oxidation was dependant on the $\mathrm{pH}$ variations, in addition to the electron donor and the potential losses. A set of mass balances that determine the time dependency of solute concentrations and suspended biomass were used to model the bulk solution processes. The bulk solution was assumed to be completely mixed, and also allowed the continuous addition of the soluble substrates into the MFC.

This model was used to evaluate the effect of different parameters, such as electron donor uptake yields, standard potential of the mediator, suspended to attached cells ratio, initial substrate and mediator concentrations and mediator diffusivity. Two- and three- dimensional studies showed the variation of the biofilm structure from heterogeneous to homogenous formations over time. One dimensional studies conducted on uniform homogenous biofilms, were found accurate when compared to experimental results obtained in batch MFCs with Geobacter fed with acetate. However, in order to extend the applicability of this model framework to practical use, it must be applied to more complex cases where the MFC is fed with waste water containing a mixture of electron donors, and complex microbial communities. Thus, Picioreanu et al., 2009 published an extended version of the Picioreanu et al., 2007 model addressing some of the requirements listed above (Picioreanu et al., 2007).

\section{b) 2009 Model}

The Picioreanu et al., 2009 model was formulated by combining the Picioreanu et al., 2007 model with a biochemical model based on IWA's anaerobic digestion model (ADM1). This allows the accurate representation of a MFC operated with a microbial community taken from an anaerobic water treatment process, where methanogenic and electroactive microorganisms coexist. The model assumes that the glucose acidification to short term carboxylic acid is followed 
by acetate production, and then by methanogenesis and hydrogen production. The electroactive microorganisms then oxidize the acetate with the help of the electron mediator, producing current. In addition to the results that could be obtained with the Picioreanu et al., 2007 model, this model also showed that biofilms produced current at a higher coulombic efficiency under low external resistances, indicating that the biofilm is highly enriched with electroactive microorganisms under these conditions. Hence, it is evident that the electron donor was converted to electricity rather than following a methanogenic path (Picioreanu et al., 2008).

\subsubsection{Kato-Marcus et al. Models (2007, 2008 and 2010)}

\section{a) 2007 Model}

In contrast to the Picioreanu et al., 2007 model, the Kato-Marcus et al. 2007 model represents a MFC that is operated under continuous flow mode, with a biofilm that is attached to the anode surface. The electron transfer from the microorganisms to the anode occurs through a conductive biofilm matrix that indicates both nanowire and c-type cytochrome based electron transfer mechanisms. This model is a dynamic, one dimensional, multi-species model, and the biofilm is assumed to grow in a plane perpendicular to the anode using acetate as the electron donor. The main purpose of this model was to study the dual limitations of the electron donor concentration and the anode potential on various biofilm processes such as, electron donor utilization, current production and biomass growth. The mathematical representation of the dual limitations is based on the Nernst-Monod equation that describes the bacterial kinetics under the influence of the anode potential. This is shown by Eq. (1) (Kato-Marcus et al., 2007):

$$
q=q_{\max } \phi_{a}\left(\frac{S_{d}}{S_{d}+K s_{d}}\right)\left(\frac{1}{1+\left[-\frac{F}{R T} \eta\right]}\right)
$$

where, $\mathrm{q}$ is the electron donor uptake rate (mmol-ED/mg VS. day), $\mathrm{q}_{\max }$ is the maximum electron donor uptake rate (mmol-ED/mg VS. day), $\phi_{\mathrm{a}}$ is the active biomass fraction (dimensionless), $S_{\mathrm{d}}$ is the electron donor concentration $\left(\mathrm{mmol}-\mathrm{ED} / \mathrm{cm}^{3}\right), \mathrm{K}_{\mathrm{sd}}$ is the half maximum rate acetate concentration $\left(\mathrm{mmol}-\mathrm{ED} / \mathrm{cm}^{3}\right), \mathrm{F}$ is the Faraday constant $(96,485$ Coulomb/mol-e), $\mathrm{T}$ is the temperature $(298.15 \mathrm{~K}), \mathrm{R}$ is the ideal gas constant (8.3145 J mol-1 K-1), and $\eta$ is the local potential (V). In this model all rates were represented in terms of the volatile solid (VS) content of the cells; and cells are determined to be about $90 \%$ volatile (Kato-Marcus et al., 2007). 
The Nernst-Monod equation was then linked with the biofilm anode processes based on a steady state mass balances for electron donor, electrons, local potential and a dynamic mass balance for active and inert biomass. The electron donor balance was based on the utilization of the electron donor and the molecular diffusion. The electron balance was also developed based on the diffusion and the production of electrons due to the electron donor oxidation and the endogenous respiration. The electron balance was then combined with the Ohm's law to create the balance for the local potential across the biofilm. This equation assumed constant conductivity all throughout the biofilm. The dynamic balances for active and inert biomass were written using the volume fractions occupied by each type of biomass. The active biomass represents the microorganisms that contribute towards current production, whereas the inert biomass represents the conductive material such as extracellular polymeric substances (EPS), nanowires and inactive biomass. The biomass equations stated that the accumulation and the advection of biomass are equal to the net effect of processes, such as growth, endogenous respiration and the decay of biomass. The endogenous respiration process provides the ATP energy required for the maintenance of the microorganism under nutrient limited conditions; and this process promotes cell lysis, releasing soluble substrates that can potentially support the regrowth of microorganisms on the anode ( $\mathrm{Hu}, 2008$; Torres et al., 2007). The advection of the biomass was characterized by the advection velocity of the biofilm matrix, and the advection velocity changes in response to the net specific growth rate of active and inert biomass. The change in biomass thickness as a function of time was related to the advection and the detachment of the biomass at the biofilm/bulk solution interface. These equations are discussed further, in Chapter 2.

The model was simulated to determine the variations in the biofilms processes, while changing a set of parameters such as the conductivity, cell density, biomass yield and the detachment rate. These model simulations illustrated that the conductivity of the biofilm plays a major role in electron donor and current fluxes, the type of limitations in the biofilm and the distribution of biomass. Higher biofilm conductivities gave rise to thicker biofilm formation, increasing the physical separation between the anode and the bulk solution. This caused the mass transfer resistance across the biofilm to increase, making the biofilm more susceptible to dual limitations due to both electron donor and local potential. These limitations reduced the current 
producing ability of the biofilm. However, inducing higher detachment rates and cell densities can decrease the biofilm thickness by reducing the dual limitations. (Kato-Marcus et al., 2007).

\section{b) 2008 Model}

These model predictions mentioned above, were followed by a series of experiments that was conducted to demonstrate the ability of the Nernst-Monod equations to describe the potential losses across biofilms. Torres et al., 2008c conducted low scan cyclic voltammetry (LSCV) studies on G. sulfurreducens biofilms to determine the midpoint potential of the microorganism. This value was reported to be $-0.425 \pm 0.002 \mathrm{~V}$ vs. $\mathrm{Ag} / \mathrm{AgCl}$. The Nernst-Monod equation was then modified by subtracting the mid-point potential value from the local potential term; and fitted with the experimental data obtained from LSCV. These studies illustrated that the NernstMonod equation showed no significant deviation compared to LSCV results at high current densities, given that the conductivity of the biofilm used was $\geq 0.5 \mathrm{mS} / \mathrm{cm}$. The higher conductivities indicated that the biofilm activity is less likely to be limited by the potential losses, rather than the electron donor concentration and the proton transfer (Torres et al., 2008c). Although these models showed the most appropriate setup for a practical continuous mode MFC using attached biofilms with direct electron transfer to the anode, they did not address the effect of proton transfer and buffer activity, on the biomass synthesis and the current production. Thus, it motivated the development of the Kato-Marcus et al., 2010 Proton Condition-BIOFILM (PCBIOFILM) model.

\section{c) 2010 Model (PCBIOFILM Model)}

The foundation of PCBIOFILM model is the CCBATCH model that was developed by VanBriesen and Rittmann, 1999. The CCBATCH model describes a system that has characteristics of a biofilm anode such as slow microbial reactions linked with fast aqueous acid/base and complexation reactions along with mass transport. However, major modifications to the CCBATCH model is essential in order to accurately represent the biofilm features such as high biomass density, mass transfer limitations and proton production. Hence, the PCBIOFILM model was constructed by expanding the CCBATCH model framework to include precipitationdissolution reactions, slow aqueous complexation reactions/transport, information on EPS, soluble microbial products, surface complexation, and bio-precipitation. In addition, the original 
CCBATCH model is equipped with a proton mass balance that links all processes involved in producing acids or bases, making the integrated PCBIOFLM model ideal for studying proton production and buffer activity that occurs in anode biofilms.

The PCBIOFILM model requires tracking the concentration of each species in the aqueous phase of the biofilm. The model relies on the general approach to reactive-transport modeling by representing all chemical species as components and complexes. The components are the fundamental building blocks that combine together to form complexes. Hence, according to the law of mass conservation, the concentration of a specific component $j$ is equal to the sum of concentration $j$ in the complexed form and concentration of $j$ in the uncomplexed form:

$$
C_{j}=c_{j}+\sum_{i=1}^{N_{p}} v_{i j} p_{i} \quad j=1, \ldots \ldots N_{C}
$$

where, $C_{j}$ is the total analytical concentration of component $j, c_{j}$ is the concentration of uncomplexed component, $p_{i}$ is the concentration for complex $i, v_{i j}$ is the stoichiometric coefficient giving the number of moles of component $j$ is complex $i$. $\mathrm{N}_{\mathrm{p}}$ and $\mathrm{N}_{\mathrm{c}}$ are the number of complexes and the number of components, respectively. In this model, the components were assumed to be neutral with respect to acidity, while proton excess and deficit complexes were regarded as acids and bases, respectively. The components produced or utilized by the activity in the biofilm were also taken into account (Kato-Marcus et al., 2010).

The concentrations calculated were then used in deriving mass balance equations for each component, by coupling both kinetically controlled reactions and mass transport phenomena. For example, the proton mass balance incorporates the change in total $\mathrm{C}_{\mathrm{H}+}$ concentration as a function of distance and the formation of protons during the oxidation (Eq. 3).

$$
\frac{\partial C_{j}}{\partial t}=\frac{\partial L\left(C_{j}\right)}{\partial x}+\sum_{k} \lambda_{j, k} r_{k}
$$

where, $x$ is the special coordinate, $t$ is time, $r_{k}$ is the reaction rate for $\mathrm{k}^{\text {th }}$ reaction and $\lambda_{j, k}$ is the stoichiometry coefficient for component $\mathrm{j}$ in the $\mathrm{k}^{\text {th }}$ reaction. $\mathrm{L}(\mathrm{)})$ is a transport operator, hence $\mathrm{L}\left(C_{j}\right)$ describes the total flux of component $j$ that depends on the transport processes occurring in the system. The transport operator for mass diffusion is shown in Eq. (4):

$$
-J_{j}=L\left(C_{j}\right)=D_{j} \frac{\partial c_{j}}{\partial x}+\sum_{i=1}^{N_{x}}\left(D_{i} \frac{\partial p_{i}}{\partial x}\right)
$$


where, $J_{j}$ is the total component flux. This phenomenon is applied in the case of a proton flux across the biofilm. The $\mathrm{c}_{\mathrm{j}}$ term that shows the uncomplexed proton concentration is used in calculating the $\mathrm{pH}$ levels. These capabilities of the PCBIOFILM model makes it possible to represent biofilms with a large amount of proton production. In addition, this model has the ability to identify the inhibition of microorganisms under low $\mathrm{pH}$ levels, the diffusion of buffer ions (phosphates and carbonates) to control $\mathrm{pH}$, the effect of alkalinity on high $\mathrm{pH}$ gradients and current densities and, the favorability of phosphates ions on the current densities compared to carbonates (Kato-Marcus et al., 2010).

\subsubsection{The Need for Metabolic Modeling of Biofilm Processes in MFCs}

Based on these model predictions and the experimental results, it is apparent that biofilm components such as current density, electron donor utilization and cell growth vary at different spatial locations, due to the exposure of variant environmental conditions across the biofilm. These are known as the spatial heterogeneities across the biofilm thickness. The differences in these spatial locations are generally caused by the gradient of the electron donor concentration, local potential, and the proton accumulation (Fig. 1.3). In general, the biofilm tends to be electron donor limited in the region closest to the anode surface, as the electron donor concentration falls below a threshold value. However, the MFCs using 10mM acetate under flow conditions are not thought to be electron donor limited (Franks et al., 2010). However, in waste water treatment application this concentration is typically around $0.3 \mathrm{mM}$; thus the biofilms are likely to be electron donor limited (Kato-Marcus et al., 2007).

If the biofilm is considered as a conductive matrix, it is considered as a part of the anode, and the electron conduction to the anode depends on the potential gradient across the biofilm thickness. The local potential at a specific location controls the driving force in which the electrons are transferred from the microorganism to the anode (Franks et al., 2010; Kato-Marcus et al., 2007). However, these electron acceptor limitations can be eliminated by using MFCs with poised anodes (Kato-Marcus et al., 2008). In these MFCs, the anode potential can be fixed at a particular value using a potentiostat controlled system. The use of a potentiostat to set the anode potential, removes any cathodic limitations. Although, poised anodes are used in experimental studies, the real world MFCs with anode and cathode compartments can have significant potential losses such as activation losses at the cathode and Ohmic losses due to charge transfer 
across membrane/external circuit (Logan, 2007; Fan et al., 2008a). It has been widely reported that cellular metabolism of G. sulfurreducens is drastically different under electron acceptor limited conditions (Cord-Ruwisch et al., 1998).

The accumulation of protons in the inner layers of the biofilms also causes a $\mathrm{pH}$ gradient to occur, across the biofilm. Based on recent studies this is considered to be one of the major limiting factors for power production in G. sulfurreducens biofilms (Franks et al., 2010). These limitations significantly alter the current producing ability of the microorganisms.

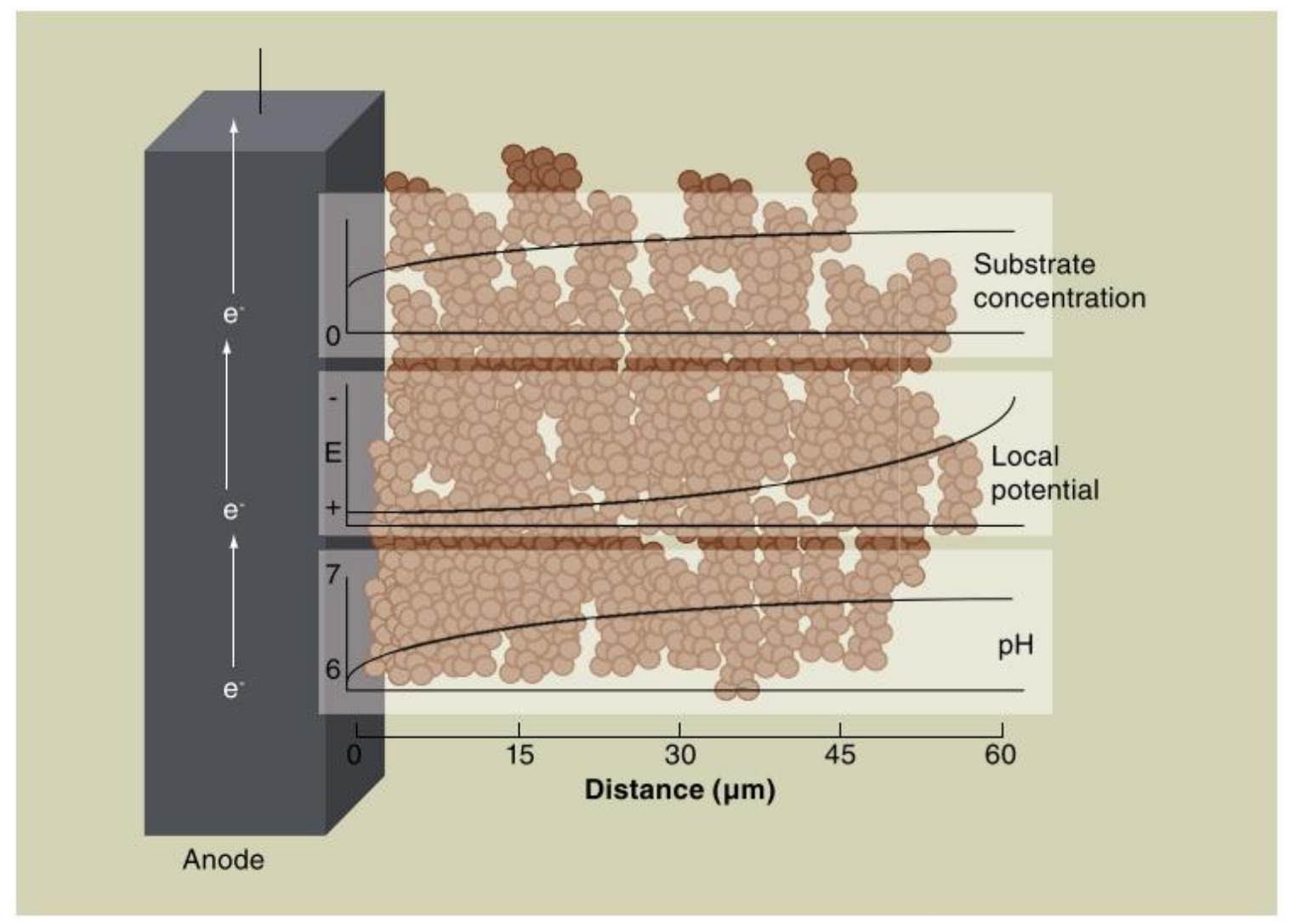

Figure 1.3: Electron donor, electron acceptor (local potential) and $\mathrm{pH}$ gradients across the spatial location of the biofilm of a microbial fuel cell (Adapted by permission from Future Science Ltd: [Biofuels] (Franks et al., 2010), copyright (2010))

Each of these limitations can cause inhibitions of the microbial activity of the biofilm, giving rise to thinner biofilm formations and lower current productions. Hence, a wide understanding of the metabolic response of $G$. sulfurreducens under different environmental 
conditions is necessary, in optimizing biofilm processes for increased current production. However, all existing biofilm models are restricted to studying the behaviour of extracellular electrochemical and microbiological components separated from the metabolic behaviour of $G$. sulfurreducens or vice versa. Thus, it is important to construct metabolic models that address the spatial heterogeneities across MFC biofilms, in order to accurately represent biofilm processes. Genome-scale models for microorganism have been used to investigate the metabolic response under varying environmental conditions (Price et al., 2004).

\subsubsection{The Use of Genome-scale Metabolic Model of G. sulfurreducens}

Previously, genome-scale metabolic models have been used to investigate the central metabolism and electron transport chain of G. sulfurreducens with available genetic and physiological data, using a constraint-based flux balance analysis (FBA) approach (Mahadevan et al., 2006). This approach has been proven effective in predicting physiological responses of microorganisms, in the absence of enzyme kinetics and detailed information about the cellular regulatory processes (Mahadevan et al., 2006). Furthermore, FBA does not assume constant yields, making this approach ideal for studying the cell behaviour under heterogeneous environments with nutrient limited conditions (Varma, et al., 1993).

The genome-scale flux balance model for G. sulfurreducens is comprised of a linear system of flux balance equations (Price et al., 2004). These equations connect the changes in the metabolite levels to intracellular fluxes of the reaction network. The model relies on a set of physicochemical constraints including thermodynamics, enzymatic capacity and stoichiometry to maintain the balance of individual metabolic fluxes in reactions (Mahadevan et al., 2006). In FBA, the stoichiometric constraints of the reaction network are represented by a stoichiometric matrix, $S$; where each row represents metabolites $(m)$ and the columns represent intracellular reaction fluxes $(n)$. In addition, each flux is constrained further by an upper and a lower bound. Reversible reactions are defined with an arbitrarily large upper bound and an arbitrarily large negative lower bound, whereas irreversible reactions have non-negative lower bounds. Insignificant reactions can be neglected by setting both upper and lower bounds to zero (Becker et al., 2007).

In general, there are more fluxes than metabolites in the reaction network, causing the system to be underdetermined; thus, more than one feasible solution for the flux distribution is 
possible (Price et al. 2004). However, an optimal flux distribution can be resolved, by setting a cellular objective and additional constraints on the fluxes predicted by the model; and solving it as a linear programming (LP) problem (Becker et al., 2007). In most cases maximization of cell growth is used as the objective function, although other optimization choices such as maximization of the ATP production rate and minimization of resource utilization could also be used (Schuster et al., 2007). The LP problem can be formulated as follows (Eq. 5):

$$
\begin{aligned}
& \text { Maximize }\left(C^{T} v\right) \\
& \text { s.t } S . v=0 \\
& v_{l b} \leq v \leq v_{u b} \\
& i=1,2,3 \ldots \ldots \ldots n
\end{aligned}
$$

where $S$ is the stoichiometric matrix and $v_{i}$ is the flux through reaction $i$. Typically, there are $m$ number of metabolites, and $n$ number of reactions, making the $S$ matrix $m x n$. The model formulation and the solution methodology used in flux balance analysis are illustrated in Fig 1.4. 
(a)

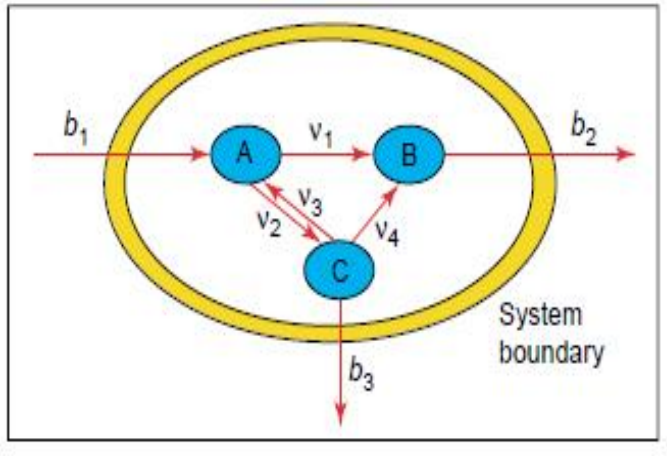

(c)

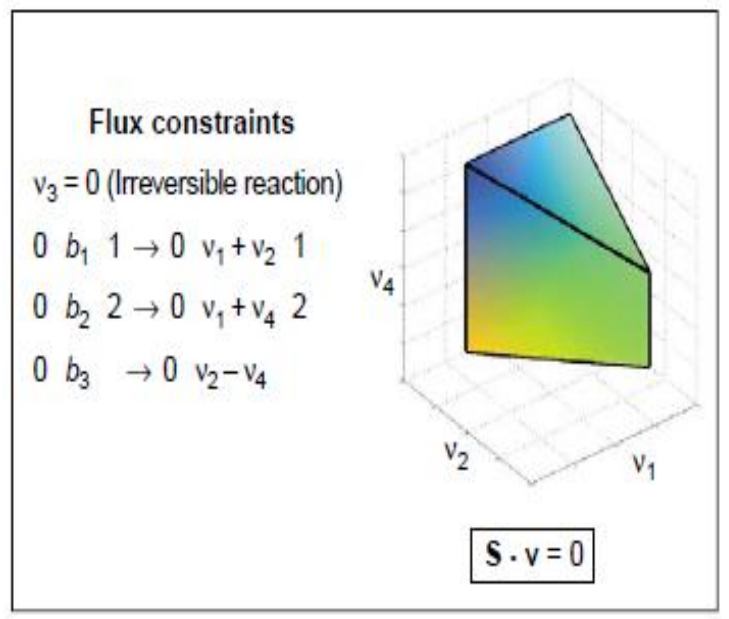

(b)

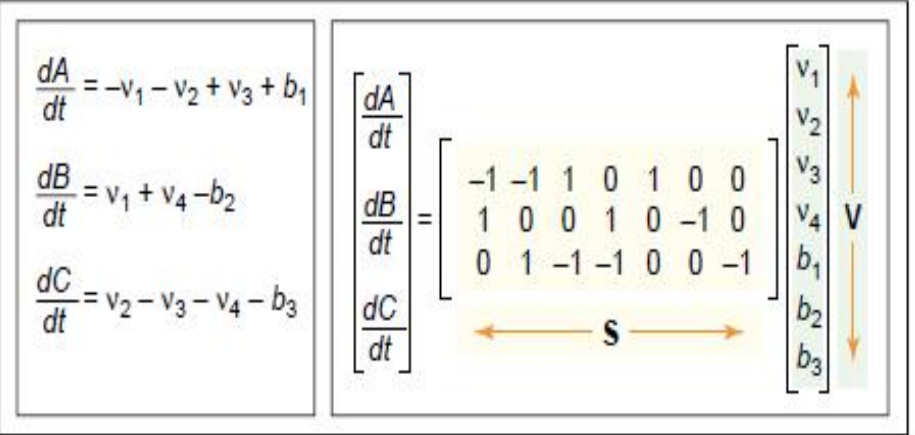

(d)

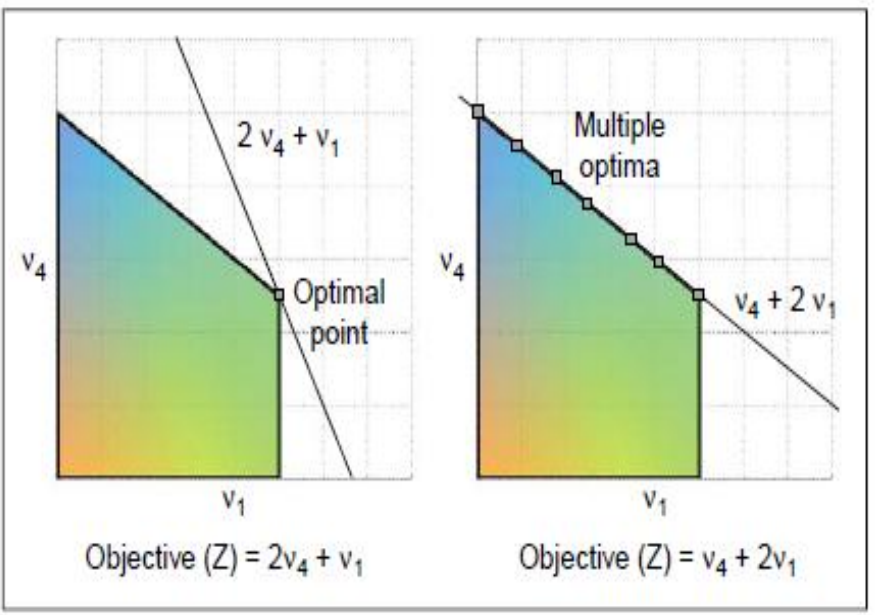

Figure 1.4: Methodology of flux balance analysis (FBA). (a) The model systems contain 3 metabolites (A, B and C) with 3 reactions and exchange fluxes. (b) Mass balance equations representing all reactions and transport mechanisms. (c) The system fluxes are constrained based on thermodynamics and experimental findings. (d) Optimizing the system with different objective functions (Adapted by permission from Elsevier Ltd.: [Current Opinion in Biotechnology] (Kauffman et al., 2003), copyright (2003)).

Studies such as identifying gene deletions to increase respiration rates of $G$. sulfurreducens were conducted using this model in conjunction with Optknock framework (Izallalen et al., 2008). Furthermore, this model was coupled with the reactive transport model HYDROBIO-GEOCHEM to model the in situ bioremediation (Scheibe et al., 2009).

Therefore, the research presented here is focused on a model framework of this type, developed by coupling a modified version of Kato-Marcus et al., 2007 biofilm model with the genome-scale metabolic model of G. sulfurreducens published by Mahadevan et al., 2006, to 
determine the effect of spatial heterogeneities across the biofilms, on the metabolic processes of G. sulfurreducens and the electrochemical and microbiological processes of the biofilm. 


\section{STATEMENT OF OBJECTIVES}

In summary, Microbial fuel cells (MFCs) are alternative energy resources that generate electricity, with the use of microorganisms such as G. sulfurreducens which can completely oxidize organic waste (electron donor) with direct electron transfer to the anode (electron acceptor). Mathematical models have proven to be useful in analyzing biofilm processes. However, the existing models rely on Nernst-Monod type expressions, and evaluate extracellular behavior separated from the intracellular metabolism of the microorganism. Hence, these models have limited ability in capturing the spatial heterogeneities across the biofilm. Therefore, developing mathematical models that can combine both extracellular and intracellular environments is crucial in improving the prediction of the biofilm processes under spatial heterogeneities. Development of such models will facilitate in-depth understanding of biofilm processes, and can be extended to allow the optimization of MFC performances for commercial applications.

As mentioned earlier, there are existing biofilm models that consist of mass balance equations that represent extracellular biofilm processes; and in silico genome-scale metabolic models that can represent intracellular metabolism of microorganisms are also available. Thus, it was hypothesized that coupling a biofilm model (Kato-Marcus et al., 2007) with the genomescale model for G. sulfurreducens (Mahadevan et al., 2006) will provide an improved representation of the inter-relation between intracellular and extracellular components of MFC biofilms, under spatial heterogeneities. 


\section{CHAPTER 2: MATERIALS AND METHODS}

This section provides a detailed description of the mass balance equations used to represent biofilm processes, which were adopted from the equations used in Kato-Marcus et al., 2007 biofilm model. Furthermore, this section discusses the modifications in the model presented here, compared to the Kato-Marcus et al., 2007 model and how these modifications can improve the accuracy of the model predictions.

Subsequently, the use of constraints and the objective function within the FBA model are illustrated, with the steps used to determine the mathematical expressions for the electron donor and electron acceptor limited constraints that vary across the biofilm thickness.

In addition, the construction of the pre-calculated lookup tables for the electron donor uptake, electron transfer, cell growth and the proton production rates at different ranges of electron donor concentrations and anode potentials, and how it is related to the FBA model is illustrated. Next, the methods used to identify the minimum electron donor concentrations and the anode potentials required for the maintenance of the microorganisms under electron donor (ED) and electron acceptor (EA) limited conditions are reported. This is followed by a summary of the coupled model framework that was created by combining modified biofilm model and the FBA model.

Finally the continuation technique that was used to solve a set of complex non-linear differential equations with boundary conditions is discussed in detail. 


\section{$\underline{2.1}$ Biofilm Model}

The major component in modeling biofilms is to develop mathematical equations that can accurately represent the processes across biofilms. The most basic principle in all quantitative models is the conservation of mass (IWA Task Group on Biofilm Modeling, 2006). The conservation of mass of a component of a dynamic and open system can be stated as follows by Eq. (6):

$$
\left(\begin{array}{c}
\text { Net rate of } \\
\text { accumulation }
\end{array}\right)=\left(\begin{array}{c}
\text { Mass flows } \\
\text { into } \\
\text { the system }
\end{array}\right)-\left(\begin{array}{c}
\text { Mass flows } \\
\text { out of } \\
\text { the system }
\end{array}\right)+\left(\begin{array}{c}
\text { Rate of } \\
\text { production }
\end{array}\right)-\left(\begin{array}{c}
\text { Rate of } \\
\text { consumption }
\end{array}\right)
$$

In biofilm systems, the accumulation of biofilm components is due to two universal types of processes: transformation and transport. These two types of processes are closely related. The transformation processes usually are the biochemical reactions that produce or consume one or more components such as electron donor utilization, electron/proton production and cell growth/decay. The transport processes that are important for biofilm models are advection, molecular diffusion and turbulent dispersion. In some cases, the transport of charged components by migration in an electric field is also included (IWA Task Group on Biofilm Modeling, 2006).

The other class of processes involved in biofilms growing on MFC anodes, is the transfer processes across the biofilm/bulk solution interface and the biofilm/anode interface. These include the exchange of dissolved chemicals across the mass transfer boundary layer, detachment of cells from the biofilm to the bulk solution, removal of cells at the external surface due to cell lysis, and transfer of electrons from the biofilm to the anode. In mathematical models these processes set the boundary conditions for the mass balance equations (IWA Task Group on Biofilm Modeling, 2006).

For each component of biofilms such as electron donor, electrons and cell growth, several transformation, transport and transfer processes occur simultaneously. Thus, the mass balances in mathematical models are useful to combine these processes to represent the behavior of each component in the biofilms. In the model reported here, the mass balances are formulated for components such as electron donor, electrons, and biomass. The balances for electron donor, electrons and the local potential are similar to the Kato-Marcus et al., 2007 model equations with minor modifications; however the biomass and advection velocity balances have been changed to 
address the capabilities of the new model. In addition, it should be noted that the biofilm model discussed here represents all biofilm processes under steady state conditions. Thus, the accumulation term is eliminated from all the mass balances shown below.

\subsubsection{Electron Donor Mass Balance}

Once the electron donor is transferred into the biofilm from the bulk solution, it is utilized by the microorganisms, forming a concentration gradient across the biofilms thickness that will promote further diffusion of electron donor into the biofilm. This phenomenon can be modeled using utilization and molecular diffusion.

$$
0=D_{E D, f} \frac{\partial^{2} S_{d}}{\partial z^{2}}-X_{f, a} \phi_{a} q_{E D, o x d}-X_{f, a} \phi_{r} q_{E D . r e s}
$$

where, $\mathrm{D}_{\mathrm{ED}, \mathrm{f}}$ is the diffusion constant for $\mathrm{ED}$ in the biofilm ( $\mathrm{cm}^{2} /$ day), $\mathrm{X}_{\mathrm{f}, \mathrm{a}}$ is the density of active biomass $\left(\mathrm{mg}-\mathrm{VS} / \mathrm{cm}^{3}\right), \mathrm{q}_{\mathrm{ED}}$ is the $\mathrm{ED}$ uptake rate $\left(\mathrm{mmol}-\mathrm{ED} / \mathrm{cm}^{3}\right.$. day) due to oxidation, $\mathrm{q}_{\mathrm{ED}, \text { res }}$ is the ED uptake rate $\left(\mathrm{mmol}-\mathrm{ED} / \mathrm{cm}^{3}\right.$. day) due to endogenous respiration, and $S_{d}$ is the ED concentration $\left(\mathrm{mmol}-\mathrm{ED} / \mathrm{cm}^{3}\right)$. The electron donor diffusion occurs through biofilm/bulk solution interface, whereas no diffusion occurs though the biofilm/anode interfaces. Thus, a continuous flux boundary is employed at the biofilm/bulk solution interfaces, whereas a no flux boundary occurs at the biofilm/anode interface. These are shown by Eq. (8) and Eq. (9), respectively.

$$
\begin{aligned}
& 0=\left.D_{E D, f} \frac{\partial S_{d}}{\partial z}\right|_{z=0} \\
& \left.D_{E D, f} \frac{\partial S_{d}}{\partial z}\right|_{z=L f}=\left(\frac{D_{E D, l}}{L}\right)\left(S_{d, \text { bulk }}-S_{d, \text { surface }}\right)
\end{aligned}
$$

where, $\mathrm{D}_{\mathrm{ED}, 1}$ is the diffusion constant for $\mathrm{ED}$ in the bulk liquid $\left(\mathrm{cm}^{2} /\right.$ day), $\mathrm{L}$ is the diffusion layer thickness $(\mathrm{cm}), \mathrm{S}_{\mathrm{d} \text {,bulk }}$ is the ED concentration at the bulk solution $\left(\mathrm{mmol}-\mathrm{ED} / \mathrm{cm}^{3}\right)$ and $\mathrm{S}_{\mathrm{d} \text {,surface }}$ is the ED concentration at the biofilm surface $\left(\mathrm{mmol}-\mathrm{ED} / \mathrm{cm}^{3}\right)$. 


\subsubsection{Electron Mass Balance}

The electron balance is generated assuming that the electron produced in the biofilm will transfer onto the anode surface across a conductive biofilm matrix. The electron mass balance is shown by Eq. (10).

$$
0=\frac{\partial j}{\partial z}+\frac{F}{\tau} X_{f, a} \phi_{a} q_{e, o x d}+\frac{F}{\tau} X_{f, a} \phi_{r} q_{e, r e s}
$$

where, $\mathrm{j}$ is the current density $\left(\mathrm{mA} / \mathrm{cm}^{2}\right), \mathrm{q}_{\mathrm{e}, \mathrm{oxd}}$ is the electron transfer rate due to oxidation process $\left(\mathrm{mmol}-\mathrm{e} / \mathrm{cm}^{3}\right.$. day), $\mathrm{q}_{\mathrm{e}, \text { res }}$ is the electron transfer rate due to endogenous respiration process (mmol-e/ $\mathrm{cm}^{3}$. day), and $\tau$ is the time conversion factor ( $86,400 \mathrm{~s} /$ day).

The first term in the right hand side shows the current density due to the electron flux across the biofilm matrix. The second and third terms represent the production of electrons due to the oxidation of the electron donor, and the self-oxidation of microorganisms through endogenous respiration to satisfy maintenance energy requirements. This was based on the assumption that a certain amount of electrons generated in the oxidation process goes towards ATP energy generation, however some goes towards biomass synthesis. The electrons contributing to energy generation is later recovered as the current, the remainder is taken up in the cell growth. Thus, in order to completely recover the electrons produced in the oxidation process, a certain amount of electrons are produced by cells that are respiring without growing.

The electron balance can be combined with the Ohm's law to represent the electron balance in terms of the local potential. The Ohm's law equation is shown below by Eq. (11):

$$
0=K_{\text {bio }} \frac{\partial \eta}{\partial z}+j
$$

where, $K_{\text {bio }}$ is the conductivity of the biofilm $(\mathrm{mS} / \mathrm{cm})$ and $\eta$ is the local potential $(V)$. This form of the Ohm's law requires the biofilm to be treated as a porous solid conductor. Kato-Marcus et $a l ., 2007$ reports that the Ohm's law can be related to the Fick's law making the following analogies possible: (1) biofilm conductivity and diffusion co-efficient, (2) local potential gradient and chemical gradient and, (3) current density and flux of chemical species. Hence, the Eq. (10) and Eq. (11) can be combined together to obtain Eq. (12) to represent local potential across the biofilm matrix. 


$$
0=K_{\text {bio }} \frac{\partial^{2} \eta}{\partial z^{2}}-\frac{F}{\tau} X_{f, a} \phi_{a} q_{e, o x d}-\frac{F}{\tau} X_{f, a} \phi_{r} q_{e . r e s}
$$

Solving Eq. (12) requires two boundary conditions to be specified. The first boundary condition assumes that the anode is poised at a fixed potential $\left(\mathrm{V}_{\text {anode }}\right)$, and is shown by Eq. (13):

$$
\left.\eta\right|_{\mathrm{z}=0}=\mathrm{V}_{\text {anode }}
$$

The electron transfer only occurs through the biofilm/anode interfaces, thus no electron transfer occurs outside of the biofilm. This is captured by the second boundary condition shown by Eq. (14):

$$
\left.\frac{\partial \eta}{\partial z}\right|_{z=L f}=\frac{\left.j\right|_{z=L f}}{K_{\text {bio }}}=0
$$

\subsubsection{Biomass Mass Balance}

The model discussed here uses a steady state mass balance for the biomass. This model uses the same concept as the Kato-Marcus et al., 2007 model, thus represents biomass in terms of volume fractions. The volume fraction gives a measure of the space occupied by each type of biomass (Kato-Marcus et al., 2007). This model assumes the presence of three types of biomass: active biomass, respiring biomass, and inert biomass. The active biomass conserves energy for its growth by oxidizing electron donor. However, experimental studies have shown that once the biofilm is fully established some of the active biomass will be converted into respiring biomass. Respiring biomass satisfies the maintenance energy requirements through endogenous respiration, however does not undergo cell growth. Thus, both active and respiring biomasses are metabolically active, and can contribute to current production. The inert biomass fraction was used to account for the presence of conductive material that does not contribute to current production, such as EPS and nanowires. Thus, at each location the sum of all types of biomass adds up to 1, as shown below (Eq. 15):

$$
\phi_{\mathrm{a}}+\phi_{\mathrm{i}}+\phi_{\mathrm{r}}=1
$$

where, $\phi_{\mathrm{a}}, \phi_{\mathrm{i}}$ and $\phi_{\mathrm{r}}$ represent active, inert and respiring biomass, respectively. 


\section{a) Formation of Biomass in the Biofilm}

First, the steady state mass balance for the active biomass is discussed in details. The active biomass undergoes several transformation processes, such as cell growth, inactivation of active biomass to form inert biomass, and conversion into respiring biomass. In addition, this biomass is transported across the biofilm due to advection processes (due to net growth). Thus, the conservation of active biomass is equal to the sum of the transformations and transport processes. This is illustrated further using the schematic below (Fig. 2.1):

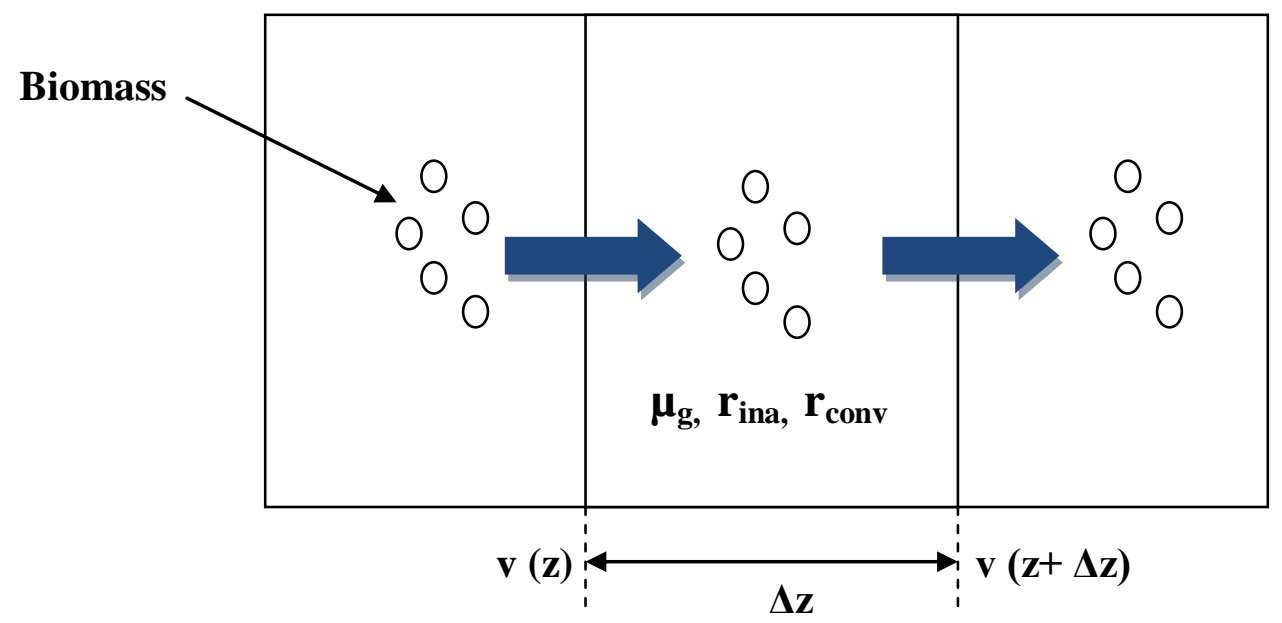

Figure 2.1: Illustration of biomass transformation: cell growth $\left(\mu_{\mathrm{g}}\right)$, rate of active biomass inactivation ( $\left.\mathrm{r}_{\text {ina }}\right)$ and rate of active biomass conversion to respiring biomass $\left(\mathrm{r}_{\text {conv }}\right)$; and transport processes: advection (v) across the biofilm thickness.

Based on these phenomena shown in Fig. 2.2, the preliminary mass balance for the active biomass fraction can be written as follows:

$$
\begin{gathered}
{\left[\phi_{\mathrm{a}}(\mathrm{t}+\Delta \mathrm{t}, \mathrm{z})-\phi_{\mathrm{a}}(\mathrm{t}, \mathrm{z})\right] \mathrm{A} \Delta \mathrm{z}=\mu_{\mathrm{a}} \mathrm{A} \Delta \mathrm{z} \Delta \mathrm{t}+\phi_{\mathrm{a}}(\mathrm{z}) \mathrm{v}(\mathrm{z}) \mathrm{A} \Delta \mathrm{t}-\phi_{\mathrm{a}}(\mathrm{z}+\Delta \mathrm{z}) \mathrm{v}(\mathrm{z}+\Delta \mathrm{z}) \mathrm{A} \Delta \mathrm{t}} \\
\frac{\left[\phi_{\mathrm{a}}(\mathrm{t}+\Delta \mathrm{t}, \mathrm{z})-\phi_{\mathrm{a}}(\mathrm{t}, \mathrm{z})\right]}{\Delta \mathrm{t}}=\mu_{\mathrm{a}}-\frac{\left[\phi_{\mathrm{a}}(\mathrm{z}+\Delta \mathrm{z}) \mathrm{v}(\mathrm{z}+\Delta \mathrm{z})-\phi_{\mathrm{a}}(\mathrm{z}) \mathrm{v}(\mathrm{z})\right]}{\Delta \mathrm{z}} \\
\frac{\partial \phi_{\mathrm{a}}}{\partial \mathrm{t}}+\frac{\partial\left(\mathrm{v} \phi_{\mathrm{a}}\right)}{\partial \mathrm{z}}=\phi_{\mathrm{a}} \mu_{\mathrm{g}}-\mathrm{r}_{\text {ina }}-\mathrm{r}_{\mathrm{conv}} \equiv \mu_{\mathrm{a}}
\end{gathered}
$$

As mentioned above, all mass balances in the biofilm model represent steady state conditions. Thus, the mass balance for active biomass can be shown as follows (Eq. 19):

$$
\frac{\partial\left(\mathrm{v} \phi_{\mathrm{a}}\right)}{\partial \mathrm{z}}=\phi_{\mathrm{a}} \mu_{\mathrm{g}}-\mathrm{r}_{\mathrm{ina}}-\mathrm{r}_{\mathrm{conv}} \equiv \mu_{\mathrm{a}}
$$


where, $\mathrm{A}$ is the cross sectional area of the biofilm $\left(\mathrm{cm}^{2}\right), \mathrm{v}$ is the advection velocity $(\mathrm{cm} / \mathrm{day}), \mu_{\mathrm{g}}$ is the cell growth $\left(\right.$ day $\left.^{-1}\right), r_{\text {ina }}$ is the rate of active biomass inactivation $\left(\right.$ day $\left.^{-1}\right), r_{\text {conv }}$ is the conversion rate of active biomass into respiring biomass $\left(\right.$ day $\left.^{-1}\right)$ and $\mu_{\mathrm{a}}$ is the net specific growth rate of active biomass $\left(\right.$ day $\left.^{-1}\right)$. The net specific growth rate of active biomass is a function of cell growth, inactivation and the conversion to respiring biomass.

The steady state mass balances for inert and respiring bacteria can also be written in a similar manner, and those are shown as follows by Eq. (20) and Eq. (21), respectively.

$$
\begin{gathered}
\frac{\partial\left(\mathrm{v} \phi_{\mathrm{i}}\right)}{\partial \mathrm{z}}=\mathrm{r}_{\mathrm{ina}} \equiv \mu_{\mathrm{i}} \\
\frac{\partial\left(\mathrm{v} \phi_{\mathrm{r}}\right)}{\partial \mathrm{z}}=\mathrm{r}_{\mathrm{conv}} \equiv \mu_{\mathrm{r}}
\end{gathered}
$$

where, $\mu_{\mathrm{i}}$ and $\mu_{\mathrm{r}}$ represent the net specific growth rate of inert and respiring biomass (day ${ }^{-1}$ ), respectively. The rate expressions for the biomass inactivation ( $\left.\mathrm{r}_{\text {ina }}\right)$ and conversion into respiring biomass $\left(\mathrm{r}_{\text {conv }}\right)$ are modelled as first-order equations with respect to $\phi_{\mathrm{a}}$, and they are shown by Eq. (22) and Eq. (23), respectively.

$$
\begin{aligned}
& r_{\text {ina }}=b_{\text {ina }} \phi_{a} \\
& r_{\text {conv }}=b_{\text {conv }} \phi_{a}
\end{aligned}
$$

where, $b_{\text {ina }}$ is the co-efficient of biomass inactivation $\left(\right.$ day $\left.^{-1}\right)$, and $b_{\text {conv }}$ is the co-efficient of active biomass conversion to respiring biomass $\left(\mathrm{day}^{-1}\right)$. The Eq. (19) - (21) are first-order ordinary different equations. Hence one boundary condition has to be specified for each equation. In this model, the volume fractions for each type of biomass were specified as the boundary conditions at the anode surface. The biomass values were estimated based on the experimental data available on the cell count of wild-type $G$. sulfurreducens at the anode surface (Kengo et al., 2010). These can be shown as follows: $\phi_{\mathrm{a}}=0.1, \phi_{\mathrm{i}}=0.5$ and $\phi_{\mathrm{r}}=0.4$.

In order to solve the biomass equations, it is important to determine the change in the advection velocity as a function of distance across the biofilm. Advection velocity can be defined as the velocity at which the biomass moves across the biofilm due to various transformation processes. Hence, the change in advection velocity can be expressed as follows by Eq. (24):

$$
\frac{\partial \mathrm{v}}{\partial \mathrm{z}}=\mu_{\mathrm{a}}+\mu_{\mathrm{i}}+\mu_{\mathrm{r}}=\left(\phi_{\mathrm{a}} \mu_{\mathrm{g}}-\mathrm{r}_{\text {ina }}-\mathrm{r}_{\text {conv }}\right)+\mathrm{r}_{\text {ina }}+\mathrm{r}_{\text {conv }}=\phi_{\mathrm{a}} \mu_{\mathrm{g}}
$$




\section{b) Removal of Biomass from the Biofilm}

As shown by Eq. (24), the change in advection velocity across biofilm is solely based on the biomass growth. However, if this mechanism is allowed to occur continuously the biofilm thickness may grow to an infinite value. In naturally occurring biofilms, the thickness of the biofilm is controlled by biomass death that occurs along the biofilm due to electron donor and acceptor limitations, biomass removal due to cell lysis at the external surface, and the biomass detachment at the external surface.

Biomass death due to electron donor/acceptor limitations: When electron donor and acceptor limitations occurs across the biofilm thickness, the electron donor concentrations and the local potential values are insufficient to provide the minimum ATP energy requirement for the microorganism. Under these conditions the metabolic activity of the cells terminates, causing cell death $\left(\mu_{\mathrm{d}}\right)$.

Biomass removal due to cell lysis at the external surface: Confocal laser scanning microscopy studies done on biofilms of approximately $50 \mu \mathrm{m}$ thickness, that are formed on graphite stick electrodes have shown, a substantial amount of inert biomass accumulation on the external biofilm surface (Nevin et al., 2008). This phenomenon also controls the biofilm thickness from growing continuously. The reason for biomass death at the external surface has not been clearly identified; however, this could be due to biomass losing direct contact with the anode surface and not having sufficient nanowire formations to facilitate long range electron transfer. In the model, it is assumed that the inert biomass accumulated at the external surface undergo complete cell lysis and will be removed from the biofilm surface. Hence, it is represented as a biomass removal rate due to cell lysis at the external surface ( $\left.\mathrm{r}_{\text {lysis }}\right)$.

Biomass detachment at the external surface: In continuous mode MFCs, there is a continuous nutrient flow into the system, which could cause turbulences in the bulk solution. These turbulences can be translated into shear stresses imposed on the biofilm. These shear stresses can promote detachment of biomass from the external surface. In the model this is represented by the rate of biomass detachment at the external surface $\left(b_{\text {det }}\right)$. 
The Kato-Marcus et al, 2007 biofilm model, used the concept of the detachment rate to control the biofilm thickness; however, in the model presented here the biomass death due to electron donor/acceptor limitations $\left(\mu_{\mathrm{d}}\right)$ and biomass removal due to cell lysis at the external surface $\left(\mathrm{r}_{\text {lysis }}\right)$ are also introduced. The introduction of cell death due to electron donor/acceptor limitations establishes one of the main inherent assumptions of this model. In the model, it was assumed that if cell growth is equivalent to the change in advection velocity in the forward direction as seen by Eq. (24), then the cell death due to electron donor/acceptor limitations that occurs along the biofilm thickness poses another type of advection velocity $\left(v_{d}\right)$ in the opposite direction. Mathematically, the change in advection due to cell death $\left(\mathrm{v}_{\mathrm{d}}\right)$ can be seen as follows:

$$
\frac{\partial \mathrm{v}_{\mathrm{d}}}{\partial \mathrm{z}}=\mu_{\mathrm{d}}
$$

where, $\mu_{d}$ is the death rate due to electron donor/ acceptor limitations (day ${ }^{-1}$ ). The value for $\mu_{d}$ was predicted by FBA model using the maximization of the cellular objective function, while setting the upper and lower bounds of the $\mathrm{ATP}_{\mathrm{M}}$ flux to 0 . The electron donor concentration and the local potential used to calculate the constraints were slightly below the minimum requirements to satisfy the maintenance demands. This determines the cell growth, when there is no ATP maintenance energy demand by the microorganism. However, all naturally occurring microorganisms require sufficient ATP for cell maintenance, and they undergo cell death if those requirements are not satisfied. Hence, by contrast the cell growth rate prediction obtained here from the FBA model represents cell death when there is an ATP energy demand for maintenance. This value was obtained to be 0.1018 day $^{-1}$. The $\mu_{\mathrm{d}}$ value was kept constant for the simplification of the model.

In obtaining the boundary conditions for the advection velocities the following mass balance for the biofilm thickness can be utilized (Eq. 26). The increase in the biofilm thickness occurs due to the process related to cell growth (v), whereas the reduction of biofilm thickness is due to the cell death through electron donor/acceptor limitations $\left(\mathrm{v}_{\mathrm{d}}\right)$, cell lysis at the external surface $\left(\mathrm{r}_{\mathrm{lysis}}\right)$ and the biomass detachment $\left(\mathrm{b}_{\mathrm{det}}\right)$.

$$
\frac{\partial \mathrm{L}_{\mathrm{f}}}{\partial \mathrm{t}}=\left.\mathrm{v}\right|_{\mathrm{z}=\mathrm{Lf}}-\left.\mathrm{v}_{\mathrm{d}}\right|_{\mathrm{z}=\mathrm{Lf}}-\mathrm{r}_{\text {lysis }} \mathrm{L}_{\mathrm{f}}-\mathrm{b}_{\mathrm{det}} \mathrm{L}_{\mathrm{f}}
$$

Since the model is operated under steady state conditions the $\partial \mathrm{L}_{\mathrm{f}} / \partial \mathrm{t}=0$, and Eq. (27) is obtained.

$$
0=\left.\mathrm{v}\right|_{\mathrm{z}=\mathrm{Lf}}-\left.\mathrm{v}_{\mathrm{d}}\right|_{\mathrm{z}=\mathrm{Lf}}-\mathrm{r}_{\text {lysis }} \mathrm{L}_{\mathrm{f}}-\mathrm{b}_{\mathrm{det}} \mathrm{L}_{\mathrm{f}}
$$


where, $b_{\text {det }}$ is the rate of biomass detachment $\left(\right.$ day $\left.^{-1}\right), r_{\text {lysis }}$ is the rate of cell lysis at the external surface and $\mathrm{L}_{\mathrm{f}}$ is the total thickness $(\mathrm{cm})$ of the biofilm. In modeling a batch mode MFC, $\mathrm{b}_{\text {det }}$ is set to 0 , whereas in a continuous mode MFC the $b_{\text {det }}$ is dependent on the shear stress caused by the nutrient flow rate into the anode compartment.

In addition, it should be noted that in solving these equations the biofilm thickness $\mathrm{L}_{\mathrm{f}}$ was also allowed to change as the extracellular conditions vary. Hence, Eq. (27) also acts as the boundary condition governing the biofilm thickness. Thus, although Eq. (27) affects the change in advection velocities across the biofilm, it is required to specify separate boundary conditions at the anode, for both $\mathrm{v}$ and $\mathrm{v}_{\mathrm{d}}$. They were chosen as follows: $\mathrm{v}=5.2 \times 10^{-4} \mathrm{~cm} / \mathrm{day}$ and $\mathrm{v}_{\mathrm{d}}=0$ $\mathrm{cm} /$ day. These values were chosen such that the model predictions agree with the experimental observations for wild-type G. sulfurreducens.

\subsection{Flux Balance Analysis (FBA) Model}

The flux balance analysis component of the model presented here was based on genomescale in silico metabolic model of G. sulfurreducens published by Mahadevan et al., 2006. As discussed in Section 1.5.4, the FBA model requires an objective function and constraints to be specified.

The main objective of MFCs is to maximize the current production. The current production by microorganisms that oxidize organic matter is directly related to their cell growth (Yi et al., 2009). Thus, in this model, the maximization of cell growth rate is used as the objective function to model intracellular metabolism. Cell growth rate under electron donor and electron acceptor limitations across the biofilm was simulated by modifying the constraints posed on the following exchange fluxes: acetate (or electron donor) uptake rate and the Fe (III) reduction or electron transfer rate. Although, the anode acts as the electron acceptor in MFCs, in subsurface environments Fe (III) commonly acts as an extracellular electron acceptor in the natural degradation of organic matter catalyzed by G. sulfurreducens (Mahadevan et al., 2006). Thus, in the FBA model, Fe (III) reduction rate is used to represent the electron transfer rate. The constraints for the acetate uptake rate and the electron transfer rate were based on the NernstMonod equation (Eq. 1). The Monod equation was used to represent the electron donor limited constraint; whereas the Nernst equation was used to represent the electron acceptor limited 
constraints. These constraints establish the connection between the FBA and the biofilm model, and can be shown as follows:

Electron donor (acetate) limited constraint:

$$
\mathrm{q}_{\mathrm{ED}, \text { constraint }}=\mathrm{q}_{\max }\left(\frac{\mathrm{S}_{\mathrm{d}}}{\mathrm{S}_{\mathrm{d}}+\mathrm{K}_{\mathrm{Sd}}}\right)
$$

\section{Electron acceptor limited constraint:}

$$
\mathrm{q}_{\mathrm{e}, \text { constraint }}=8 \times \mathrm{q}_{\max }\left(\frac{1}{1+\exp \left[-\frac{\mathrm{F}}{\mathrm{RT}}(\eta-(-0.345))\right]}\right)
$$

The maximum electron donor uptake parameter, $\mathrm{q}_{\max }$ used in the Monod equation was set to be $4.98 \mathrm{mmol} \mathrm{ED} / \mathrm{gdw}$. hr. This value was calculated based on the maximum acetate uptake for G. sulfurreducens, $1.2 \mu$ mol-e/mg-protein. min, reported in Bond and Lovley, 2003. The unit conversion was made assuming a protein content of about 55\% (Kato-Marcus et al., 2007). As reported by Esteve-Nunez et al., 2005, a half maximum rate of acetate concentration, $\mathrm{K}_{\mathrm{sd}}$, of $1 \mathrm{mM}$ was used for a medium of $10 \mathrm{mM}$ acetate.

Cyclic voltammetry studies done by Richter et al., 2009, showed that heterogeneous electron transfer involves the outer membrane c-type cytochrome, OmcB, and type IV pili. The type IV pili are also known as nanowires. The mid-point potential of this electron transfer is $0.345 \mathrm{~V}$ vs. $\mathrm{Ag} / \mathrm{AgCl}$. Hence, this information was included in electron acceptor limited constraint shown by Eq. (29). Thus, the new model allows extracellular electron transfer when $\eta$ $\geq-0.345 \mathrm{~V}$, and limited electron transfer when $\eta<-0.345 \mathrm{~V}$.

In the original model formulated by Kato-Marcus et al., 2007, the electron donor uptake rate, electron transfer rate and the cell growth rate were calculated based on the Nernst-Monod equation (Eq. 1). The Nernst-Monod expression relies on a set of constant parameters and assumptions. The use of constants parameters to represent cellular physiology decreases its robustness and makes it less suitable for predicting rates under variant environmental conditions. In addition, the cell growth rate in the original model was based on Eq. (30), assuming constant yield across the biofilm thickness.

$$
\mu_{\mathrm{g}}=\mathrm{Y} \times \mathrm{q}_{\mathrm{ED}, \mathrm{oxd}}
$$


where, $\mathrm{Y}$ is the constant biomass yield (mg-VS/ mmol-ED). However, as the new biofilm model is coupled to the genome-scale FBA model of G. sulfurreducens, the electron donor uptake $\left(\mathrm{q}_{\mathrm{ED}, \mathrm{oxd}}\right)$, electron transfer $\left(\mathrm{q}_{\mathrm{e}, \mathrm{oxd}}\right)$ and the cell growth $\left(\mu_{\mathrm{g}}\right)$ rates were based on the metabolic fluxes predicted by the FBA model that has the ability to equilibrate metabolite concentrations rapidly when exposed to extracellular perturbations (Price et al., 2004).

However, the $\mathrm{q}_{\mathrm{ED}, \text { res }}$ rate that corresponds to the rate of electron donor uptake by the respiring biomass was calculated based on Eq. (31). The respiring biomass only require minimum electron donor uptake to supply ATP energy required for cell maintenance, hence it can be shown by Eq. (31). A detailed description of determining minimum possible electron donor concentration $\left(\mathrm{S}_{\mathrm{d}, \mathrm{min}}\right)$ and minimum electron donor uptake rate $\left(\mathrm{q}_{\mathrm{M}}\right)$ to satisfy maintenance energy requirements are shown by Eq (33) and (34).

$$
\mathrm{q}_{\mathrm{ED}, \mathrm{res}}=\mathrm{q}_{\max }\left(\frac{\mathrm{S}_{\mathrm{d}, \min }}{\mathrm{S}_{\mathrm{d}, \text { min }}+\mathrm{K}_{\mathrm{Sd}}}\right)=\mathrm{q}_{\mathrm{M}}
$$

Similarly, the $\mathrm{q}_{\mathrm{e}, \text { res }}$ can be calculated based on the Eq. 31 by multiplying $\mathrm{q}_{\mathrm{ED}, \text { res }}$ by a factor of 8 , as 8 moles of electrons are produced for every one mole of electron donor consumed. In addition to the modifications in the rates of the new biofilm model, the following conditions were also imposed to improve the accuracy of the coupled model results under the spatial heterogeneities.

$$
\mathrm{q}_{E D}, \mu_{\mathrm{g}}, \mathrm{q}_{\mathrm{e}}, \mu_{\mathrm{d}}= \begin{cases}q_{E D}, \mu_{\mathrm{g}}, \mathrm{q}_{\mathrm{e}} \neq 0 \text { and } \mu_{\mathrm{d}}=0 & \text { if } \mathrm{s}_{\mathrm{d}}>\mathrm{s}_{\mathrm{d}, \min } \text { and } \eta>\eta_{\min } \\ q_{E D}, \mu_{\mathrm{g}}, \mathrm{q}_{\mathrm{e}}=0 \text { and } \mu_{\mathrm{d}} \neq 0 & \text { Else }\end{cases}
$$

These conditions ensure that when the electron donor concentration or the local potential is below the minimum values the cell death takes place, inhibiting growth activity and current production in the biofilm. 


\section{$\underline{2.3}$ Lookup Table Approach}

The coupling between the FBA model and the biofilm model can be done in two ways: direct integration and lookup tables. Direct integration method requires the FBA model to be called at each spatial location along which the biofilm model is solved. This approach is computationally expensive, as it requires a separate LP problem to be solved, each time the FBA model is called. Therefore, the model reported here uses the lookup table approach as demonstrated in Scheibe et al., 2009.

The lookup table was generated by solving the FBA model offline. Separate lookup tables were created for acetate uptake rate, electron transfer rate, proton transfer rate, $\mathrm{CO}_{2}$ transfer rate and the cell growth, under different electron donor concentrations and local potential availability across the biofilm thickness. All lookup tables were constructed to obtain 400 different combinations, by selecting 20 different values for each electron donor concentration and local potential. For each combination of the electron donor concentration and the local potential, the electron donor and electron acceptor limited constraints were calculated; and they were used to solve the FBA model with the same cellular objective function in each case. The fluxes corresponding to each rate stated above, along with the concentration and the local potential values used were then stored in lookup tables.

In selecting the range of electron donor concentration and the local potential for which the lookup table is constructed, it is important to ensure the availability of sufficient ATP to meet the maintenance energy demand. Thus, the minimum possible electron donor concentration $\left(S_{d, \min }\right)$, and local potential $\left(\eta_{\min }\right)$ were calculated for each ATP energy required towards maintenance, $\operatorname{ATP}_{M}$, used in the model simulation studies. The expressions for $S_{d, \text { min }}$ and $\eta_{\min }$ were determined by combining Eq. (33) with Eq. (28) and Eq. (29). The $S_{\mathrm{d}, \min }$ and $\eta_{\min }$, are shown by Eq. (34) and Eq. (35), respectively.

$$
\begin{gathered}
\mathrm{q}_{M}=\frac{\mathrm{ATP}_{\mathrm{M}}}{\mathrm{Y}_{\max }} \\
\mathrm{S}_{\mathrm{d}, \min }=\frac{\mathrm{K}_{\mathrm{sd}}}{\left[\left(\mathrm{q}_{\max } / \mathrm{q}_{\mathrm{M}}\right)-1\right]} \\
\eta_{\min }=\left[\ln \left[\left(\mathrm{q}_{\max } / \mathrm{q}_{\mathrm{M}}\right)-1\right] \times \frac{-\mathrm{RT}}{\mathrm{F}}\right]+(-0.345)
\end{gathered}
$$


where, $\mathrm{q}_{M}$ is the electron donor uptake rate to satisfy maintenance energy requirements, $\operatorname{ATP}_{M}$ flux (0.45 mmol ATP/gdw.hr), $\mathrm{Y}_{\max }$ is the maximum theoretical yield of ATP generation, with $\mathrm{Fe}$ (III) as the electron acceptor (0.5 mmol ATP/ mmol ED) (Mahadevan et al., 2006). The value -0.345 represents the mid point potential of heterogeneous electron transfer.

The electron donor concentration and the local potential within the chosen range are used to refer to the flux data stored in the lookup table, at each spatial location across the biofilm thickness that is evaluated by the biofilm model. Linear interpolation method was used to obtain flux data at these spatial locations. 


\subsection{Coupled Model Framework}

As mentioned in previous sections, the coupled model framework was established by combining the modified biofilm model with the FBA model, using the constraints representing electron donor and electron acceptor limitations. This allows the determination of the metabolic behaviour of $G$. sulfurreducens under different extracellular conditions at various spatial locations along the biofilm thickness. This process is illustrated in Fig. 2.2.

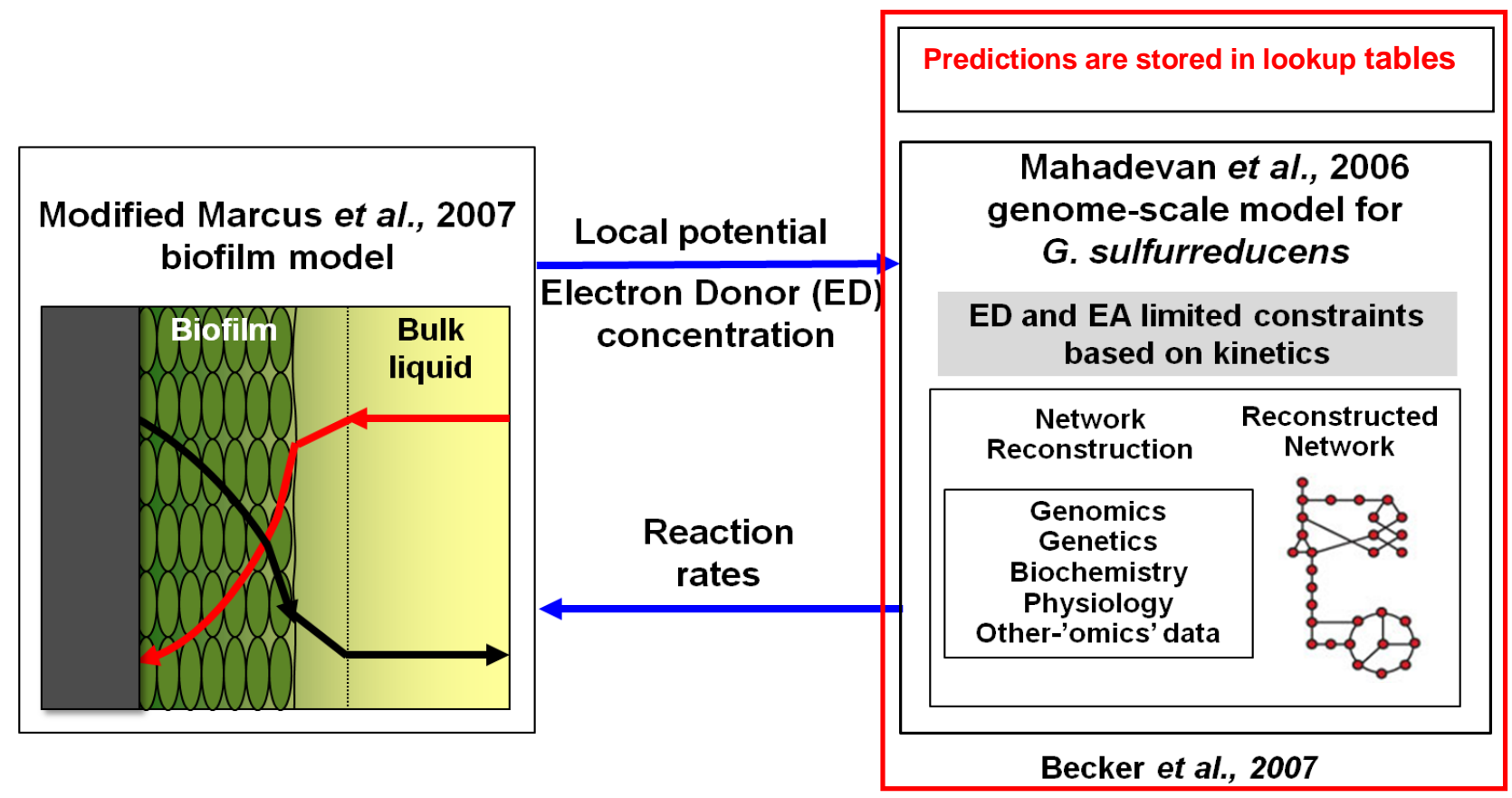

Figure 2.2: Schematic representation of the coupling between the modified biofilm model and the FBA model, using ED and EA limited constraints. The FBA model schematic was adapted by permission from Macmillan Publishers Ltd: [Nature Protocols] (Becker et al., 2007), copyright (2007).

As shown by Fig. 2.2, at each spatial location across the biofilm, the electron donor and acceptor limited constraints are evaluated based on the electron donor concentrations and the local potential obtained from the modified biofilm model. Based on these constraints, the FBA model is referenced at each spatial location to obtain the reaction fluxes of the metabolic network. As mentioned earlier, in this approach, the FBA model is referenced by using precalculated lookup tables, instead of the direct integration method. These FBA predicted metabolic fluxes are then incorporated into the modified biofilm model, as the rates representing the electron donor uptake, electron transfer, proton transfer and cell growth. This procedure is 
repeated continuously, until the biofilm thickness is covered starting from the anode surface $(\mathrm{z}=0)$ to the external surface of the biofilm $\left(\mathrm{z}=\mathrm{L}_{\mathrm{f}}\right)$.

\section{$\underline{\text { 2.5 }}$ Continuation Technique for Complex Non-Linear Equations}

The coupled model framework gave rise to a system of non-liner ordinary differential equations, with boundary conditions at either the anode surface $(\mathrm{z}=0)$, external surface of the biofilm $\left(\mathrm{z}=\mathrm{L}_{\mathrm{f}}\right)$ or both. Hence, the multipoint boundary value problem (BVP) solver, bvp4c in MATLAB was used to solve these equations. This solver is also capable of solving BVPs with unknown parameters. Thus, the biofilm thickness was treated as the unknown parameter, and was estimated by the solver, based on the initial guess and the boundary conditions provided. The inclusion of the biofilm thickness as an unknown parameter increased the complexity of the BVPs; thus it was difficult to obtain an accurate solution based on the initial guess alone. Hence, the continuation method was used to solve the set of BVPs.

This method relies on solving the system of equations where $\mathrm{F}(\mathrm{x})=0$ by constructing a homotopy $\mathrm{H}(\mathrm{x}, \mathrm{s})$. The mathematical representation of homotopy in Eq. (36) was based on assuming smooth mapping exists between two points (Allgower et al., 2003).

$$
H\left(x, s_{i}\right)=F(x)-s_{i} F\left(x_{1}\right) \quad \text { where, } s \in\left[1=s_{0}, \ldots \ldots s_{1}=0\right]
$$

Using Eq. (36) to solve the set of non-linear equations require following the steps shown below:

(1) The first step in using the continuation method was to establish an $\mathrm{H}\left(\mathrm{x}_{1}, 1\right)$ solution with a unique, easily determined solution for the set of equations. This will provide an initial guess $\left(\mathrm{x}_{1}\right)$ for the variables and parameters in equations. In this case $\mathrm{s}=1$.

(2) Next the $\mathrm{x}_{1}$ solution obtained in Step 1 was used to establish the homotopy in Eq. (36) and it acts as the guess for the first iteration. Thus, each iteration was started with the solution of the preceding problem $\times\left(\mathrm{s}_{\mathrm{i}-1}\right)$ and the $\mathrm{s}_{\mathrm{i}}$ values. Step (2) was repeated until it reaches $\mathrm{s}=0$ where $F\left(x_{0}\right)=0$ is satisfied. In each step the $s_{i}$ value was chosen such that the error in using the solution $\mathrm{x}\left(\mathrm{s}_{\mathrm{i}-1}\right)$ is below a certain tolerance. If the error goes above the tolerance, the step was repeated while reducing the step size $s_{i}$.

This technique was used to determine solutions for each case discussed in Chapter 3. 


\subsection{Evaluation of the pH Levels Across the Biofilm Thickness}

The $\mathrm{pH}$ gradient across the biofilm thickness depends on the concentration of protons and $\mathrm{CO}_{2}$ produced in the oxidation and respiration, as well as the composition of the bulk solution that contains the buffer, electron donor and other nutrients for biomass growth. For the purposes, of this study we looked at the local concentrations of protons, $\mathrm{CO}_{2}$, acetate, phosphate and the carbonate buffer, across the biofilm thickness. Mass balance equations were written for the concentration of each component based on the processes shown in Table 1.

Table 1: Processes and Mass balances for each component used in $\mathrm{pH}$ calculations.

\begin{tabular}{|c|c|c|}
\hline Components & Processes & Mass Balance Equations \\
\hline $\mathrm{CH}_{3} \mathrm{COO}^{-}$ & $\begin{array}{l}\text { Diffusion } \\
\text { and } \\
\text { Utilization }\end{array}$ & Eq. (7) \\
\hline $\mathrm{H}_{2} \mathrm{CO}_{3}$ & $\begin{array}{l}\text { Production } \\
\text { and } \\
\text { Diffusion }\end{array}$ & $0=\mathrm{D}_{\mathrm{CO}_{2}, \mathrm{f}} \frac{\partial^{2} \mathrm{C}_{\mathrm{CO}_{2}}}{\partial \mathrm{z}^{2}}+\mathrm{X}_{\mathrm{f}, \mathrm{a}} \mathrm{q}_{\mathrm{CO}_{2}}$ \\
\hline $\mathrm{H}^{+}$ & $\begin{array}{l}\text { Production } \\
\text { and } \\
\text { Diffusion }\end{array}$ & $0=\mathrm{D}_{\mathrm{H}^{+}, \mathrm{f}} \frac{\partial^{2} \mathrm{C}_{\mathrm{H}^{+}}}{\partial \mathrm{z}^{2}}+\mathrm{X}_{\mathrm{f}, \mathrm{a}} \mathrm{q}_{\mathrm{H}^{+}}$ \\
\hline $\mathrm{HCO}_{3}{ }^{-}$ & $\begin{array}{l}\text { Diffusion } \\
\text { and } \\
\text { Migration }\end{array}$ & $0=\mathrm{D}_{\mathrm{HCO}_{3}}{ }^{-}, \mathrm{f} \frac{\partial^{2} \mathrm{C}_{\mathrm{HCO}_{3}}{ }^{-}}{\partial \mathrm{z}^{2}}+\frac{\mathrm{FD}_{\mathrm{HCO}_{3}}{ }^{-} \mathrm{f}}{\mathrm{RT}} \frac{\partial}{\partial \mathrm{z}}\left(\mathrm{z} * \mathrm{C}_{\mathrm{HCO}_{3}}{ }^{-} * \frac{\partial \eta}{\partial \mathrm{z}}\right)$ \\
\hline $\mathrm{H}_{2} \mathrm{PO}_{4}^{-}$ & $\begin{array}{l}\text { Diffusion } \\
\text { and } \\
\text { Migration }\end{array}$ & 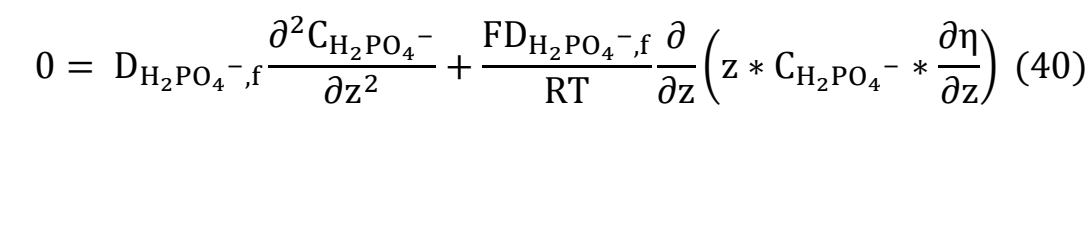 \\
\hline
\end{tabular}

As illustrated by Table 1, the mass transfer of uncharged particles occurs due to the molecular diffusion across the concentration gradient. However, in addition to the diffusion 
process, the charged particles in the media can be transported through migration effects formed due to the potential gradient across the biofilm thickness. The degree to which each ion participates in the migration process is described by the transference number. Transference number of an ion $\left(\mathrm{t}_{\mathrm{i}}\right)=$ migration flux of $\mathrm{i} /$ total ion migration flux. The concentration of $\mathrm{H}^{+}$ions in the media is typically very low $(\mathrm{pH} \sim 7,0.1 \mu \mathrm{M})$ compared to other ions (such as $\mathrm{HCO}_{3}{ }^{-}$and $\mathrm{H}_{2} \mathrm{PO}_{4}{ }^{-}$) which are normally present in $\mathrm{mM}$ concentrations. Thus, the transference number of $\mathrm{H}^{+}$ is negligible and hence it can be determined that $\mathrm{H}^{+}$is not transported due to migration effects (Torres et al., 2008b). Furthermore, it should be noted that the concentration of $\mathrm{CO}_{2}$ across the biofilm was modeled assuming that the $\mathrm{CO}_{2}$ gas produced in the oxidation is immediately mixed with water to form $\mathrm{H}_{2} \mathrm{CO}_{3}$. The boundary conditions for the equations in Table 1 were similar to the boundary conditions used in electron donor mass balance (Eq. 7). The diffusion co-efficient and the bulk concentrations for each component are shown in Table 6 (Appendix I). However, it should be noted that the experimental bulk solution concentrations for all the components were available except for $\mathrm{H}_{2} \mathrm{CO}_{3}$. Thus, the bulk concentration of $\mathrm{H}_{2} \mathrm{CO}_{3}$ was adjusted such that the bulk medium $\mathrm{pH}$ will be equal to the default $\mathrm{pH}$ value $(\mathrm{pH}=7)$ for the bulk medium.

The concentrations calculated for all the components mentioned above were entered into the OLI software to determine the $\mathrm{pH}$ levels across the biofilm thickness. The OLI software is a predictive thermodynamic framework for calculating physical and chemical properties of multiphase, aqueous-based systems. The software allows the automatic calculation of thermodynamic properties such as $\mathrm{pH}$, ionic strength, enthalpy, density, osmotic pressure and transport properties such as viscosity and self-diffusivity, over the general range of 0 to $30 \mathrm{~mol} / \mathrm{kg},-50$ to $300{ }^{\circ} \mathrm{C}$, and 0 to 1500 bar. However, a default value of $25{ }^{\circ} \mathrm{C}, 1 \mathrm{~atm}$ and 55.508 moles of water are used in most calculations. The number of moles of water corresponds to $1 \mathrm{~L}$ of water. These default conditions were used in calculating the $\mathrm{pH}$ levels across the biofilm. The OLI software is equipped with a large database of organic and inorganic substances; however the concentration of protons produced in the model could not be directly represented in OLI. Thus, the strong acid $\mathrm{HCl}$ was used to represent the proton concentration for OLI calculations, as strong acids completely dissociate into its constituent ions in an aqueous medium. A complete discussion of the $\mathrm{pH}$ profile across the biofilm thickness is found in Chapter 3. 


\subsection{Modeling the Wild-type DL1 Strain}

An essential step prior to conducting studies using the coupled biofilm model was to identify a fundamental set of parameters that can clearly represent the processes and characteristics of an MFC biofilm. The parameters in this model were chosen to fit the wild-type G. sulfurreducens strain called DL1. Majority of the parameters were kept similar to the KatoMarcus et al., 2007 model; a complete list of these parameters is found in the Table 6 (Appendix I). The remaining parameters were either modified based on the available experimental data, or adjusted in order to match the actual biofilm features. These parameters are shown in Table 2 below:

Table 2: List of experimentally determined and adjusted model parameters for the DL1 strain

\begin{tabular}{|l|l|c|c|c|}
\hline Symbols & \multicolumn{1}{|c|}{ Descriptions } & $\begin{array}{c}\text { Numerical } \\
\text { Values }\end{array}$ & Units & References \\
\hline $\mathrm{K}_{\mathrm{bio}}$ & Conductivity of the biofilm & 0.525 & $\mathrm{mS} / \mathrm{cm}$ & Experiments \\
\hline $\mathrm{X}_{\mathrm{f}, \mathrm{a}}$ & Density of the biofilm & 1042 & $\mathrm{mg}$-gdw/cm & Experiments \\
\hline $\mathrm{b}_{\text {ina }}$ & Co-efficient of biomass inactivation & 0.03 & day $^{-1}$ & Adjusted \\
\hline $\mathrm{b}_{\mathrm{conv}}$ & $\begin{array}{l}\text { Co-efficient of active biomass } \\
\text { conversion to respiring biomass }\end{array}$ & 0.09 & Adjusted \\
\hline $\mathrm{r}_{\text {lysis }}$ & $\begin{array}{l}\text { Rate of biomass removal due to lysis } \\
\text { at the external surface }\end{array}$ & 0.0504 & day ${ }^{-1}$ & Adjusted \\
\hline$\left.\mathrm{L}\right|_{\mathrm{z}=0}$ & $\begin{array}{l}\text { Boundary condition for advection } \\
\text { velocity due to growth, at the anode } \\
\text { surface }\end{array}$ & $5.2 \times 10^{-4}$ & cm/day & Adjusted \\
\hline
\end{tabular}

The experimentally determined thickness for a DL1 biofilm for an MFC operating at the batch mode was approximately $46 \mu \mathrm{m}$, with a current density of about $0.2 \mathrm{~mA} / \mathrm{cm}^{2}$. Thus, in the [50] 
model, the above parameters were adjusted in order to match the experimental values for thickness and the current density, respectively. These parameters establish the basis for all the studies involving the wild-type DL1 strain that are presented in Chapter 3. 


\section{CHAPTER 3: RESULTS AND DISCUSSION}

\subsection{Key Characteristics of MFC Biofilms}

The biofilm model presented here, has the ability to give information about the processes across the biofilm thickness under different operating conditions such as the poised anode potential and electron donor (ED) concentration (Fig.3.1). Specifically, the Fig. 3.1 shows the model predictions for a biofilm growing on an electrode poised at $0.3 \mathrm{~V}$ vs. $\mathrm{Ag} / \mathrm{AgCl}$, with a bulk concentration of $10 \mathrm{mM}$ for an MFC operating under batch conditions.
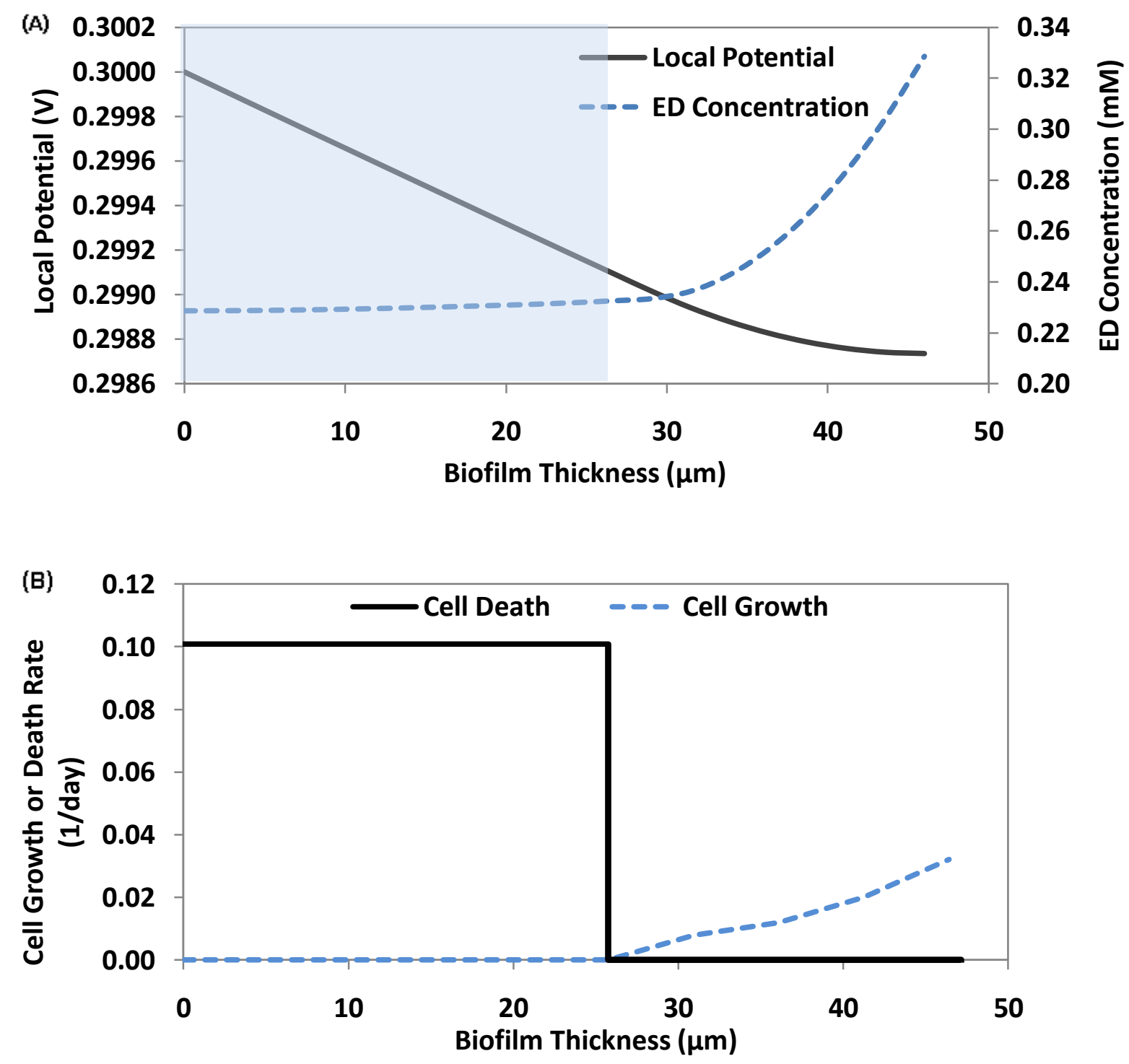

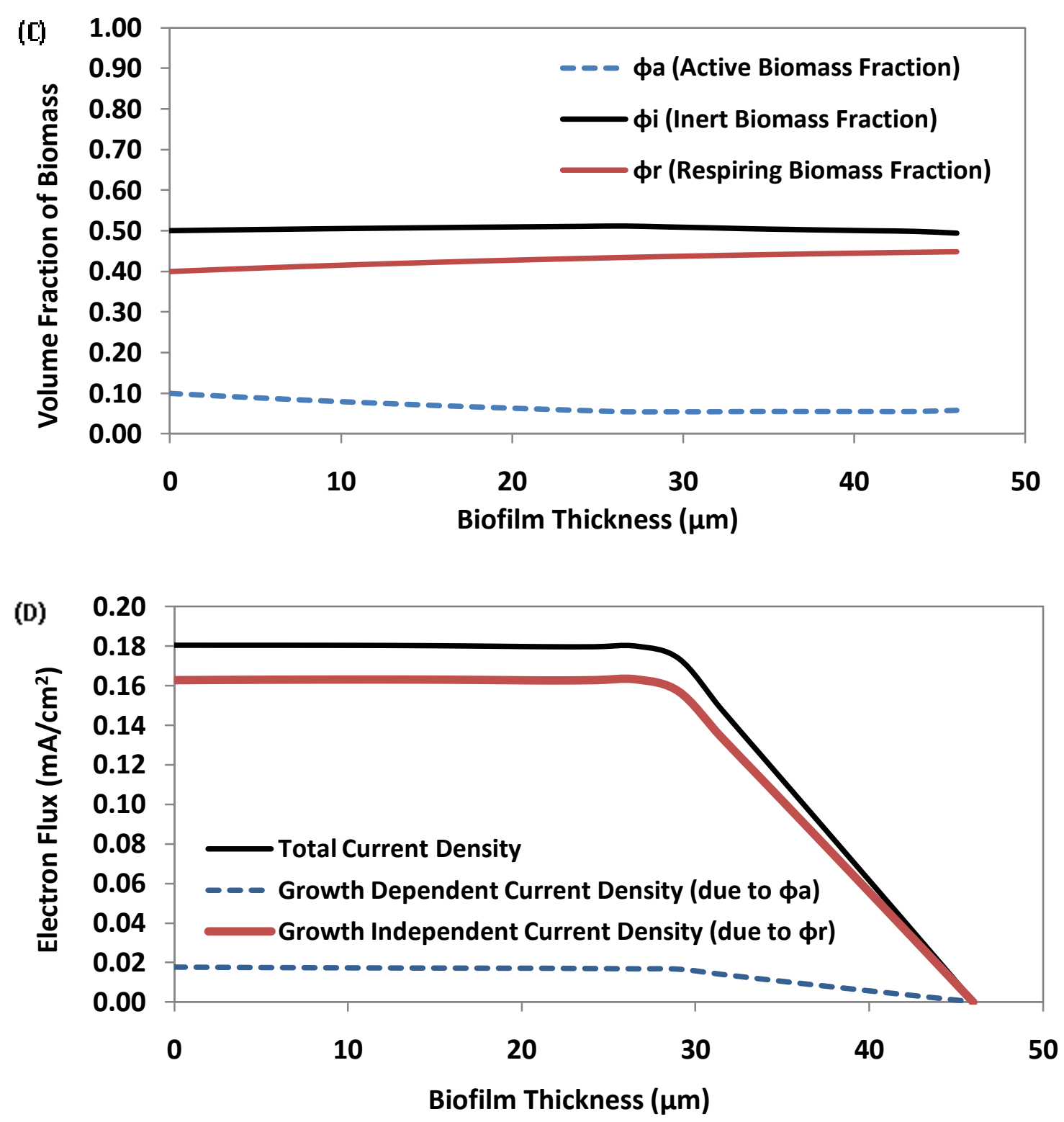

Figure 3.1: (A) The change in ED concentration and the local potential across the biofilm thickness. The shaded area shows the ED limited region. (B) The regions of cell death and cell growth across the biofilm thickness. (C) The distribution of all types of biomass across the biofilm thickness. (D) Comparison of total current density across the biofilm with the current densities produced due to growth independent and growth dependant biomass.

The Fig. 3.1a provides information regarding the change in electron donor concentration and local potential as function of distance across the biofilm. Across the $46 \mu \mathrm{m}$ thickness of the 
biofilm, the local potential drop is insignificant, indicating that the wild type G. sulfurreducens form highly conductive biofilms. The electron donor concentration started at lower values and gradually increased as it gets closer to the bulk solution. When the local potential or the electron donor concentration goes below the minimum values required to satisfy ATP energy demand towards cell maintenance $\left(S_{\mathrm{d}, \min }\right.$ and $\left.\eta_{\min }\right)$, the biofilm becomes electron donor and electron acceptor limited, respectively. Under these limitations the cell growth becomes completely inhibited. However, under the operating conditions used here, the biofilm is only electron donor limited. This region is shown by the shaded area in Fig. 3.1a.

As shown by Fig. 3.1b, in the electron donor limited region the cell growth rate is completely inhibited; however, the cell death starts to occur. Approximately, an area of $25 \mu \mathrm{m}$ of the biofilm undergoes cell death. Although model predictions show the presence of a region of cell death, this was not observed in experimental studies (Nevin et al., 2008). In actual biofilms of MFCs, the inert cells can undergo cell lysis and the resulting cell components can be consumed by the growing and respiring cells as the nutrients under electron donor limited conditions. Thus, a region of complete cell death might not be seen through experiments. This cell lysis mechanism across the biofilm thickness is not included within this model, thus the region of cell death seen in model predictions can be justified.

Fig. 3.1c shows the change in each type of biomass across the biofilm thickness. The active biomass tends to drop slightly as the effects of electron donor limitations start to appear in the biofilm. Although the cell growth rate starts to increase away from the anode surface, the active biomass fraction remained almost constant throughout the biofilm, as some of the active biomass is also converted to both respiring and inert biomass. Furthermore, these results show that the majority of the metabolically active biomass in a fully grown biofilm is formed of respiring biomass rather than active biomass. It has been shown experimentally that the coulombic efficiency of an MFC is almost 100\%, indicating that most of the biofilm consist of respiring biomass as only a small fraction of electrons are consumed by active biomass growth. Hence, the model predictions agree with the experimental observations, and the coulombic efficiency calculated from the model predictions was $99.8 \%$. 
Fig. 3.1d gives a measure of the current densities produced by each type of metabolically active biomass. It clearly shows that the current is mostly produced by respiring biomass through the growth independent endogenous respiration process, whereas the remaining current is produced by the growth dependent active biomass through the oxidation process.

These model results provide insight into biofilm processes under electron donor and electron acceptor limitations. These results show that this model framework can be utilized to obtain a better understanding of the biofilm processes under varying biofilm conditions. 


\subsection{Effect of $\mathrm{NH}_{4}{ }^{+}$on the Current Production and the Biofilm Thickness}

Experiments have shown that the biofilm formation and the current production in the MFCs depend on the nutrient availability in the bulk solution. Previous studies have been conducted on determining the effect of electron donor and acceptor limitations on the biofilms growth (Esteve-Nunez et al., 2005). However, the $\mathrm{NH}_{4}{ }^{+}$uptake and related mechanisms have not been studied in detail. Hence, the coupled biofilm model was used to identify the variations in biofilm processes in the presence and absence of $\mathrm{NH}_{4}{ }^{+}$in the medium.

(A)

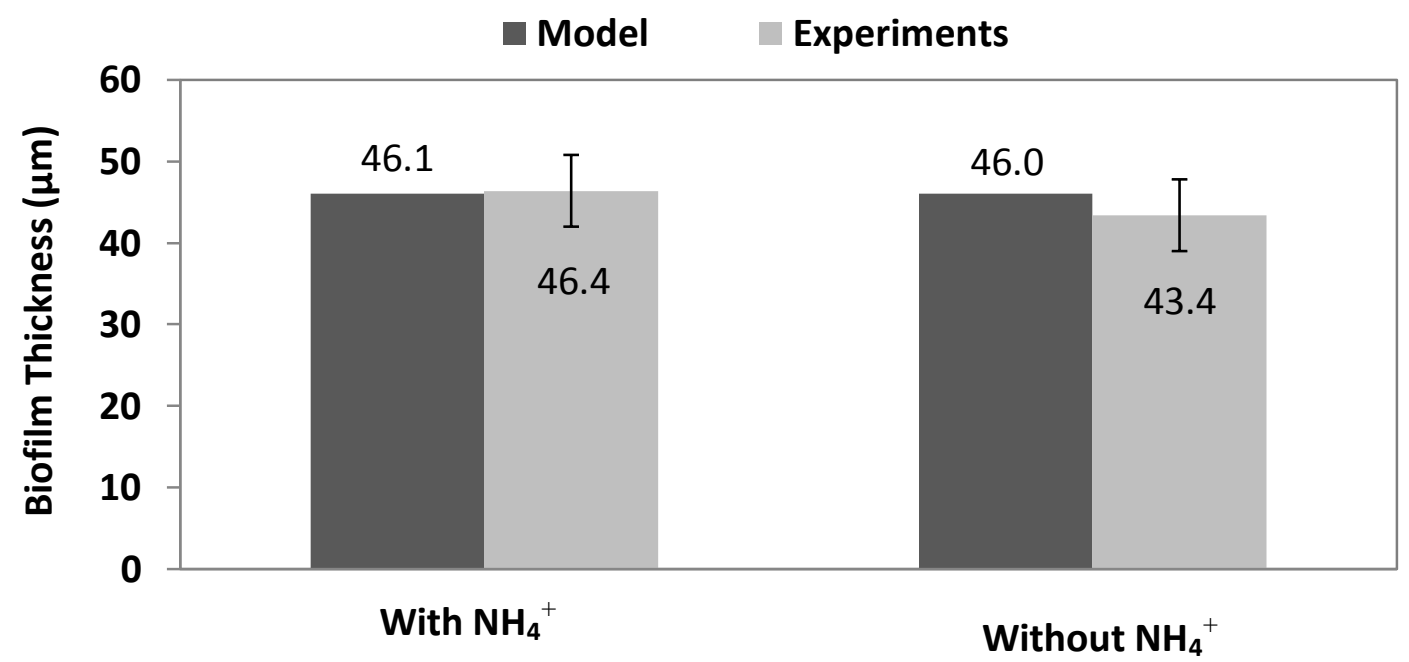

(B)

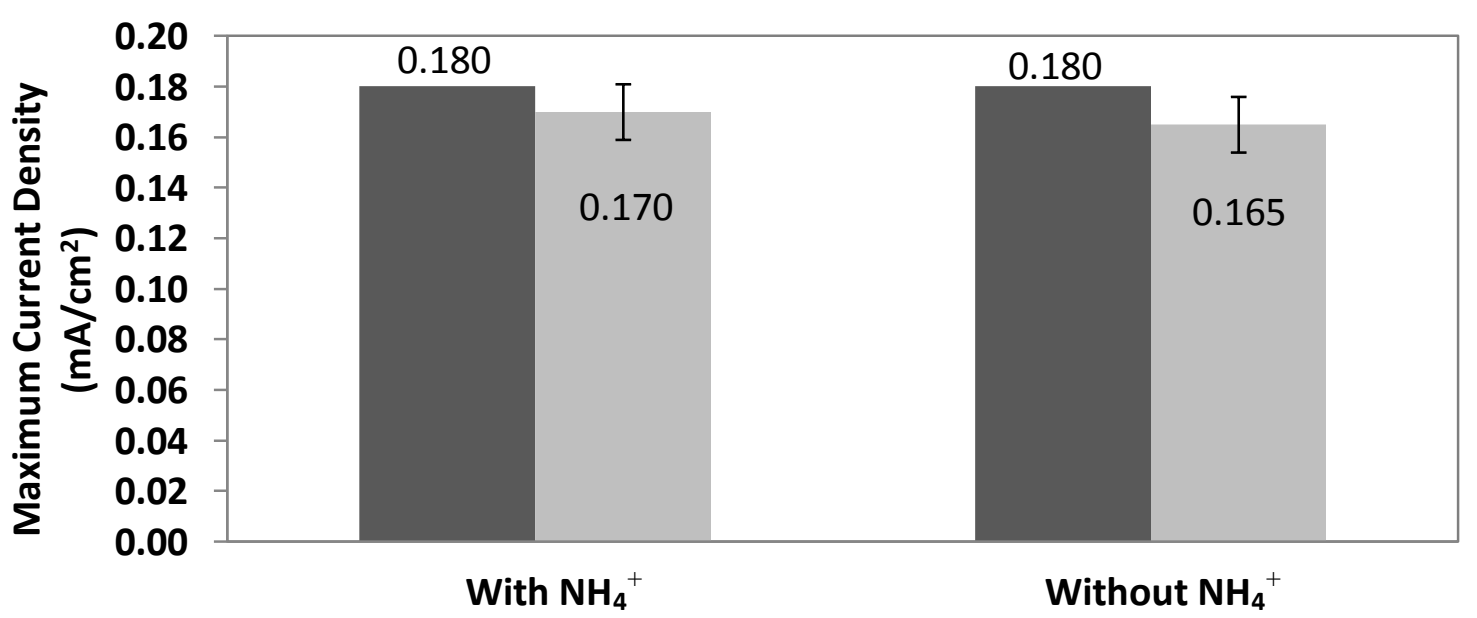

Figure 3.2: A comparison of experimental and model predicted (A) biofilm thicknesses and (B) maximum steady-state current densities under the presence and the absence of $\mathrm{NH}_{4}{ }^{+}$in the medium. 
In general, $\mathrm{NH}_{4}{ }^{+}$is added to the MFC bulk solution as the nitrogen source essential for the biomass growth. The base model established for DL1 strain was used to represent the conditions in the presence of $\mathrm{NH}_{4}{ }^{+}$. However, in representing the condition in the absence of $\mathrm{NH}_{4}{ }^{+}$, the same model parameters were used with new lookup tables that were constructed by setting the upper and lower bounds of $\mathrm{NH}_{4}{ }^{+}$flux in the FBA model to 0. The model predictions were compared with the experimental results as shown by Fig. 3.2.

As seen by the Fig. 3.2a the model predicted biofilm thicknesses in both absence and presence of $\mathrm{NH}_{4}{ }^{+}$were found within the error tolerances of the experimentally determined values. When $\mathrm{NH}_{4}{ }^{+}$is removed from the medium, it resulted in a slight decrease in the experimentally determined biofilm thicknesses. In the absence of $\mathrm{NH}_{4}{ }^{+}$, Geobacter species have the ability to fix atmospheric nitrogen to satisfy the nitrogen requirements (Izallalen et al., 2008). Nitrogen fixation is an energetically demanding process that requires the hydrolysis of 16ATPs for each fixed nitrogen molecule. As more ATP goes towards the nitrogen fixation process, less energy becomes available for biomass synthesis. This results in decreased yields, which give rise to thinner biofilm formation. The slightly lower experimental current densities seen in the absence of $\mathrm{NH}_{4}{ }^{+}$can be explained by the availability of lower cell number due to thinner biofilm formation. However, the model predicted biofilm thicknesses remained almost constant. This could be due to the use of the same death rate parameter, in both the presence and absence of $\mathrm{NH}_{4}{ }^{+}$. The decrease in the biomass yield caused by the increased $\mathrm{ATP}_{\mathrm{M}}$ demand can result in an increased death rate; however, the model does not account for these changes. In addition, the energetic cost towards nitrogen fixation might not be as high compared to the $\mathrm{ATP}_{\mathrm{M}}$ energy consumption towards other maintenance activities in microorganisms. Thus according to the predictions, the model might not be sensitive enough to capture slight changes in the energetic levels of the microorganism.

The model predicted maximum current production in both presence and absence of $\mathrm{NH}_{4}{ }^{+}$ remained constant (Fig. 3.2b). The student's t- test statistical analysis conducted on the experimental current densities also showed that there is no significant difference in the current production in the both presence and absence of $\mathrm{NH}_{4}{ }^{+}$. Hence, this study shows that eliminating the $\mathrm{NH}_{4}{ }^{+}$from the bulk solution does not have a favourable effect in increasing the electron transfer rates of G. sulfurreducens. In addition, it proves that model can be used as a predictive 
tool to determine the trends in current production under different operating conditions. As hypothesized earlier, these results show that the coupled model allows the determination of changes in the energetic levels of microorganisms, under different environmental conditions.

\subsection{Effect of Shear Stress in the Bulk Solution on the Biofilm Thickness}

The MFCs can operate in both continuous and batch modes. In batch fuel cells the thickness of the biofilm depends on the availability of the electron donor, electron acceptor and the $\mathrm{pH}$ variations. However in addition to the above factors, the biofilm thickness of continuous mode MFCs is affected by the detachment of biomass at the external biofilm surface. The cell detachment occurs due to the shear stress induced by the continuous nutrient flow rate into the anode compartment. The shear stress has significant impact on the cell growth and the formation of biofilms on the anode surface. Higher shear stresses are known to suppress the biofilm growth and disrupt established biofilms (Xu et al., 2010; Pham et al., 2007). Thus, Xu et al. carried out experiments to determine the effect of shear stress on the current production and biofilm thicknesses of a continuous mode MFC. The results presented here compare the model predicted biofilm thickness to the experimental results under different levels of shear stress in the bulk solution (Fig. 3.3).

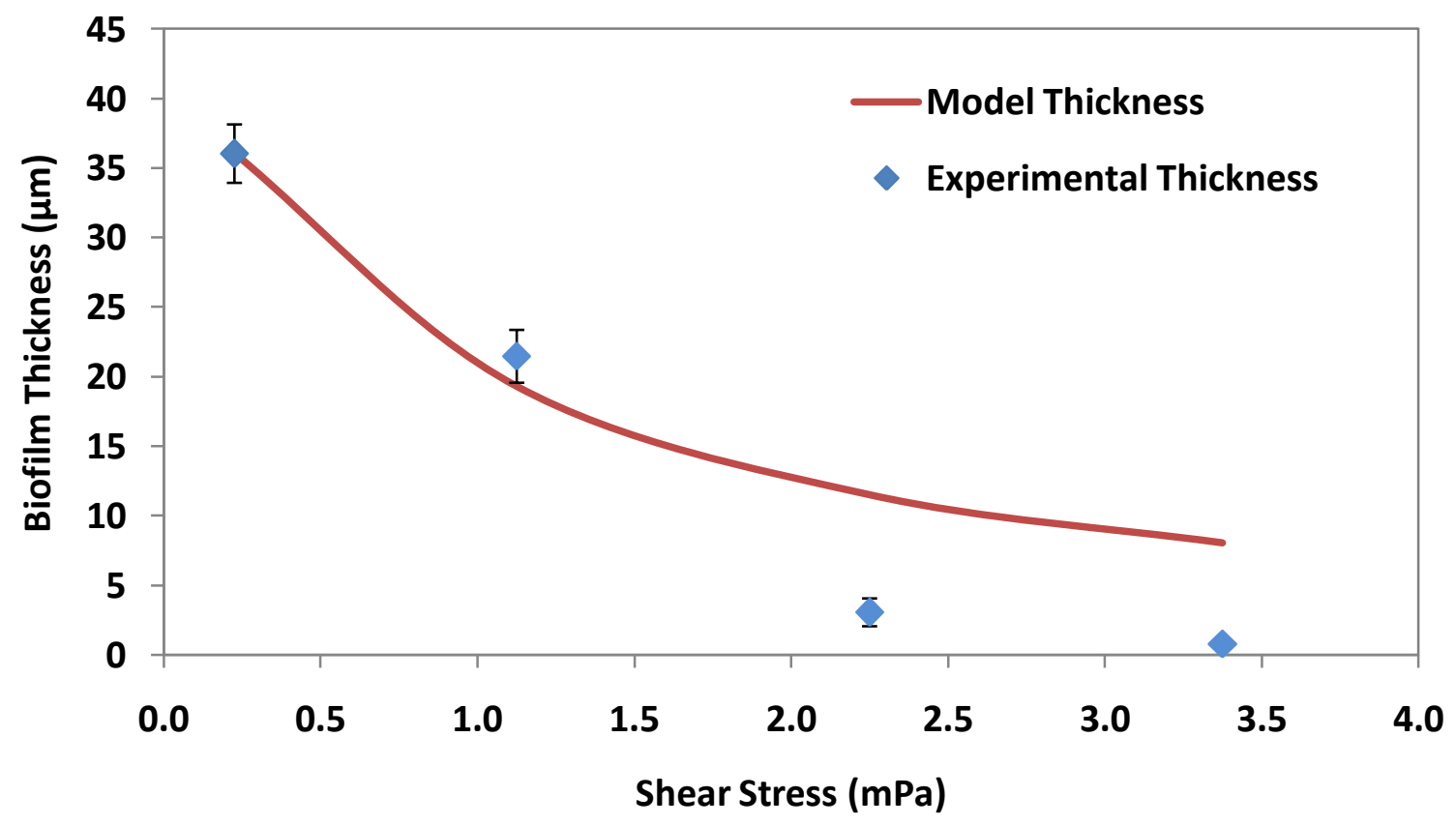

Figure 3.3: A comparison of the experimental and model predicted biofilm thicknesses under different shear stresses. 
In the coupled biofilm model presented here, the effect of shear stress in the bulk liquid is represented by the detachment rate parameter as shown by Eq. (26). Thus, in simulating the shear stress in this model, a linear correlation between the shear stress and the detachment rate was established based on the first data point shown on Fig. 3.3. The thickness at the first data point was fitted in order to obtain the corresponding detachment rate; and the proportionality constant was determined from the shear stress and the detachment rate at that point (detachment rate $=$ $0.187 \mathrm{x}$ shear stress). This linear correlation is included in the Appendix II. The detachment rates at other 3 shear stress points in the Fig. 3.3 were determined based on this correlation; and these rates were incorporated into the model to predict the biofilm thickness at each respective shear stress. As seen by Fig. 3.3, the model predictions and the experimental results followed similar trends; increase in the shear stress resulted in decreased biofilm thicknesses due to higher biomass detachment at the external surface.

However, there are discrepancies between the model predictions and the experimental results. These discrepancies can mainly be attributed to the inaccuracies in assuming a linear correlation between the detachment rate and the shear stress. Hence, further experiments with more precise thickness measurements are required in order to establish better correlations in the future. In addition, the shear stress can also alter the biofilm growth and the cell density (Peyton and Characklis, 1992); however these factors are not being addressed by the model here. In the model, the cell density was assumed to be constant for all the cases, and the cell growth is only dependant on the spatial heterogeneities of the biofilm, rather than the fluid dynamics of the bulk solution. Therefore, incorporating these factors in the future, can improve the accuracy of the model predictions.

Overall, these results show that the coupled model framework can be adapted to represent both continuous and batch mode MFCs, by including and eliminating the detachment rate, respectively; and the model allows the comparison of model predictions with experimental data from different MFC modes. 


\subsection{Effect of ATP $\mathrm{M}$ Levels on the Current Production and the Biofilm Thickness}

Although Geobacter species are known to be among the most effective microorganisms in the current production of MFC biofilms, finding ways to increase electron transfer rates can optimize the biofilm processes. Izallalen et al., 2008 reported a methodology to predict gene deletion strategies to increase respiration rates through an in silico study conducted by coupling the Optknock framework with the FBA model for G. sulfurreducens. This study showed that all the strategies predicted by Optknock were accompanied by an increase in the cellular ATP demand due to the formation of ATP consuming futile cycles. Hence, they conducted further studies using the FBA model for G. sulfurreducens; to examine the effect of increased ATP consumption on the metabolism of G. sulfurreducens. These results showed that higher ATP consumption increased the respiration rate, while decreasing the cell growth rate. However, this study also reported that the increased respiration did not translate into increased current generation in MFC experiments (Izallalen et al., 2008).

The results presented here discuss the impact of these variations associated with increased ATP consumption, on the current production and the thickness of an MFC biofilm. In simulating this process, the increase of the ATP consumption due to futile cycles was modeled by increasing the value of ATP maintenance $\left(\mathrm{ATP}_{\mathrm{M}}\right)$ in the FBA model, and integrating it with the biofilm model. The $\mathrm{ATP}_{\mathrm{M}}$ represents the rate of ATP consumed on non-biosynthetic functions (Izallalen et al., 2008). In general, the FBA model $\mathrm{ATP}_{\mathrm{M}}$ value is set to $0.45 \mathrm{mmol}$ ATP/gdw.hr (Mahadevan et al., 2006). Thus, the current production and the biofilm thickness under increased values of $\mathrm{ATP}_{\mathrm{M}}$ with respect to $0.45 \mathrm{mmol} \mathrm{ATP} / \mathrm{gdw} . \mathrm{hr}$ was compared (Fig. 3.4). It should be noted that in Fig 3.4 the current production is normalized based on the current produced at $0.45 \mathrm{mmol} \mathrm{ATP} / \mathrm{gdw}$.hr. We compared the model predictions (Fig. 3.4) with the results from Izallalen et al., 2008. As shown by Fig. 3.4 the increase in $\mathrm{ATP}_{\mathrm{M}}$ flux from 0.45 to $0.95 \mathrm{mmol}$ ATP/gdw.hr did not increase the current production of the biofilm. These model predictions agree with the MFC experiment results obtained by Izallalen et al., 2008. Therefore, it can be seen that the increased respiration rates under higher $\mathrm{ATP}_{M}$ levels does not have a favorable effect in improving current production in biofilms. 


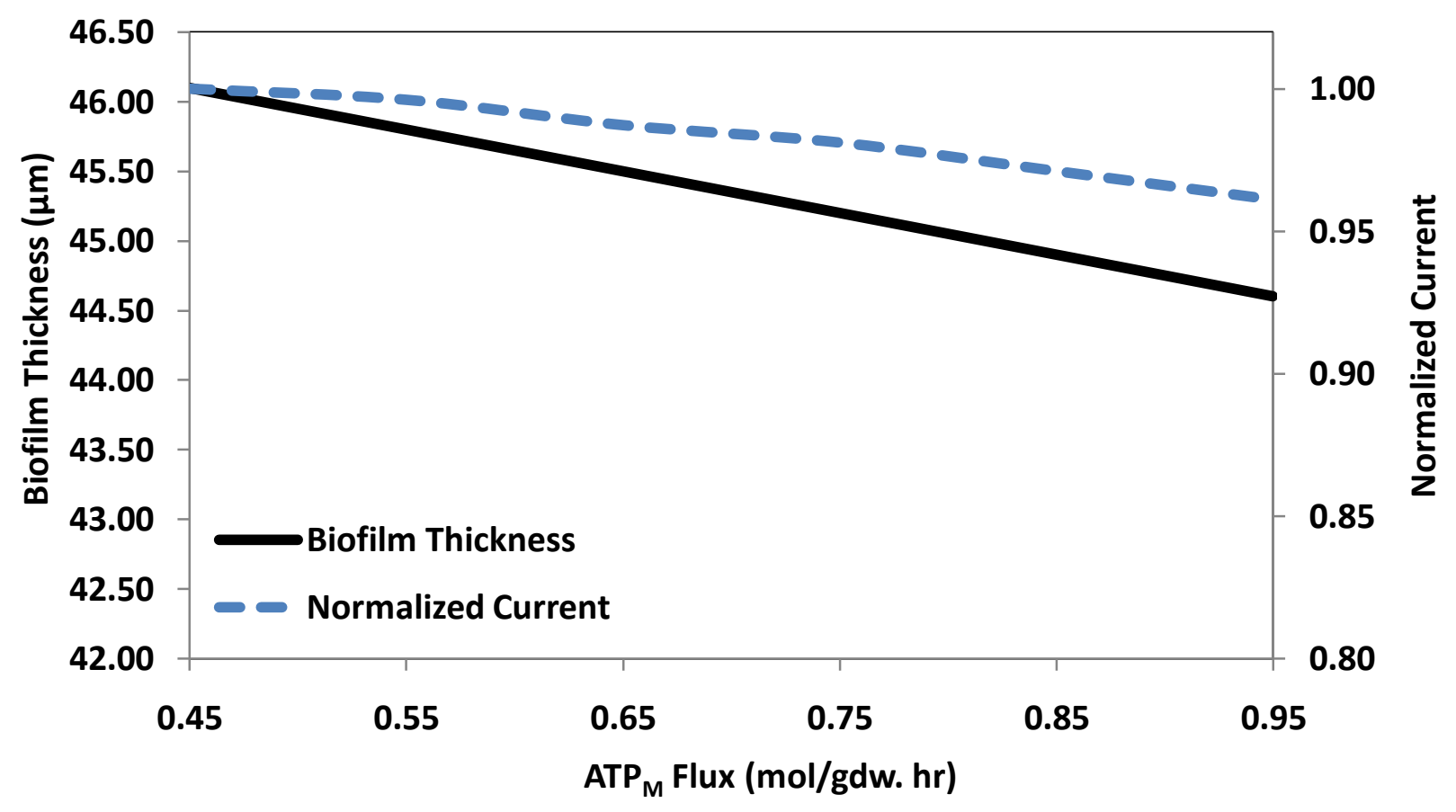

Figure 3.4: The effect of different ATP consumption levels on the current production and the biofilm thicknesses.

Although, the current production did not increase due to higher respiration rates, a slight drop in the current production could be seen from 0.45 to $0.95 \mathrm{mmol}$ ATP/gdw.hr. This drop in the current production could be due to the decrease in cell growth rates caused by increased $\mathrm{ATP}_{\mathrm{M}}$. Higher ATP energy towards maintenance results in lower biomass yields; thus give rise to thinner biofilm formation, decreasing the number of cells available for the current production. This result suggests that when higher energy demand is enforced, the decreases in cell yield leads to reduced current production, providing an explanation for the observations reported in Izallalen et al., 2008.

These results show that coupling the biofilm model with the genome-scale model, provides the ability to determine the effect of varying intracellular energetic levels on the current production and the biofilm formation of MFCs. 


\subsection{Effect of pH Variations across the Biofilm Thickness}

In addition to electron donor and electron acceptor limitations, the $\mathrm{pH}$ levels in the biofilm also play a key role in determining the amount of current producible by a biofilm. Franks et al., 2009 reported that the biofilm activity tends to be limited when the $\mathrm{pH}$ levels fall below a value of 6; and the inner biofilm layers are more susceptible to $\mathrm{pH}$ inhibitions due to limited mass transfer of protons and buffer solution across the biofilms thickness. The PCBIOFILM model constructed by Kato-Marcus et al., 2010 incorporated the effects of buffer on the $\mathrm{pH}$ levels in the biofilm and allowed the determination of various buffer effects on the current production.

Thus, a pH profile was constructed here to obtain a better understanding of the biofilm processes simulated by the model. The $\mathrm{pH}$ profile is shown below in Fig. 3.5.

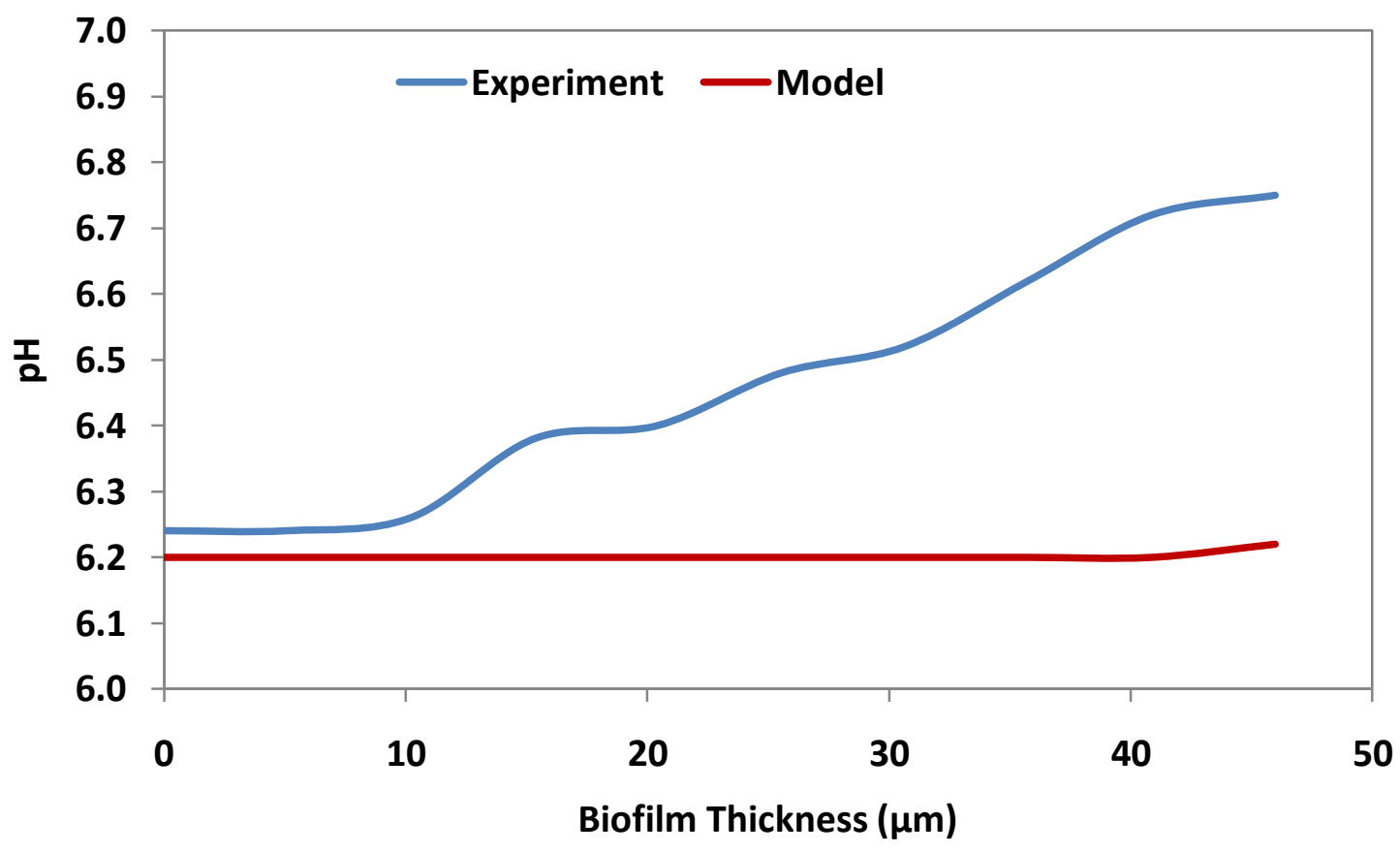

Figure 3.5: A comparison of model predicted and experimentally determined $\mathrm{pH}$ levels across the biofilm thickness.

As shown by Fig. 3.5 the $\mathrm{pH}$ levels remained above a value of 6 throughout the biofilm thickness, indicating that the biofilm activity is independent of inhibitions due to $\mathrm{pH}$, under the 
conditions specified. The model predicted $\mathrm{pH}$ levels beyond a thickness of $10 \mu \mathrm{m}$, show large differences compared to the experimental observations.

In the model the cell density of all types of biomass across the biofilm was assumed to be constant. However, experiments have shown that the cell density varies as a function of distance across the biofilm thickness. The inner biofilm layers tend to be denser than the outer layers (Kengo et al., 2010). The variations of the cell density can translate into variations in the degree of mass transfer across the biofilm thickness. As the $\mathrm{pH}$ levels across the biofilm is calculated based on the concentration of the components (mentioned in Table 1), there can be inaccuracies in the concentration profiles caused by variations in mass transfer; thus, the $\mathrm{pH}$ calculations can also be affected. The discrepancies of the $\mathrm{pH}$ levels in the outer biofilm layer could be due to limitations of the model caused by assuming a constant cell density across the entire biofilm.

In addition, the model assumes that the wild-type strain biofilm forms a homogenous structure throughout the biofilm, with smooth external surfaces. However, in reality these biofilms form highly irregular heterogeneous outer layers with mushroom like pillar structures, whereas the inner layers are mostly homogenous. These heterogeneities in the structure can alter the mass transport across the biofilm, and can promote mass diffusion in three- dimensional space. Thus, in experimentally determining the local pH levels Franks et al., 2009 obtained the average of $\mathrm{pH}$ values from different locations of the biofilm cross-section at a certain distance away from the anode. However, the model allows the determination of mass diffusion only in one- dimensional plane across the biofilm thickness, and does not capture the mass transport variations due to biofilm structure. Therefore, improving the accuracy of the model prediction require the development of models that can evaluate biofilm processes in multi-dimensional planes.

Furthermore, it should be noted that the model only calculates the $\mathrm{pH}$ profile across the biofilm, and does not connect the $\mathrm{pH}$ levels with the microbial activity. However, in the future the $\mathrm{pH}$ inhibitions can be implemented in to the model, in order to give a complete representation of the processes taking place in an MFC biofilm. 


\section{$\underline{\text { 3.6 }}$ Sensitivity Analysis on Conductivity and Cell density Parameters}

The variation of the conductivity and the cell density can promote changes in the biofilm thickness and the current production. For example, the newly isolated G. sulfurreducens strain, KN400, which produces higher current densities with thinner biofilms compared to DL1 strain, is known to have higher conductivities and cell densities than the DL1 strain (Yi et al., 2009). Thus, the biofilm model coupled with the FBA model was used to evaluate the effect of biofilm conductivity and cell density on the biofilm processes (Fig. 3.6). The biofilm thicknesses and the current productions for each case are compared with respect to the DL1 strain values. The conductivity and the cell density of the DL1 strain were $0.525 \mathrm{mS} / \mathrm{cm}$ and $1042 \mathrm{mg}-\mathrm{gdw} / \mathrm{cm}^{3}$, respectively. Hence, the current is normalized based on the current produced at these reference values; and they are shown by the vertical dotted line in Fig. 3.6.

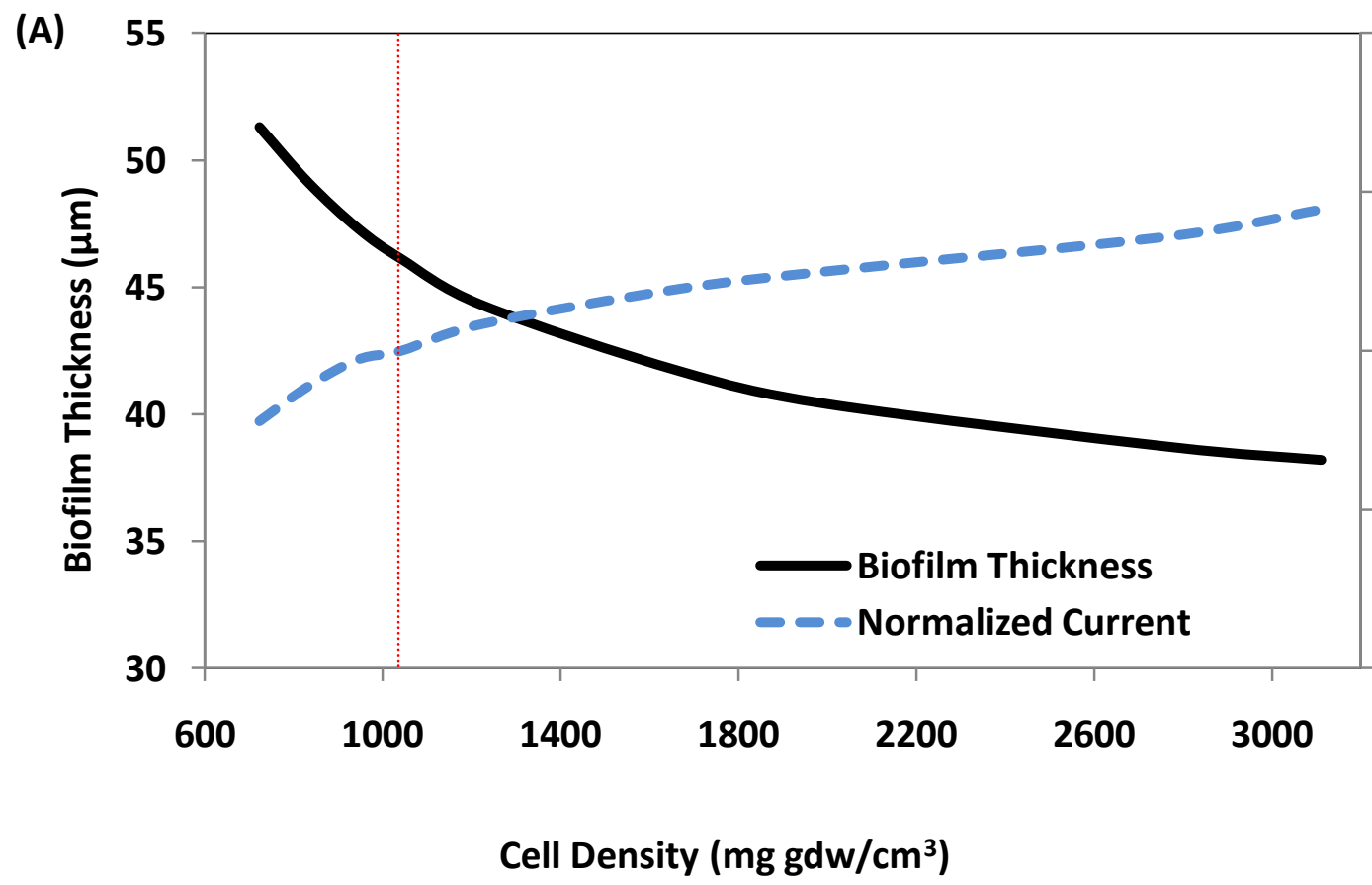




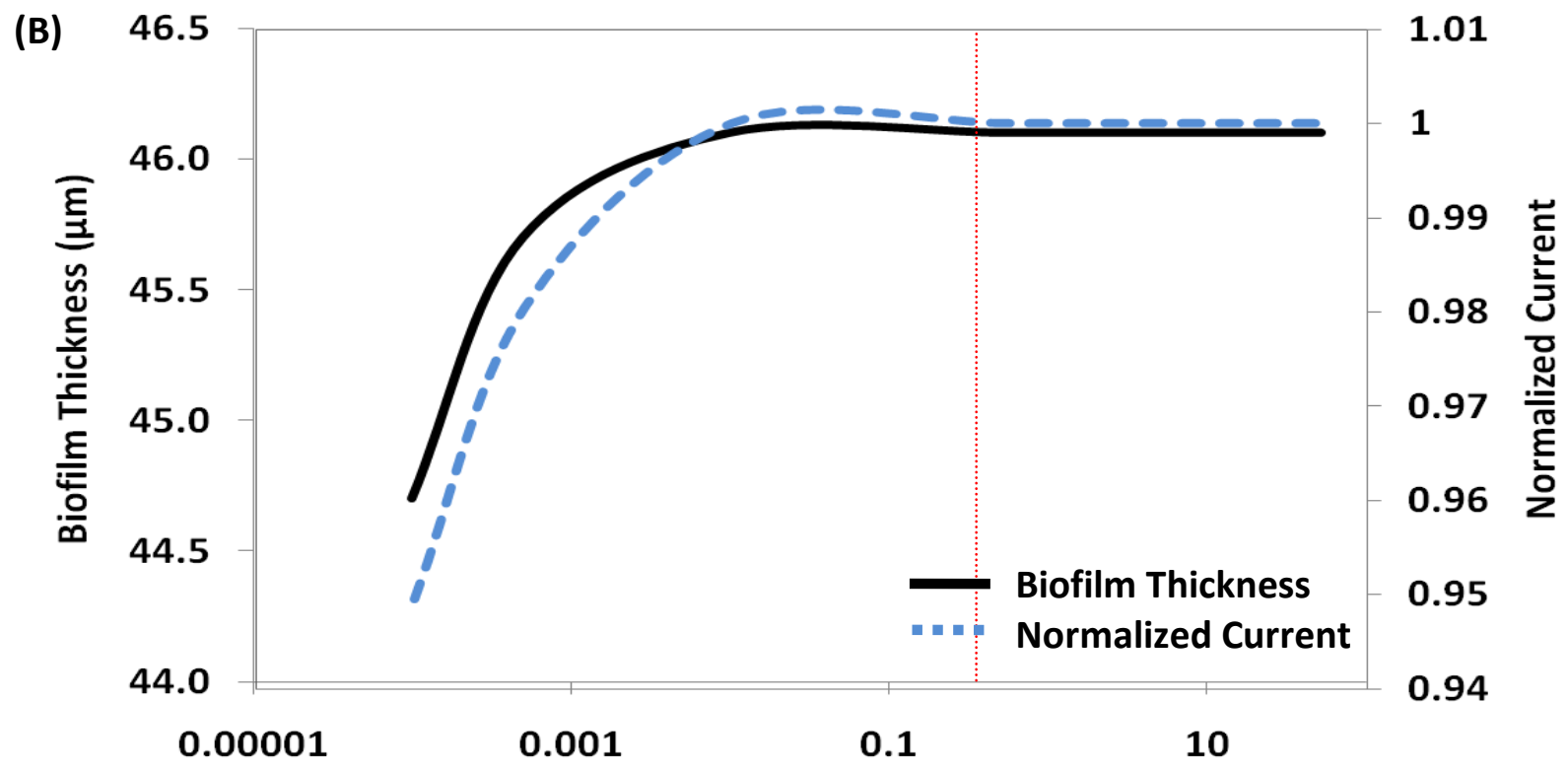

Biofilm Conductivity $(\mathrm{ms} / \mathrm{cm})$

Figure 3.6: The effect of varying (A) cell density and (B) biofilm conductivity on the biofilm thickness and the current production of the biofilm.

The Fig. 3.6a shows that higher cell densities increased the current production in the biofilm, while decreasing the biofilm thickness. When the cell density is increased a larger number of cells are fitted into a smaller volume of the biofilm, promoting the formation of thinner biofilms. The formation of thinner, denser biofilms not only decreases the mass transfer resistance for the electron donor across the biofilm, but also makes the biofilm less susceptible for the electron acceptor and electron donor limitations as the separation between the bulk solution and the anode is reduced. Thus, under similar conditions with no nutrient limitations, denser biofilms are likely to have larger quantities of metabolically active cells contributing towards current production than the thicker biofilms.

The results in Fig. 3.6b show that increasing the biofilm conductivity above $1 \mathrm{mS} / \mathrm{cm}$, does not have a significant effect on the biofilm thickness; however lowering the conductivity decreases the biofilm thickness. When the biofilm conductivity is lowered, it results in larger local potential drops across the biofilm thickness, giving rise to electron acceptor limited regions in the outer layers of the biofilm that are further away from the anode surface. Lower the biofilm 
conductivity, larger the electron acceptor limited region in the biofilm where biomass growth and current production is completely inhibited. Thus, lower biofilm conductivity results in thinner biofilms with low current producing capacities, whereas increasing conductivities does not significantly affect the biofilm processes.

Overall, sensitivity analysis shows that biofilm processes have more favorable effects when cell density is increased, as opposed to the biofilm conductivity. Hence, based on these results improving G. sulfurreducens strains to have higher cell densities will enhance MFC current production more effectively, rather than higher conductivities. Currently, most MFC researchers argue that the 10-fold increase in the biofilm conductivity seen in KN400 strain, compared to the DL1 strain is responsible for the higher levels of current densities observed with the KN400 strain. Yi et al., 2009 reported that the increase in the conductivity of KN400 strain is due to the increased amount of conductive nanowires present in the strain. However, as discussed earlier, nanowires can also act as a structural component of the biofilm that allow the formation denser biofilms. Thus, based on the model predictions it can be suggested that the increased current production of the KN400 strain might be due to the increased cell density caused by the high nanowire content.

In the future this model can be used to compare other characteristics of G. sulfurreducens strains such as the midpoint potentials of the dominant cytochromes, maximum acetate uptake rates and growth rates, based on additional experimental data. These capabilities of the model show the robustness of the coupled framework in capturing biofilm processes under various intracellular and extracellular biofilm processes. 


\section{CHAPTER 4: CONCLUSIONS AND RECOMMENDATIONS}

The results presented in this report show that the coupled model framework developed by combining a biofilm model with the genome scale model for G. sulfurreducens provides a means to analyze the biofilm processes under various conditions, without having to do expensive and time consuming experimental work. The results further confirm that this model has successfully established a method to determine the interaction between the extracellular and intracellular biofilm processes, while taking the spatial heterogeneities across the biofilm into account. Thus, it provides higher capabilities compared to the previous models developed using Nernst-Monod type expressions that evaluated extracellular processes separate from the intracellular metabolism of the microorganism. This can be proven by the studies regarding the effect on current production and biofilm thickness, under varying extracellular conditions such as $\mathrm{NH}_{4}{ }^{+}$and shear stress in the bulk medium, in addition to varying intracellular condition such as the $\mathrm{ATP}_{\mathrm{M}}$ flux. The evaluation of the $\mathrm{pH}$ levels across the biofilm was also made possible due to the coupled model framework. Thus, as hypothesized the coupled model framework provides a better representation of the actual biofilm processes, compared to the previous models.

The coupled model framework represented the spatial heterogeneity across the biofilm successfully. The use of genome-scale model allowed the variation in the biomass yield under nutrient limited conditions to be captured; hence it eliminated the inaccuracies in the previous model caused by using a constant yield across the biofilm.

The $99.8 \%$ coulombic efficiency obtained shows that the current production predicted by the model is consistent with the experimentally observed values. This proves that the introduction of respiring biomass improved the accuracy of the model predictions.

In addition, the introduction of cell death due to electron donor/acceptor limitations, and the biomass removal rate due to cell lysis at the external surface, provided the model with higher flexibility in representing both bath and continuous mode MFCs. 
Thus, overall the coupled model framework provides better predictions with respect to experimental observations, than the previous models.

The studies conducted using this model showed that absence of $\mathrm{NH}_{4}{ }^{+}$from the medium, or increasing the $\mathrm{ATP}_{\mathrm{M}}$ flux cannot be used to enhance current production. Furthermore, the shear stress study showed that higher shear stresses can give to thinner biofilms with lower number of cells for current production. Thus, it is important to choose an optimum nutrient flow rate for continuous mode MFCs that allows the formation of biofilms with sufficient thicknesses for current production. In addition, the sensitivity analysis illustrated that increasing the cell density has a favorable impact in enhancing the current density, rather than increasing the conductivity of the biofilm. Although, the model provided a preliminary evaluation of the $\mathrm{pH}$ changes across the biofilm, it did not include the inhibitions of the metabolic activity under low $\mathrm{pH}$ values. Thus, the inclusion of $\mathrm{pH}$ inhibition in future studies can improve the current density predictions of the model.

There were few discrepancies present in the model predictions compared to the experimental results. These inaccuracies can be reduced by establishing experimentally valid representation for the parameters that were adjusted in this model to fit the base case for the DL1 strain. This requires a clear understanding of biofilm processes such as biomass growth, conversion to respiring biomass, biomass inactivation and cell death mechanisms. In addition, experimental studies have shown biofilms have variable cell densities across the biofilm thickness, where inner biofilm layers are denser than the outer layers. The cell densities affect the degree of mass transfer and the current producing ability of different regions of the biofilm. Incorporation of the cell density variations can reduce the relatively large electron donor limited region predicted by the model, and improve the accuracy of the shear stress study. 
The model presented in this thesis, provides a general framework to understand and evaluate biofilm processes under different extracellular and intracellular conditions. This information is valuable in improving MFC current production and efficiency. In the future, this model can be extended to allow the optimization of MFC operating conditions and intracellular/extracellular biofilm characteristics. Some of the suggested future directions for this model are discussed below.

Currently, the coupled model framework represents a biofilm formed on the anode surface of an MFC; however, in the future it can be used to represent biofilms in BESs that are used for producing chemicals, through microbially assisted electrosynthesis. In recent years, highest potentials for commercial success have been seen towards using MFC technology for producing chemicals in an environmentally friendly manner. As mentioned earlier, this technology is used by Emefcy Ltd. and the Bilexys system for producing various chemicals such as $\mathrm{H}_{2}$ and caustic soda, respectively. In addition, a significant amount of current research have been dedicated towards improving microbially assisted electrosynthesis ; and a timeline showing the shift of research focus towards developing this technology is shown Fig. 4.1. Therefore, having mathematical models that can represent biofilms in BESs are essential for the development of microbially assisted electrosynthesis. The robustness of the coupled model framework shown in this thesis makes it possible to easily represent biofilms in BESs, with modifications to the biofilm model equations to account for the additional power input, different substrates and operating conditions. 


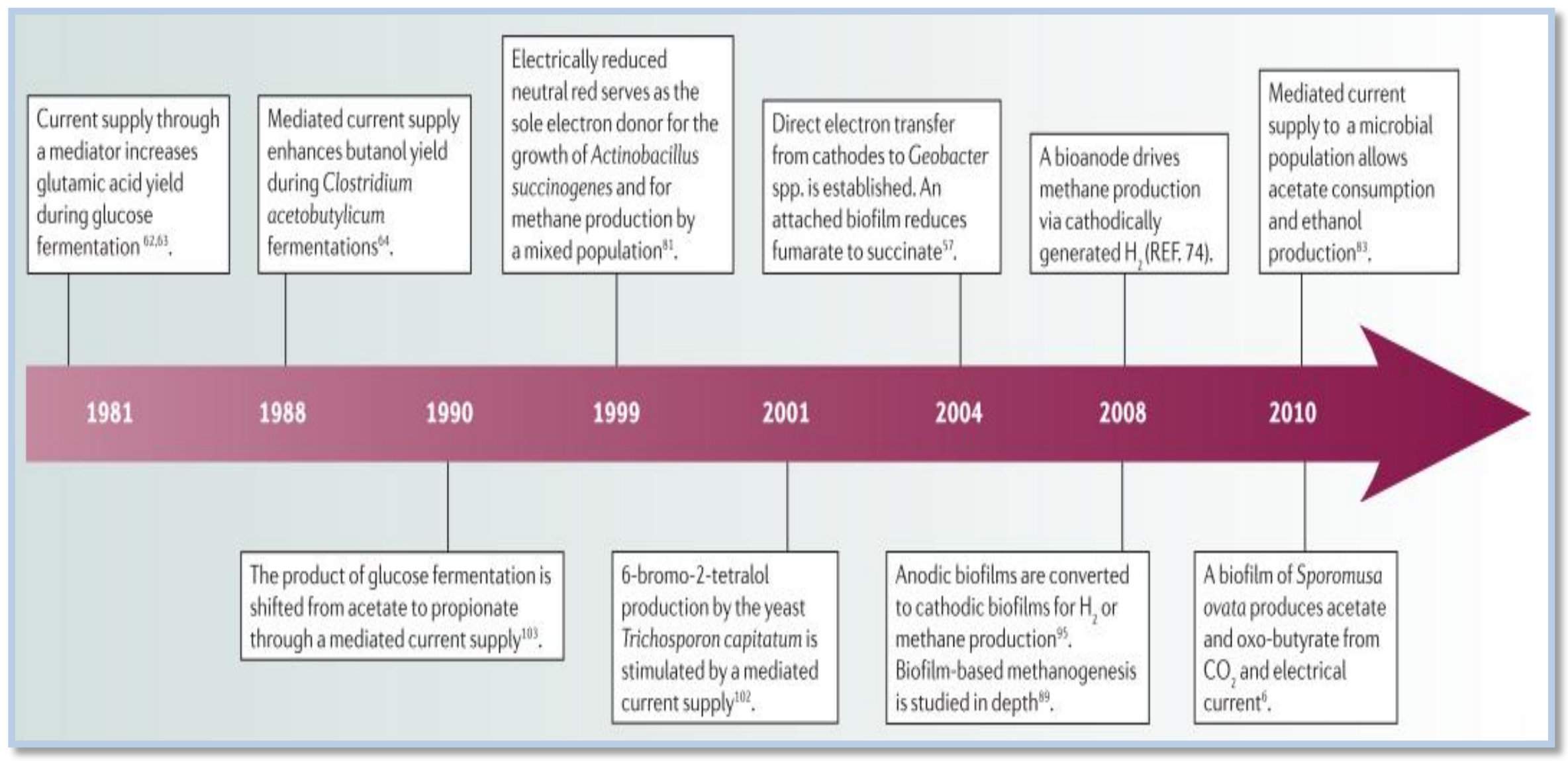

Figure 4.1: Major achievement towards microbially assisted electrosynthesis (Adapted by permission from Macmillan Publisher Ltd: [Nature Review] (Rabaey and Rozendal, 2010), copyright (2010)). 
Although most MFCs used in experimental studies operate with a poised anode, the real world MFCs consist of a cathode side that significantly affect the overall performance of an MFC. Thus, a considerable amount of research has been focused on enhancing cathodic processes, through the development of novel material, design parameters and catalysts. Recently, it was found that the MFC power output is constraint by the cathode surface area (Oh and Logan, 2006). However, existing MFC models are restricted to represent only the anode side processes. Therefore, it will be useful to extend the model presented here, to represent also the cathode side processes. Extending an anode biofilm model to include the cathode processes, require the modeling of the proton exchange membrane in order to account for the charged particles transferred from anode to the cathode side (Rismani-yazdi et al., 2008). This can improve the accuracy of the model, in terms of accounting for the potential losses across the anode and cathode compartments, as well as the potential losses across the biofilm thickness. 


\section{5: REFERENCES}

1. Aelterman ${ }^{\mathrm{a}} \mathrm{P}$, Rabaey K, Clauwaert P, Verstraete W. Microbial fuel cells for wastewater treatment. Water Science \& Technology. 2006; 54(8):9.

2. Aelterman ${ }^{\mathrm{b}}$ P, Rabaey K, The Pham H, Boon N, Verstraete W. Continuous electricity generation at high voltages and currents using stacked microbial fuel cells. Communications in agricultural and applied biological sciences. 2006; 71(1):63-6.

3. Allgower EL, Georg K, Introduction to numerical continuation methods. Wiley \& Sons (New York). 2003.

4. Becker Sa, Feist AM, Mo ML, Hannum G, Palsson B, , Herrgard MJ. Quantitative prediction of cellular metabolism with constraint-based models: the COBRA Toolbox. Nature protocols. 2007; 2(3):727-38.

5. Bond DR, Holmes DE, Tender LM, Lovley DR. Electrode-reducing microorganisms that harvest energy from marine sediments. Science (New York, N.Y.). 2002; 295(5554):483-5.

6. Bond DR, Lovley DR. Electricity Production by Geobacter sulfurreducens Attached to Electrodes. American Society for Microbiology. 2003; 69(3):1548-1555.

7. Bond DR, Lovley DR. Evidence for Involvement of an Electron Shuttle in Electricity Generation by Geothrix fermentans. American Society for Microbiology. 2005; 71(4):21862189.

8. Cheng S, Liu H, Logan B. Increased performance of single-chamber microbial fuel cells using an improved cathode structure. Electrochemistry Communications. 2006; 8(3):489494.

9. Cord-Ruwisch R, Lovley DR, Schink B. Growth of Geobacter sulfurreducens with acetate in syntrophic cooperation with hydrogen-oxidizing anaerobic partners. Applied and environmental microbiology. 1998; 64(6):2232-6.

10. Esteve-Núñez A, Sosnik J, Visconti P, Lovley DR. Fluorescent properties of c-type cytochromes reveal their potential role as an extracytoplasmic electron sink in Geobacter sulfurreducens. Environmental microbiology. 2008; 10(2):497-505.

11. Fan ${ }^{\mathrm{a}} \mathrm{Y}, \mathrm{Hu} \mathrm{H}, \mathrm{Liu} \mathrm{H}$. Enhanced Coulombic efficiency and power density of air-cathode microbial fuel cells with an improved cell configuration. Journal of Power Sources. 2008; 171(2):348-354.

12. Fan $^{b} Y$, Sharbrough E, Liu H. Quantification of the internal resistance distribution of microbial fuel cells. Environmental science \& technology. 2008; 42(21):8101-7. 
13. Franks AE, Malvankar N, Nevin KP. Bacterial biofilms: the powerhouse of a microbial fuel cell. Biofuels Review. 2010; 1589-604.

14. Franks AE, Nevin KP, Jia H, Izallalen M, Woodard TL, Lovley DR. Novel strategy for three-dimensional real-time imaging of microbial fuel cell communities: monitoring the inhibitory effects of proton accumulation within the anode biofilm. Energy \& Environmental Science. 2009; 2(1):113.

15. Gorby Y, Yanina S, McLean JS, Rosso KM, Moyles D, Dohnalkova A, et al. Electrically conductive bacterial nanowires produced by Shewanella oneidensis strain MR-1 and other microorganisms. Proceedings of the National Academy of Sciences of the United States of America. 2006; 103(30):11358-63.

16. Hu Z. Electrochemical determination of anaerobic microbial decay coefficients. Chemosphere. 2008; 72(2):312-8.

17. IWA Task Group on Biofilm Modeling. Mathematical Modeling of Biofilms. IWA Publishing (London). 2006.

18. Izallalen M, Mahadevan R, Burgard A, Postier B, Didonato R, Sun J, et al. Geobacter sulfurreducens strain engineered for increased rates of respiration. Metabolic engineering. 2008; 10(5):267-75.

19. Kato-Marcus A, Torres I, Rittmann BE, Conduction-Based Modeling of the Biofilm Anode of a Microbial Fuel Cell. Biotechnology \& Bioengineering. 2007; 98(6):1171-1182.

20. Kato-Marcus A, Torres CI, Rittmann BE. Analysis of a microbial electrochemical cell using the proton condition in biofilm (PCBIOFILM) model. Bioresource technology. 2010

21. Kauffman KJ, Prakash P, Edwards JS. Advances in flux balance analysis. Current Opinion in Biotechnology. 2003; 14(5):491-496.

22. Kengo I, Franks AE, Leang C, Lovley DR, Current densities and anode conductivity are correlated with the degree of packing in Geobacter sulfurreducens. Personal Communications. 2010; (June).

23. Leang C, Qian X, Mester T, Lovley DR. Alignment of the c-Type Cytochrome OmcS Along Pili of Geobacter sulfurreducens. Applied and environmental microbiology. 2010; 76(12):4080-4084.

24. Lee H, Parameswaran P, Kato-Marcus A, Torres CI, Rittmann BE. Evaluation of energyconversion efficiencies in microbial fuel cells (MFCs) utilizing fermentable and nonfermentable substrates. Water research. 2008; 42(6-7):1501-10. 
25. Liu H, Logan BE. Electricity generation using an air-cathode single chamber microbial fuel cell in the presence and absence of a proton exchange membrane. Environmental science \& technology. 2004; 38(14):4040-6.

26. Logan BE, Hamelers HV, Rozendal Ra, Schröder U, Keller J, Freguia S, et al. Critical Review Microbial Fuel Cells: Methodology and Technology. Environmental Science \& Technology. 2006; 40(17):5181-5192.

27. Logan BE. Microbial Fuel Cells. The Pennsylvania State University. Wiley-Interscience. 2007.

28. Logan BE. Exoelectrogenic bacteria that power microbial fuel cells. Nature reviews. Microbiology. 2009; 7(5):375-81.

29. Lovley ${ }^{\mathrm{a}}$ DR. Bug juice: harvesting electricity with microorganisms. Nature reviews. Microbiology. 2006; 4(7):497-508.

30. Lovley ${ }^{\mathrm{b}}$ DR. Microbial fuel cells: novel microbial physiologies and engineering approaches. Current opinion in biotechnology. 2006; 17(3):327-32.

31. Lovley ${ }^{\mathrm{a}} \mathrm{DR}$. Extracellular electron transfer: wires, capacitors, iron lungs, and more. Geobiology. 2008; 6(3):225-31.

32. Lovley ${ }^{\mathrm{b}}$ DR. The Microbe Electric: Conversion of organic matter to electricity. Current opinion in biotechnology. 2008; 19(6):564-71.

33. Mahadevan R, Bond DR, Butler JE, Coppi MV. Characterization of Metabolism in the Fe (III) -Reducing Organism Geobacter sulfurreducens by Constraint-Based Modeling. American Society for Microbiology. 2006; 72(2):1558-1568.

34. Marsili E, Baron DB, Shikhare ID, Coursolle D, Gralnick Ja, Bond DR. Shewanella secretes flavins that mediate extracellular electron transfer. Proceedings of the National Academy of Sciences of the United States of America. 2008; 105(10):3968-73.

35. Megawatter Technology. Emefcy - Bioenergy Systems, 2010; (September). Available at: http://www.emefcy.com/index.php?option=com_content\&view=article \&id=6\&Itemid=25

36. Min B, Logan BE. Continuous electricity generation from domestic wastewater and organic substrates in a flat plate microbial fuel cell. Environmental science \& technology. 2004; 38(21):5809-14.

37. Nevin KP, Richter H, Covalla SF, Johnson JP, Woodard TL, Orloff aL, et al. Power output and columbic efficiencies from biofilms of Geobacter sulfurreducens comparable to mixed community microbial fuel cells. Environmental microbiology. 2008 ;10(10):2505-14. 
38. Oh S, Logan BE. Proton exchange membrane and electrode surface areas as factors that affect power generation in microbial fuel cells. Applied microbiology and biotechnology. 2006; 70(2):162-9.

39. Peyton BM, Characklis WG. A statistical analysis of the effect of substrate utilization and shear stress on the kinetics of biofilm detachment. Biotechnology and bioengineering. 1993; 41(7):728-35.

40. Pham HT, Boon N, Aelterman P, Clauwaert P, De Schamphelaire L, van Oostveldt P, et al. High shear enrichment improves the performance of the anodophilic microbial consortium in a microbial fuel cell. Microbial Biotechnology. 2008; 1(6):487-496.

41. Picioreanu C, Head IM, Katuri KP, van Loosdrecht MC, Scott K. A computational model for biofilm-based microbial fuel cells. Water research. 2007; 41(13):2921-40.

42. Picioreanu C, van Loosdrecht MC, Katuri KP, Scott K, Head IM. Mathematical model for microbial fuel cells with anodic biofilms and anaerobic digestion. Water science and technology: a journal of the International Association on Water Pollution Research. 2008; 57(7):965-71.

43. Price ND, Reed JL, Palsson B $\emptyset$. Genome-scale models of microbial cells: evaluating the consequences of constraints. Nature reviews. Microbiology. 2004; 2(11):886-97.

44. Rabaey K, Boon N, Siciliano SD, Verhaege M, Verstraete W. Biofuel Cells Select for Microbial Consortia That Self-Mediate Electron Transfer. American Society for Microbiology. 2004; 70(9):5373-5382.

45. Rabaey K, Boon N, Siciliano SD, Verhaege M, Verstraete W. Biofuel Cells Select for Microbial Consortia That Self-Mediate Electron Transfer. American Society for Microbiology. 2004; 70(9):5373-5382.

46. Rabaey K, Rodríguez J, Blackall LL, Keller J, Gross P, Batstone D, et al. Microbial ecology meets electrochemistry: electricity-driven and driving communities. The ISME journal. 2007; 1(1):9-18.

47. Rabaey K, Verstraete W. Microbial fuel cells: novel biotechnology for energy generation. Trends in biotechnology. 2005; 23(6):291-8.

48. Rabaey K, Rozendal Ra. Microbial electrosynthesis - revisiting the electrical route for microbial production. Nature reviews. Microbiology. 2010; 8(10):706-16.

49. Reguera G, McCarthy KD, Mehta T, Nicoll JS, Tuominen MT, Lovley DR. Extracellular electron transfer via microbial nanowires. Nature. 2005; 435(7045):1098-101. 
50. Reguera G, Nevin KP, Nicoll JS, Covalla SF, Woodard TL, Lovley DR. Biofilm and nanowire production leads to increased current in Geobacter sulfurreducens fuel cells. Applied and environmental microbiology. 2006; 72(11):7345-8.

51. Richter H, Nevin KP, Jia H, Lowy Da, Lovley DR, Tender LM. Cyclic voltammetry of biofilms of wild type and mutant Geobacter sulfurreducens on fuel cell anodes indicates possible roles of OmcB, OmcZ, type IV pili, and protons in extracellular electron transfer. Energy \& Environmental Science. 2009; 2(5):506.

52. Rismani-yazdi H, Carver S, Christy a, Tuovinen O. Cathodic limitations in microbial fuel cells: An overview. Journal of Power Sources. 2008 ;180(2):683-694.

53. Rozendal Ra, Hamelers HV, Molenkamp RJ, Buisman CJ. Performance of single chamber biocatalyzed electrolysis with different types of ion exchange membranes. Water research. 2007; 41(9):1984-94.

54. Scheibe TD, Mahadevan R, Fang Y, Garg S, Long PE, Lovley DR. Coupling a genomescale metabolic model with a reactive transport model to describe in situ uranium bioremediation. Microbial Biotechnology. 2009; 2(2):274-286.

55. Schuster S, Fell DA. Modeling and simulating metabolic networks. Bioinformatics- From Genome to Therapies. (2), Wiley-VCH. Wienheim, 2007; (2) 755-805.

56. Scott K, Cotlarciuc I, Hall D, Lakeman JB, Browning D. Power from marine sediment fuel cells: the influence of anode material. Journal of Applied Electrochemistry. 2008; 38(9):1313-1319.

57. Shizas I, Bagley DM. Fermentative hydrogen production in a system using anaerobic digester sludge without heat treatment as a biomass source. Water science and technology: a journal of the International Association on Water Pollution Research. 2005; 52(12):139-44.

58. Srinivasan K, Mahadevan R. Characterization of proton production and consumption associated with microbial metabolism. BMC biotechnology. 2010; 102.

59. The Bilexys System. Bilexys, 2010; (September). Available at: http://www.bilexys.com

60. Torres CI, Marcus AK, Rittmann BE. Kinetics of consumption of fermentation products by anode-respiring bacteria. Applied microbiology and biotechnology. 2007 ;77(3):689-97.

61. Torres ${ }^{\mathrm{a}}$ CI, Kato Marcus A, Rittmann BE. Proton transport inside the biofilm limits electrical current generation by anode-respiring bacteria. Biotechnology and bioengineering. 2008; 100(5):872-81. 
62. Torres ${ }^{\mathrm{b}} \mathrm{CI}$, Lee H, Rittmann BE. Carbonate species as $\mathrm{OH}$ - carriers for decreasing the $\mathrm{pH}$ gradient between cathode and anode in biological fuel cells. Environmental science \& technology. 2008; 42(23):8773-7.

63. Torres ${ }^{c}$ CI, Marcus AK, Parameswaran P, Rittmann BE. Kinetic experiments for evaluating the Nernst-Monod model for anode-respiring bacteria (ARB) in a biofilm anode. Environmental science \& technology. 2008; 42(17):6593-7.

64. Vanbriesen JM, Rittmann BE. Modeling speciation effects on biodegradation in mixed metal / chelate systems. Biodegradation. 2000; 315-330.

65. Varma a, Palsson BO. Stoichiometric flux balance models quantitatively predict growth and metabolic by-product secretion in wild-type Escherichia coli W3110. Applied and environmental microbiology. 1994; 60(10):3724-31.

66. Xu C, Franks AE, Nevin KP, Russell TP, Lovley DR. Effect of shear stress of the power production of microbial fuel cells of Geobacter sulfurreducens. Personal Communications. 2010; (July).

67. Yi H, Nevin KP, Kim B, Franks AE, Klimes A, Tender LM, et al. Selection of a variant of Geobacter sulfurreducens with enhanced capacity for current production in microbial fuel cells. Biosensors \& bioelectronics. 2009; 24(12):3498-503. 


\section{6: APPENDIX I}

\subsection{Equations and Parameters Used in the Biofilm Model Component of the Coupled Model Framework}

\section{a) Set of Mass Balances for Modeling Wild - type DL1 Strain for G. sulfurreducens}

The mass balances for the biofilm components were represented as ordinary differential equations in the biofilm Model. These equations are shown below in Table 3:

Table 3: Ordinary differential equations representing the mass balances for the components in the biofilm model

\begin{tabular}{|c|c|c|}
\hline & Mass Balances & Ordinary Differential Equations (Steady State) \\
\hline (1) & Electron donor & $0=D_{E D, f} \frac{\partial^{2} S_{d}}{\partial z^{2}}-X_{f, a} \phi_{a} q_{E D, o x d}-X_{f, a} \phi_{r} q_{E D, r e s}$ \\
\hline (2) & Current density & $0=\frac{\partial j}{\partial z}+\frac{F}{\tau} X_{f, a} \phi_{a} q_{e, o x d}+\frac{F}{\tau} X_{f, a} \phi_{r} q_{e, r e s}$ \\
\hline (3) & Local potential & $0=K_{\text {bio }} \frac{\partial^{2} \eta}{\partial z^{2}}-\frac{F}{\tau} X_{f, a} \phi_{a} q_{e, o x d}-\frac{F}{\tau} X_{f, a} \phi_{r} q_{e, r e s}$ \\
\hline (4) & Active biomass fraction & $\frac{\partial\left(\mathrm{v} \phi_{\mathrm{a}}\right)}{\partial \mathrm{z}}=\phi_{\mathrm{a}} \mu_{\mathrm{g}}-\mathrm{r}_{\mathrm{ina}}-\mathrm{r}_{\mathrm{conv}} \equiv \mu_{\mathrm{a}}$ \\
\hline (5) & Respiring biomass fraction & $\frac{\partial\left(\mathrm{v} \phi_{\mathrm{r}}\right)}{\partial \mathrm{z}}=\mathrm{r}_{\mathrm{conv}} \equiv \mu_{\mathrm{r}} \quad$ where, $\quad \mathrm{r}_{\mathrm{conv}}=\mathrm{b}_{\mathrm{conv}} \phi_{\mathrm{a}}$ \\
\hline (6) & Inert biomass fraction & $\frac{\partial\left(\mathrm{v} \phi_{\mathrm{i}}\right)}{\partial \mathrm{z}}=\mathrm{r}_{\mathrm{ina}} \equiv \mu_{\mathrm{i}} \quad$ where, $\quad \mathrm{r}_{\mathrm{ina}}=\mathrm{b}_{\mathrm{ina}} \phi_{\mathrm{a}}$ \\
\hline (7) & $\begin{array}{l}\text { Advection velocity due to cell } \\
\text { growth }\end{array}$ & $\frac{\partial \mathrm{v}}{\partial \mathrm{z}}=\phi_{\mathrm{a}} \mu_{\mathrm{g}}$ \\
\hline (8) & $\begin{array}{l}\text { Advection velocity due to cell } \\
\text { death }\end{array}$ & $\frac{\partial \mathrm{v}_{\mathrm{d}}}{\partial \mathrm{z}}=\mu_{\mathrm{d}}$ \\
\hline
\end{tabular}


These equations were solved using the boundary value problem solver (bvp4c) in MATLAB. The bvp4c solver requires all ordinary differential equations to be specified as first order ordinary differential equations. Hence, in this model the second order ordinary differential equations for electron donor and the local potential mass balances are separated into first order differential equations. 


\section{b) Boundary Conditions for the Ordinary Differential Equations and Parameters Used in the Biofilm Model}

In using the bvp4c solver, it is necessary to specify a set of boundary conditions for each equation in the model. It should be noted that the bvp4c solver also allows the estimation of unknown parameters. In this model, the biofilm thickness was treated as the unknown parameter, and it was estimated using the bvp4c solver. The parameter estimation also requires the specification of boundary conditions. A summary of all the boundary conditions used in the model are shown in Table 4 below.

Table 4: Boundary conditions for the ordinary differential equations in Table 3

\begin{tabular}{|c|c|}
\hline Mass Balances & Boundary Conditions \\
\hline Electron donor & $\begin{array}{l}\text { i. No flux boundary at the anode }(\mathrm{z}=0) \\
\qquad 0=\left.\mathrm{D}_{\mathrm{ED}, \mathrm{f}} \frac{\partial \mathrm{S}_{\mathrm{d}}}{\partial \mathrm{z}}\right|_{\mathrm{z}=0} \\
\text { ii. Continuous flux boundary at the external surface } \\
\left(\mathrm{z}=\mathrm{L}_{\mathrm{f}}\right) \\
\left.\mathrm{D}_{\mathrm{ED}, \mathrm{f}} \frac{\partial \mathrm{S}_{\mathrm{d}}}{\partial \mathrm{z}}\right|_{\mathrm{z}=\mathrm{Lf}}=\left(\frac{\mathrm{D}_{\mathrm{ED}, \mathrm{l}}}{\mathrm{L}}\right)\left(\mathrm{S}_{\mathrm{d}, \text { bulk }}-\mathrm{S}_{\mathrm{d}, \text { surface }}\right)\end{array}$ \\
\hline Current density & $\begin{array}{l}\text { No flux boundary at the external surface }\left(\mathrm{z}=\mathrm{L}_{\mathrm{f}}\right) \\
\qquad \frac{\left.\mathrm{j}\right|_{\mathrm{z}=\mathrm{Lf}}}{\mathrm{K}_{\mathrm{bio}}}=0\end{array}$ \\
\hline Local potential & $\begin{array}{l}\text { i. Fixed anode potential at the anode }(\mathrm{z}=0) \\
\qquad\left.\eta\right|_{\mathrm{z}=0}=\mathrm{V}_{\text {anode }} \\
\text { ii. No flux boundary at the external surface }\left(\mathrm{z}=\mathrm{L}_{\mathrm{f}}\right) \\
\qquad\left.\frac{\partial \eta}{\partial \mathrm{z}}\right|_{\mathrm{z}=\mathrm{Lf}}=0\end{array}$ \\
\hline Active biomass fraction & $\begin{array}{l}\text { Fixed biomass fraction at the anode }(\mathrm{z}=0) \\
\qquad\left.\phi_{\mathrm{a}}\right|_{\mathrm{z}=0}=0.1\end{array}$ \\
\hline
\end{tabular}




\begin{tabular}{|c|c|}
\hline Respiring biomass fraction & $\begin{array}{l}\text { Fixed biomass fraction at the anode }(\mathrm{z}=0) \\
\qquad\left.\phi_{\mathrm{r}}\right|_{\mathrm{z}=0}=0.4\end{array}$ \\
\hline Inert biomass fraction & $\begin{array}{l}\text { Fixed biomass fraction at the anode }(\mathrm{z}=0) \\
\qquad\left.\phi_{\mathrm{a}}\right|_{\mathrm{z}=0}=0.5\end{array}$ \\
\hline Advection velocity due to cell growth & $\begin{array}{l}\text { Fixed biomass fraction at the anode }(\mathrm{z}=0) \\
\qquad\left.\mathrm{v}\right|_{\mathrm{z}=0}=5.2 \times 10^{-4} \mathrm{~cm} / \text { day }\end{array}$ \\
\hline Advection velocity due to cell death & $\begin{array}{l}\text { Fixed biomass fraction at the anode }(\mathrm{z}=0) \\
\qquad\left.\mathrm{v}_{\mathrm{d}}\right|_{\mathrm{z}=0}=0 \mathrm{~cm} / \text { day }\end{array}$ \\
\hline $\begin{array}{l}\text { Biofilm thickness } \\
\text { (parameter estimation ) }\end{array}$ & $0=\left.v\right|_{z=L f}-\left.v_{d}\right|_{z=L f}-r_{\text {lysis }} L_{f}-b_{d e t} L_{f}$ \\
\hline
\end{tabular}




\section{c) The pH Modeling}

Table 5: Additional ordinary differential equations representing the components affecting the $\mathrm{pH}$ levels

\begin{tabular}{|c|c|}
\hline Components & Mass Balances \\
\hline $\mathrm{H}_{2} \mathrm{CO}_{3}$ & $0=\mathrm{D}_{\mathrm{CO}_{2}, \mathrm{f}} \frac{\partial^{2} \mathrm{C}_{\mathrm{CO}_{2}}}{\partial \mathrm{z}^{2}}+\mathrm{X}_{\mathrm{f}, \mathrm{a}} \mathrm{q}_{\mathrm{CO}_{2}}$ \\
\hline $\mathrm{H}^{+}$ & $0=\mathrm{D}_{\mathrm{H}^{+}, \mathrm{f}} \frac{\partial^{2} \mathrm{C}_{\mathrm{H}^{+}}}{\partial \mathrm{z}^{2}}+\mathrm{X}_{\mathrm{f}, \mathrm{a}} \mathrm{q}_{\mathrm{H}^{+}}$ \\
\hline $\mathrm{HCO}_{3}{ }^{-}$ & $0=\mathrm{D}_{\mathrm{HCO}_{3}{ }^{-}, \mathrm{f}} \frac{\partial^{2} \mathrm{C}_{\mathrm{HCO}_{3}}{ }^{-}}{\partial \mathrm{z}^{2}}+\frac{\mathrm{FD}_{\mathrm{HCO}_{3}}{ }^{-}, \mathrm{f}}{\mathrm{RT}} \frac{\partial}{\partial \mathrm{z}}\left(\mathrm{z} * \mathrm{C}_{\mathrm{HCO}_{3}}{ }^{-} * \frac{\partial \eta}{\partial \mathrm{z}}\right)$ \\
\hline $\mathrm{H}_{2} \mathrm{PO}_{4}^{-}$ & 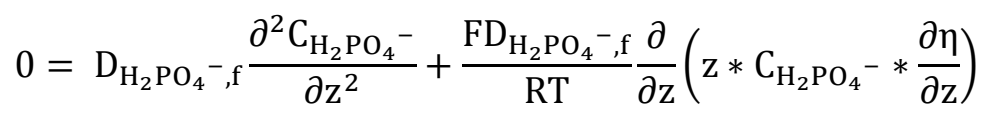 \\
\hline
\end{tabular}

Note: The boundary conditions used to solve these equations were similar to the electron donor boundary conditions. However, the parameters corresponding to each of these parameters are different. A complete set of these parameters are shown in Table 6. 


\section{d) Set of Parameters used to represent Wild-type G. sulfurreducens DL1 Strain}

Table 6: A complete list of model parameters based on Kato-Marcus et al. 2007 model and the experimental results

\begin{tabular}{|c|c|c|c|c|}
\hline Parameters & Descriptions & $\begin{array}{l}\text { Numerical } \\
\text { Values }\end{array}$ & Units & References \\
\hline $\mathrm{K}_{\mathrm{Sd}}$ & $\begin{array}{l}\text { Half Maximum rate ED } \\
\text { concentration }\end{array}$ & 1 & $\mathrm{mM}$ & Esteve-Nunez et al., 2005 \\
\hline $\mathrm{q}_{\max }$ & $\begin{array}{l}\text { Maximum ED uptake } \\
\text { rate }\end{array}$ & 0.132 & $\begin{array}{l}\mathrm{mmol} \mathrm{ED} / \mathrm{mg} \\
\text { VS. day }\end{array}$ & Kato-Marcus et al., 2007 \\
\hline $\mathrm{D}_{\mathrm{ED}, 1}$ & $\begin{array}{l}\text { ED diffusion co- } \\
\text { efficient }\end{array}$ & 0.941 & $\mathrm{~cm}^{2} /$ day & Kato-Marcus et al., 2007 \\
\hline $\mathrm{D}_{\mathrm{ED}, \mathrm{f}}$ & $\begin{array}{l}\text { ED diffusion co- } \\
\text { efficient in biofilm }\end{array}$ & 0.188 & $\mathrm{~cm}^{2} /$ day & Kato-Marcus et al., 2010 \\
\hline $\mathrm{D}_{\mathrm{H}}^{+}, 1$ & $\begin{array}{l}\text { Proton diffusion co- } \\
\text { efficient }\end{array}$ & 10.05 & $\mathrm{~cm}^{2} /$ day & $\begin{array}{l}0.8^{*} \mathrm{D}_{\mathrm{H}^{+}, 1}=\mathrm{D}_{\mathrm{H}}{ }^{+}, \mathrm{f} \\
\text { Kato-Marcus et al., } 2007\end{array}$ \\
\hline $\mathrm{D}_{\mathrm{H}}^{+}{ }_{, \mathrm{f}}$ & $\begin{array}{l}\text { Proton diffusion co- } \\
\text { efficient in biofilm }\end{array}$ & 8.04 & $\mathrm{~cm}^{2} /$ day & Torres et al., 2008 \\
\hline $\mathrm{D}_{\mathrm{CO}, 1}$ & $\begin{array}{l}\mathrm{CO}_{2} \text { diffusion co- } \\
\text { efficient }\end{array}$ & 1.66 & $\mathrm{~cm}^{2} /$ day & Kato-Marcus et al., 2010 \\
\hline $\mathrm{D}_{\mathrm{CO} 2, \mathrm{f}}$ & $\begin{array}{l}\mathrm{CO}_{2} \text { diffusion co- } \\
\text { efficient in biofilm }\end{array}$ & 1.00 & $\mathrm{~cm}^{2} /$ day & Kato-Marcus et al., 2010 \\
\hline $\mathrm{D}_{\mathrm{H} 2 \mathrm{PO} 4-, 1}$ & $\begin{array}{l}\text { Phosphate diffusion co- } \\
\text { efficient }\end{array}$ & 0.83 & $\mathrm{~cm}^{2} /$ day & Kato-Marcus et al., 2010 \\
\hline $\mathrm{D}_{\mathrm{H} 2 \mathrm{PO} 4-\mathrm{f}}$ & $\begin{array}{l}\text { Phosphate diffusion co- } \\
\text { efficient in biofilm }\end{array}$ & 0.12 & $\mathrm{~cm}^{2} /$ day & Kato-Marcus et al., 2010 \\
\hline $\mathrm{D}_{\mathrm{HCO} 3-1}$ & $\begin{array}{l}\text { Carbonate diffusion co- } \\
\text { efficient }\end{array}$ & 1.02 & $\mathrm{~cm}^{2} /$ day & Kato-Marcus et al., 2010 \\
\hline $\mathrm{D}_{\mathrm{HCO} 3-\mathrm{f}}$ & $\begin{array}{l}\text { Carbonate diffusion co- } \\
\text { efficient in biofilm }\end{array}$ & 0.61 & $\mathrm{~cm}^{2} /$ day & Kato-Marcus et al., 2010 \\
\hline $\mathrm{S}_{\mathrm{d}}$, bulk & Bulk ED concentration & 10 & $\mathrm{mM}$ & $\begin{array}{l}\text { Experimental bulk } \\
\text { concentrations. }\end{array}$ \\
\hline $\mathrm{S}_{\mathrm{H}}^{+}$, bulk & $\begin{array}{l}\text { Bulk proton } \\
\text { concentration }\end{array}$ & $1 \times 10^{-4}$ & $\mathrm{mM}$ & $\begin{array}{l}\text { Experimental bulk } \\
\text { concentrations. }\end{array}$ \\
\hline $\mathrm{S}_{\mathrm{HCO} 3-,}$ bulk & $\begin{array}{l}\text { Bulk carbonate } \\
\text { concentration }\end{array}$ & 31.67 & $\mathrm{mM}$ & $\begin{array}{l}\text { Experimental bulk } \\
\text { concentrations }\end{array}$ \\
\hline $\mathrm{S}_{\mathrm{H} 2 \mathrm{PO} 4-, \text {, bulk }}$ & $\begin{array}{l}\text { Bulk phosphate } \\
\text { concentration }\end{array}$ & 4.33 & $\mathrm{mM}$ & $\begin{array}{l}\text { Experimental bulk } \\
\text { concentrations }\end{array}$ \\
\hline $\mathrm{S}_{\mathrm{CO} 2, \text { bulk }}$ & $\begin{array}{l}\text { Bulk } \mathrm{CO}_{2} \\
\text { concentration }\end{array}$ & 9.67 & $\mathrm{mM}$ & $\begin{array}{l}\text { Assumed in order to obtain } \\
\mathrm{pH}=\sim 7 \text { using OLI software }\end{array}$ \\
\hline
\end{tabular}

- Note: All concentration units were converted to $\mathrm{mmol} / \mathrm{cm}^{3}$ in the model. 
6.2 Equations Used in the Genome-scale Model Component of the Coupled Model Framework

a) Objective function and the general and the general constraint formulation.

$$
\begin{aligned}
& \text { Maximize }\left(C^{T} v\right) \\
& \text { s.t } S . v=0 \\
& \boldsymbol{v}_{\boldsymbol{l b}} \leq \boldsymbol{v} \leq \boldsymbol{v}_{\boldsymbol{u} \boldsymbol{b}} \\
& i=1,2,3 \ldots \ldots \ldots n
\end{aligned}
$$

b) Electron donor limited constraint (in FBA model - acetate uptake rate):

$$
\mathrm{q}_{\mathrm{ED}, \mathrm{constraint}}=\mathrm{q}_{\max }\left(\frac{\mathrm{S}_{\mathrm{d}}}{\mathrm{S}_{\mathrm{d}}+\mathrm{K}_{\mathrm{Sd}}}\right)
$$

c) Electron acceptor limited constraint (in FBA model - Fe (III) reduction rate):

$$
\mathrm{q}_{\mathrm{e}, \text { constraint }}=8 \times \mathrm{q}_{\max }\left(\frac{1}{1+\exp \left[-\frac{\mathrm{F}}{\mathrm{RT}}(\eta-(-0.345))\right]}\right)
$$




\subsection{MATLAB Code for Coupled Model Framework}

\section{a) Biofilm Model Equations, Parameters and the Boundary Conditions}

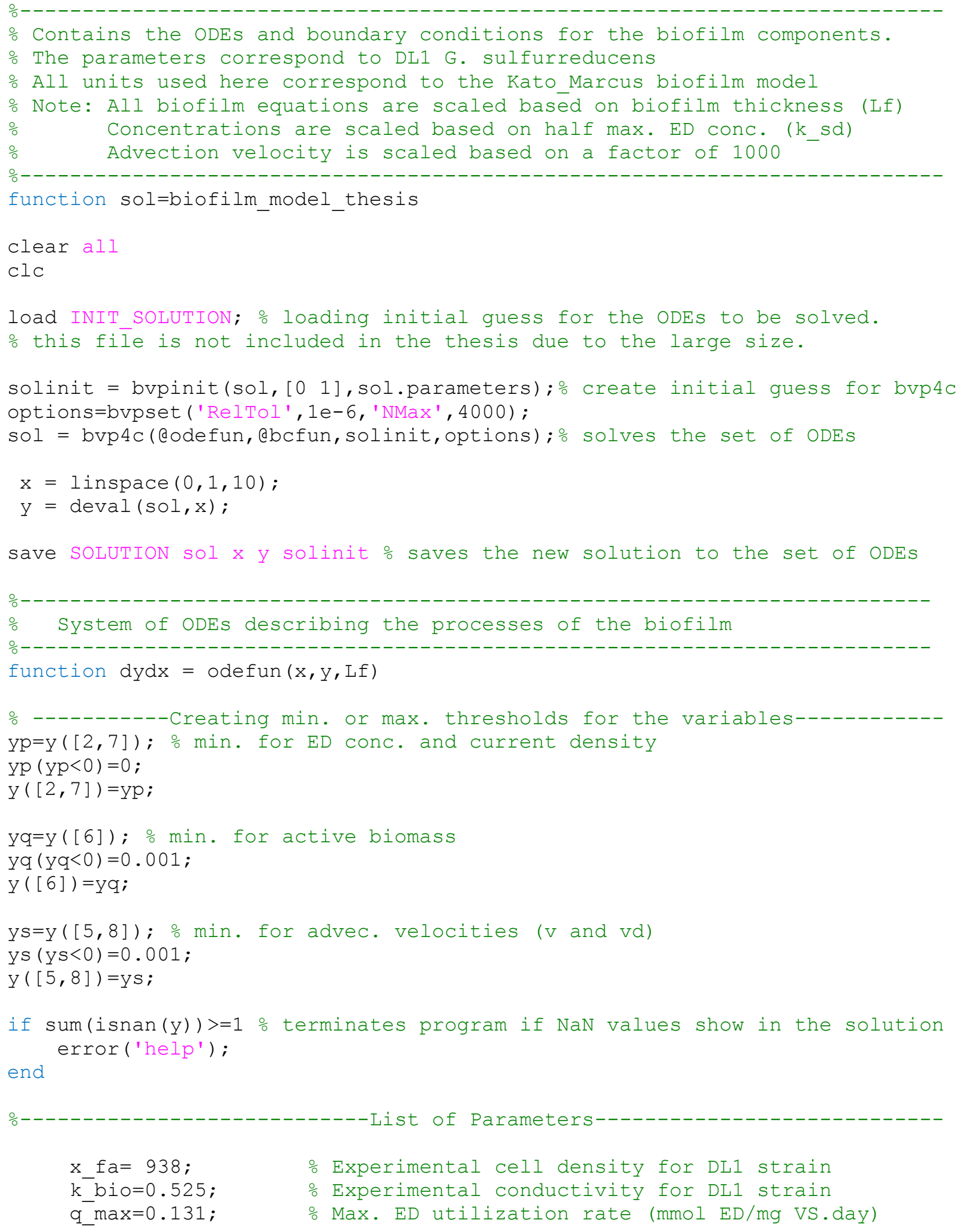




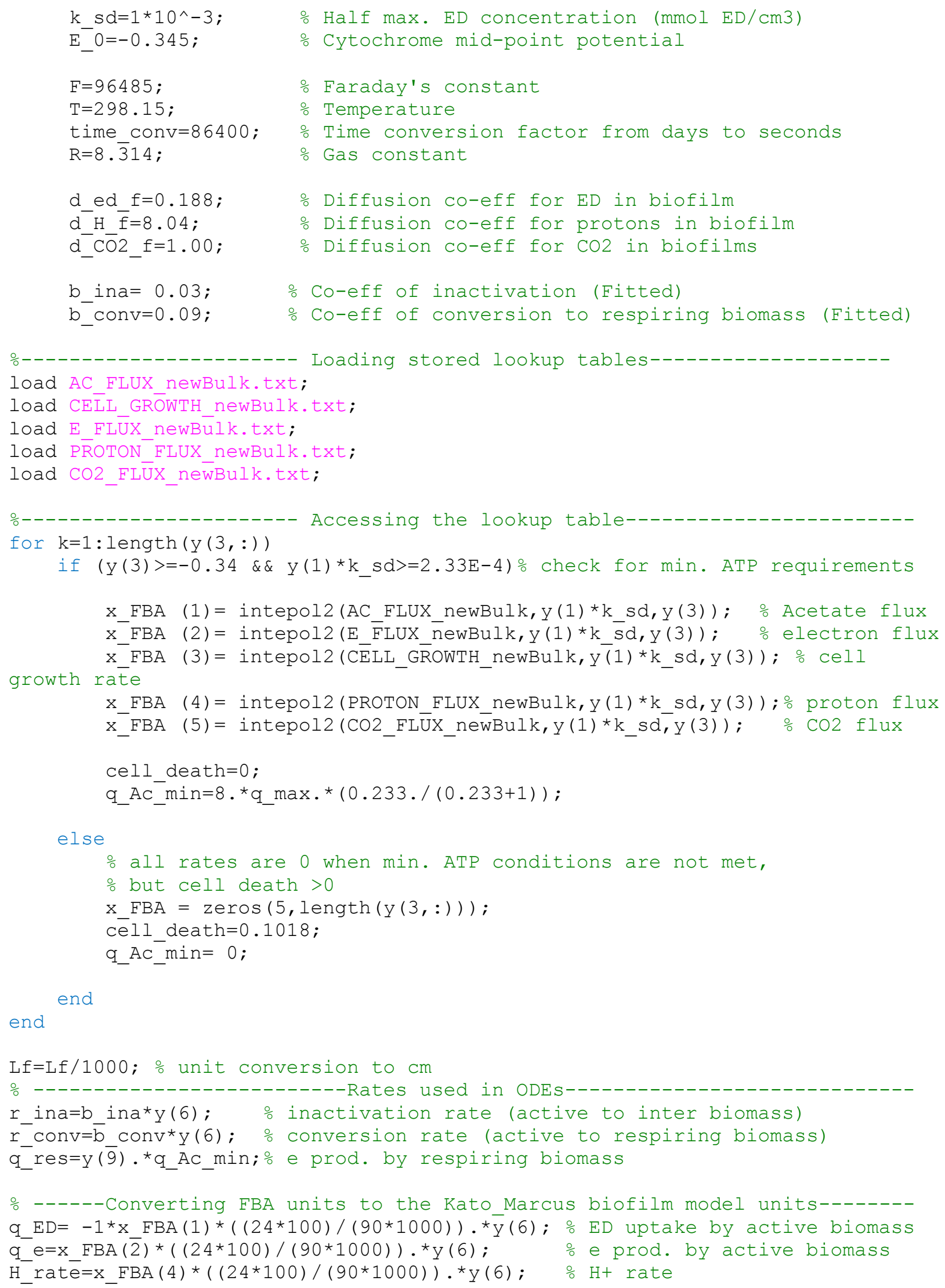




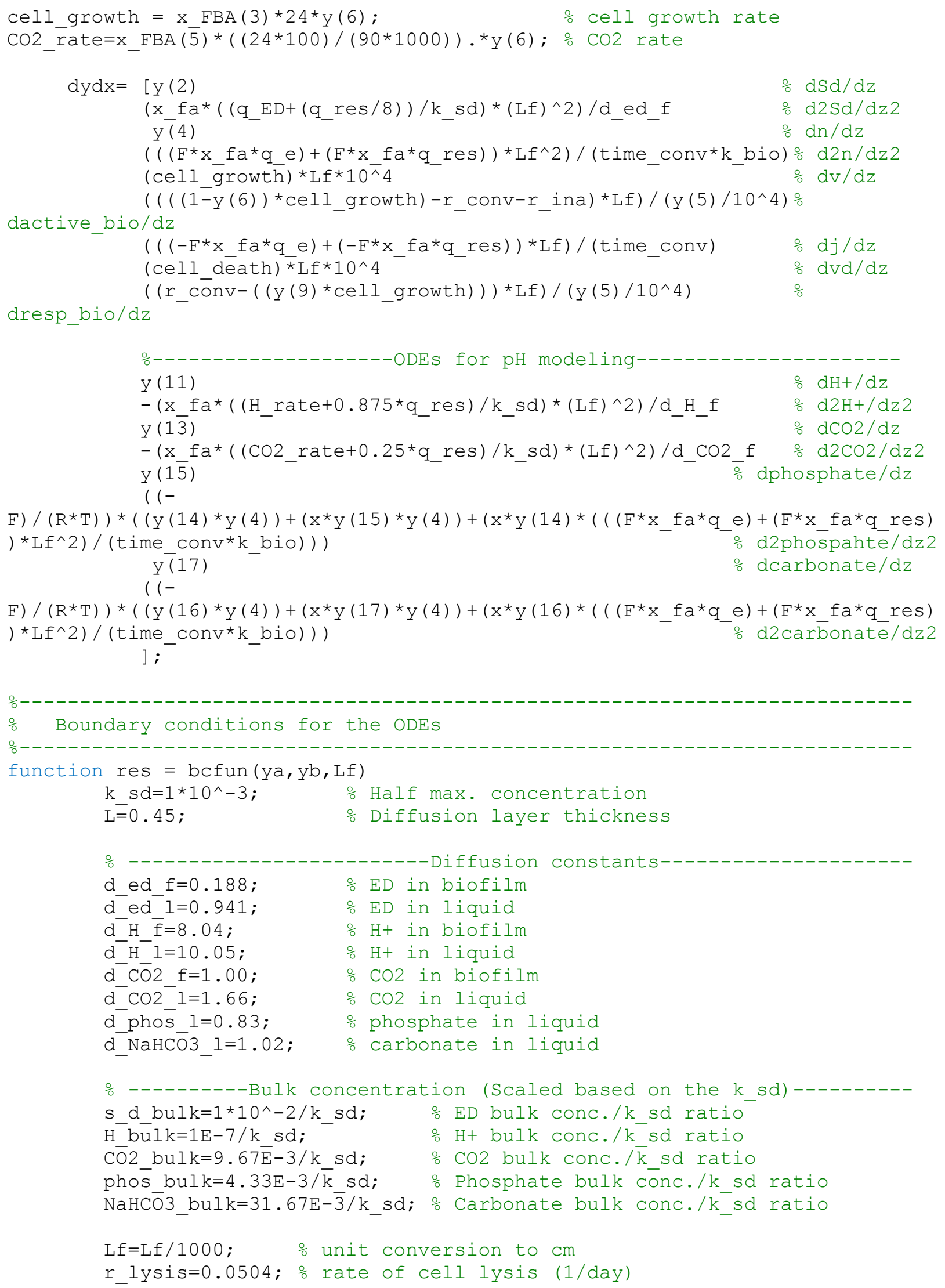




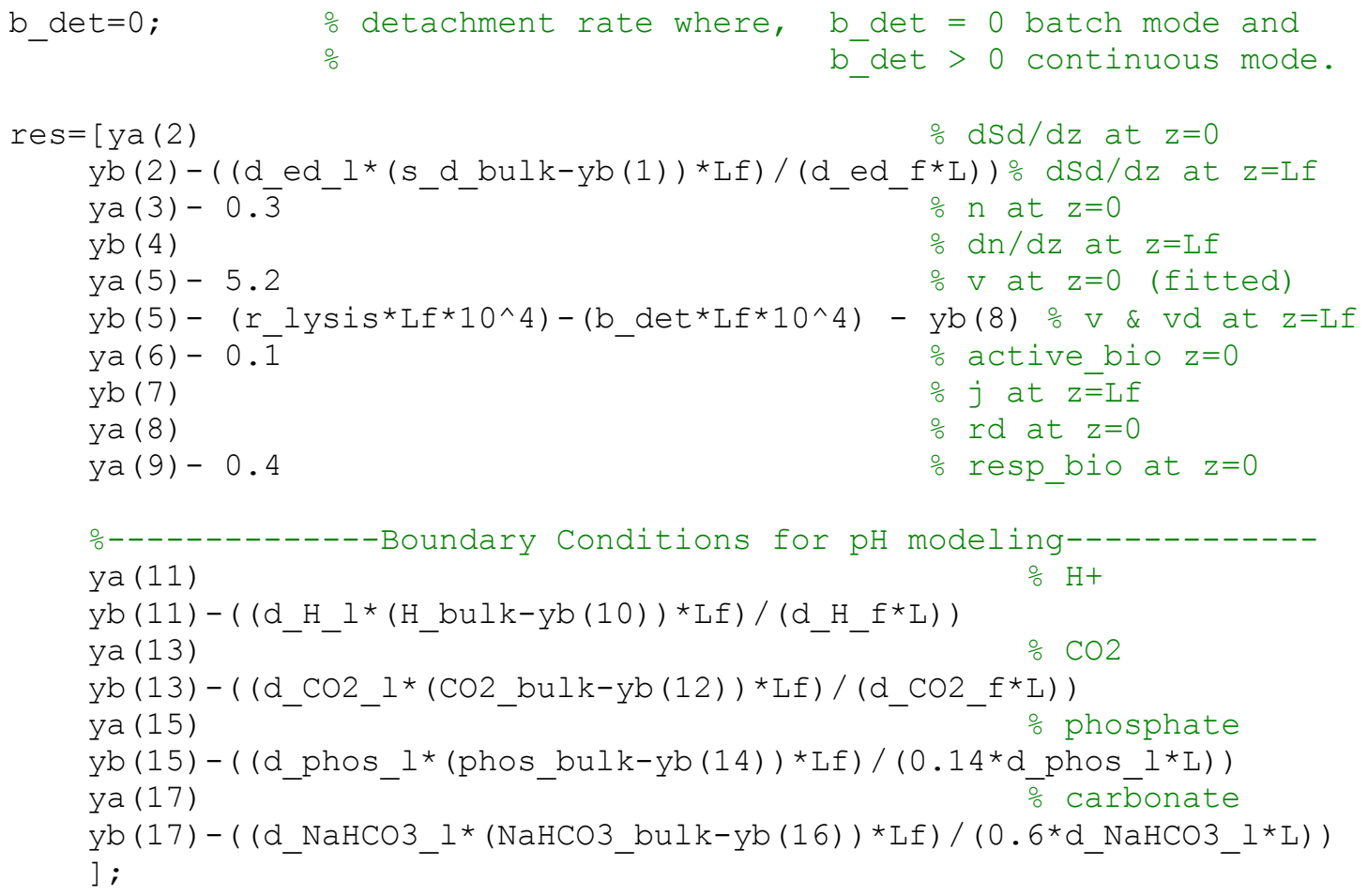




\section{b) Generating Lookup Tables}

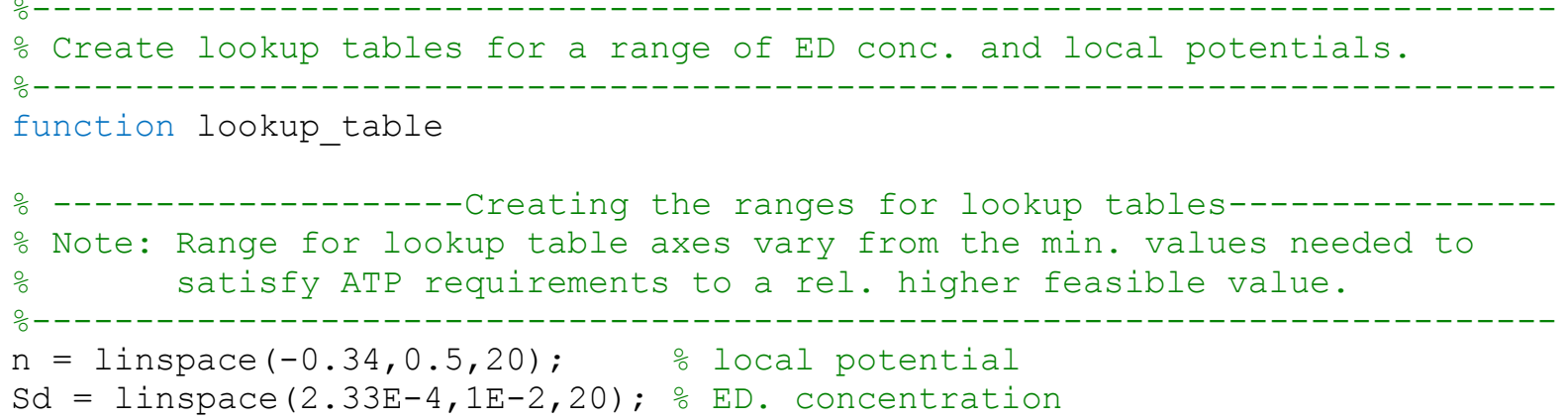




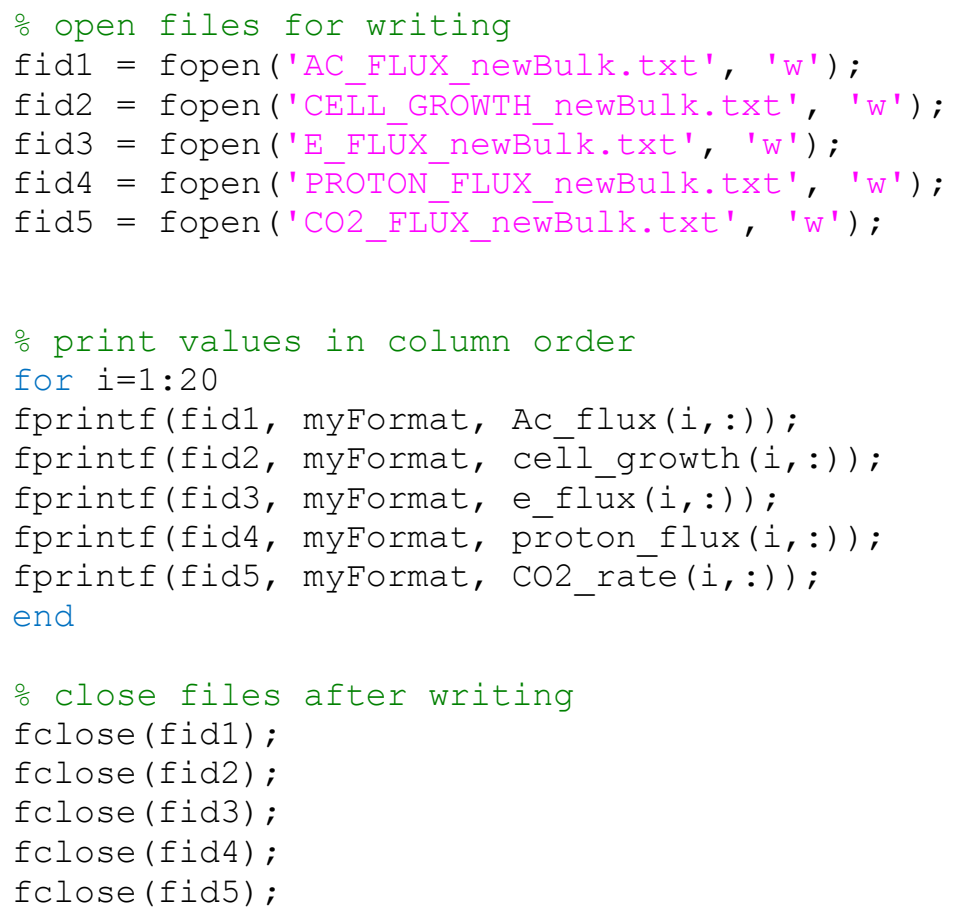




\section{c) Referring to the Lookup Table}

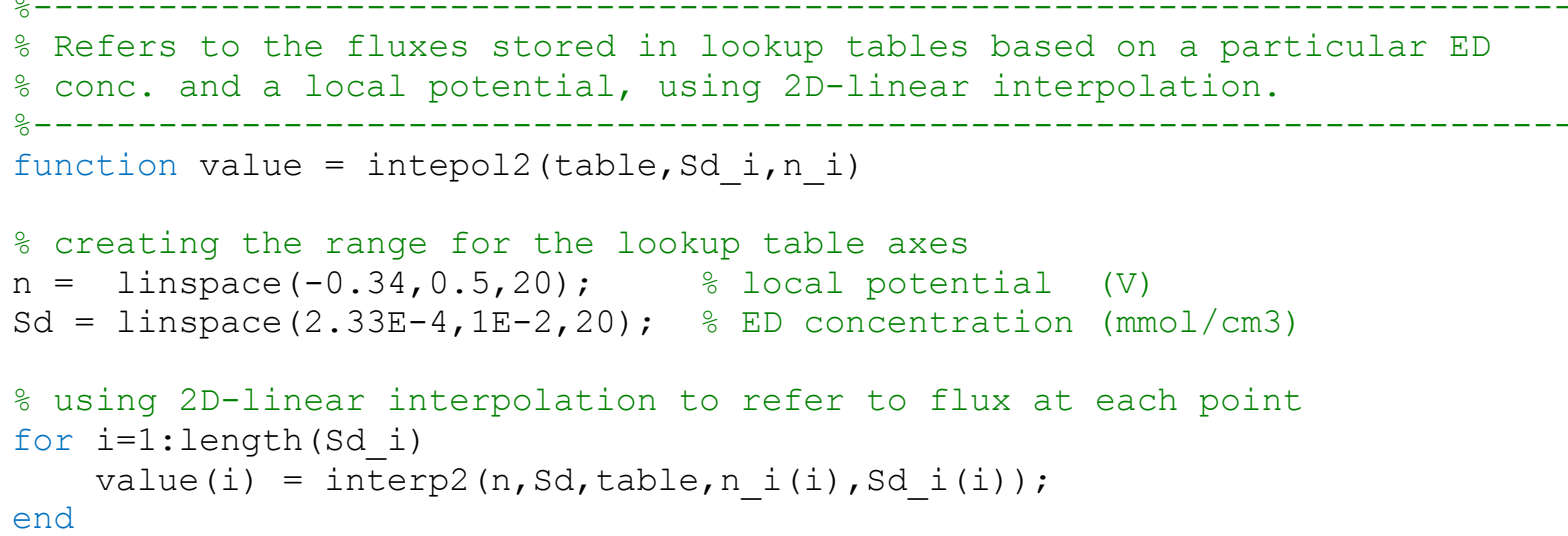

d) Formulation of the Objective Function and Constraints of the Genome-scale Model

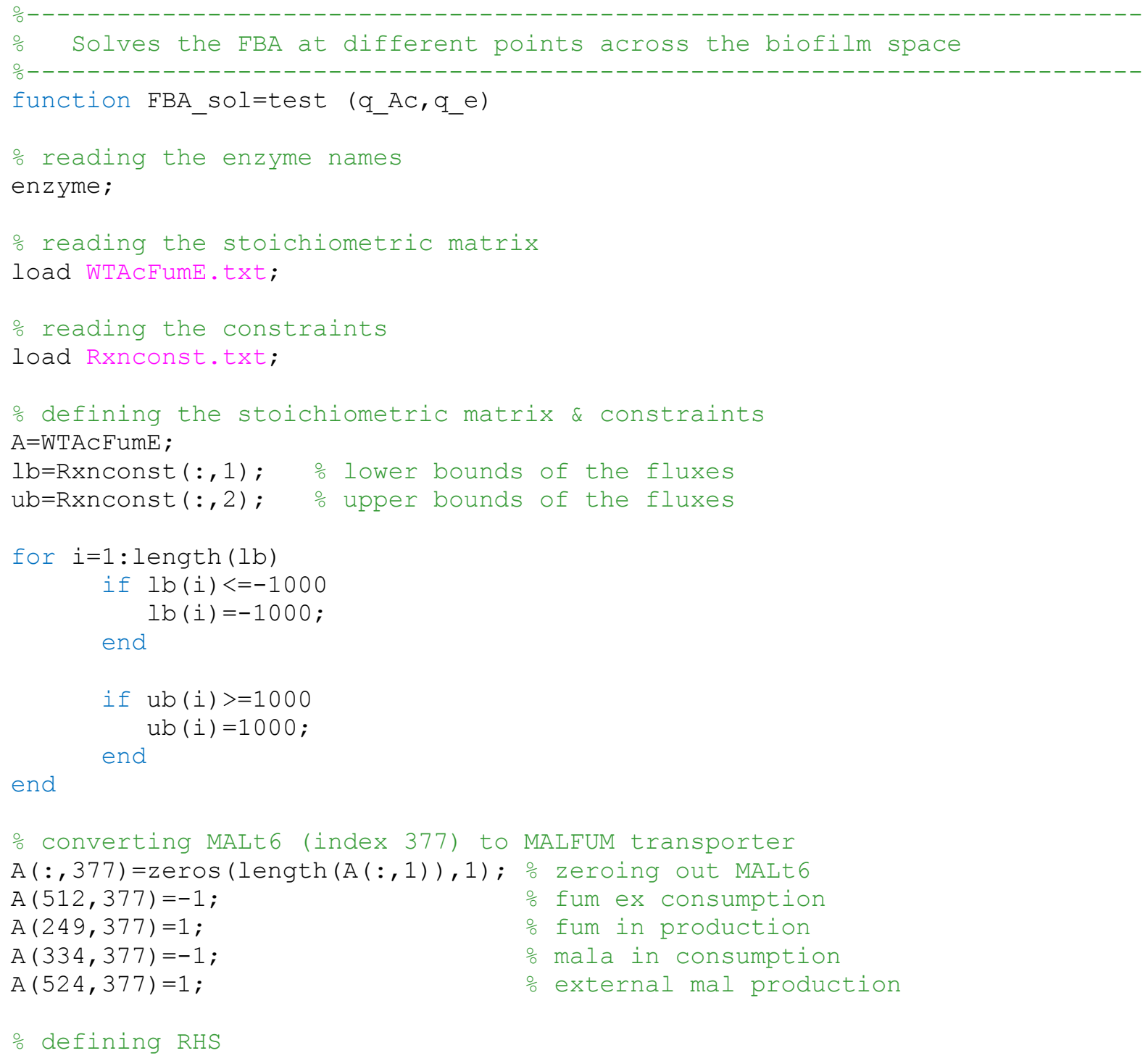




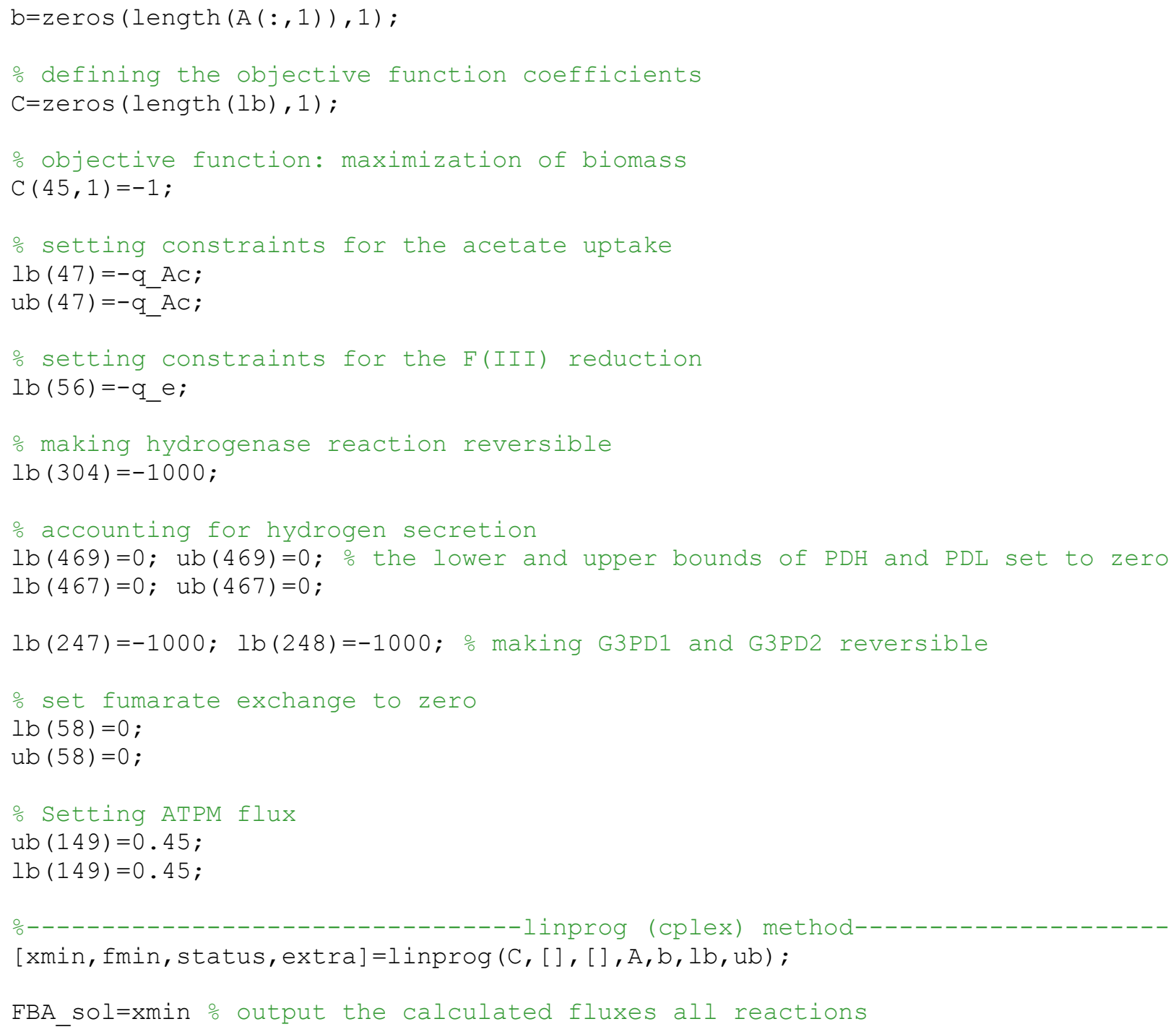




\section{7: APPENDIX II}

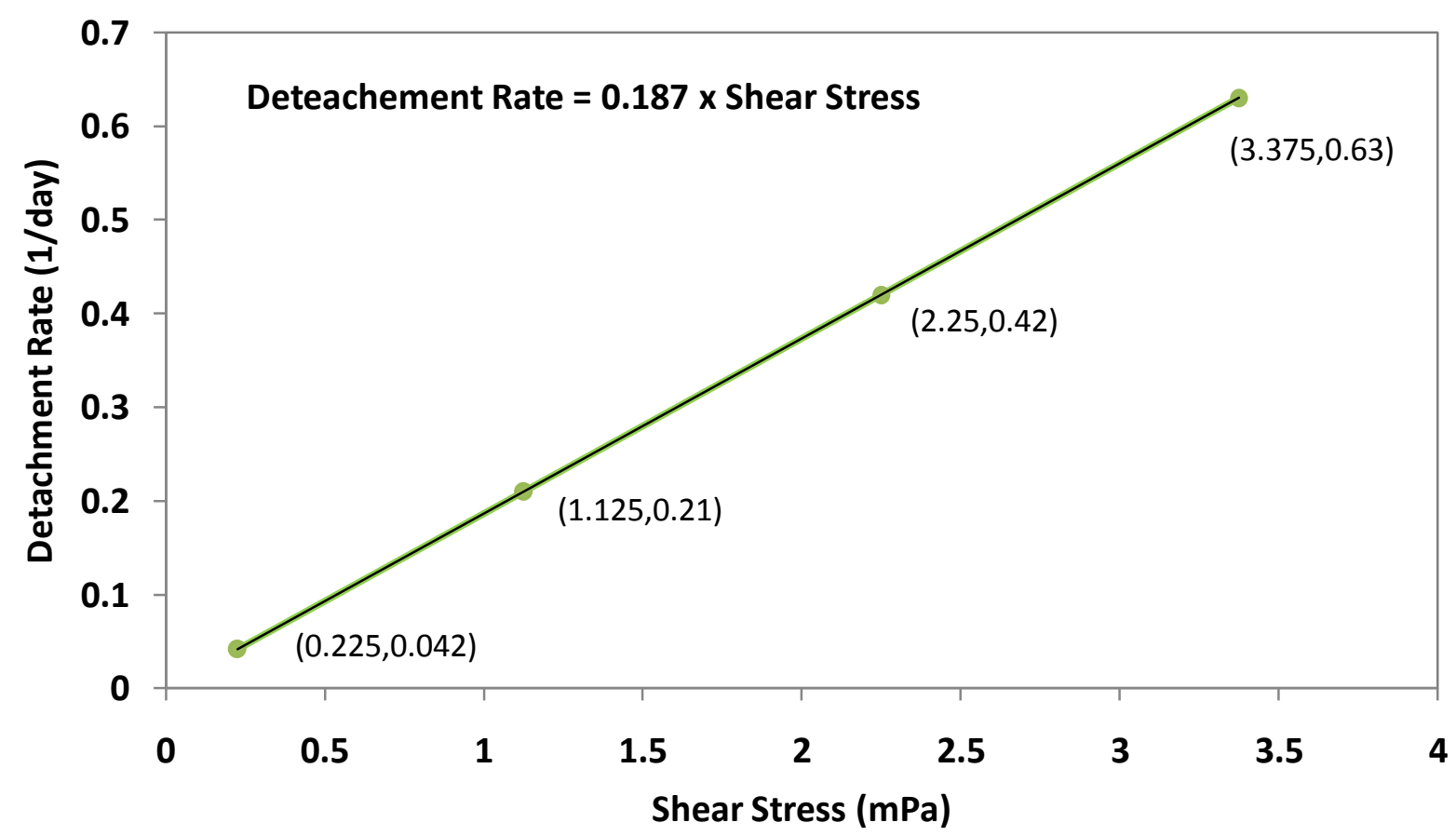

Figure 7.1: Linear correlation used to establish the relationship between the detachment rate and the shear stress. 